Aus der Abteilung Neurologie

$$
\text { (Prof. Dr. med. M. Bähr) }
$$

im Zentrum Neurologische Medizin

der Medizinischen Fakultät der Universität Göttingen

\title{
Einfluss einer intrazerebralen Infektion mit Streptococcus pneumoniae auf den Verlauf der Alzheimer-Demenz im Mausmodell
}

\author{
INAUGURAL - DISSERTATION \\ zur Erlangung des Doktorgrades \\ der Medizinischen Fakultät \\ der Georg-August-Universität zu Göttingen
}

vorgelegt von

Benedikt Kellert

aus

Erfurt 
Dekan: Prof. Dr. med. Frömmel

I. Berichterstatter: Prof. Dr. med. Nau

II. Berichterstatter: Prof. Dr. med. Reichard

III. Berichterstatter: Prof. Dr. med., Dr. rer. nat. Crozier

Tag der mündlichen Prüfung: 20.06.2012 


\section{Abkürzungsverzeichnis}

$A \beta$

$A D$

ALS

ANOVA

APP

Aqua bidest.

AUC

${ }^{\circ} \mathrm{C}$

ca.

$\mathrm{cm}$

CFU

CT

DMSO

dNTP

DSM

E. coli

E-Cup

EDTA

ELISA

$g$

g

hAPP

$\mathrm{Hb}$

$\mathrm{HE}$

$\mathrm{H}_{2} \mathrm{O}_{2}$

$\mathrm{kg}$

KG

$\mathrm{KMnO}_{4}$

$\mathrm{K}_{2} \mathrm{~S}_{2} \mathrm{O}_{5}$

LPS

$\mathrm{mg}$

$\min$
$\beta$-Amyloid

Alzheimer-Demenz

Amyotrophe Lateralsklerose

Analysis of variance

Amyloid-Vorläuferprotein (Amyloid Precursor Protein)

doppelt destilliertes Wasser

Area under the curve

Grad Celsius

circa

Zentimeter

Kolonie-bildende-Einheiten (Colony Forming Units)

Computertomographie

Dimethylsulfoxid

Desoxyribonukleosidtriphosphat

Diagnostic and Statistical Manual of Mental Disorders

Escherichia coli

Eppendorf-Reaktionsgefäß

Ethylendiamintetraacetat

Enzyme-Linked Immunosorbent Assay

Erdbeschleunigung, $9,81 \mathrm{~m} / \mathrm{s}^{2}$

Gramm

humanes Amyloid-Vorläuferprotein (human Amyloid Precursor

Protein)

Hämoglobin

Hämatoxylin-Eosin

Wasserstoffperoxid

Kilogramm

Körpergewicht

Kaliumpermanganat

Kaliumpyrosulfit

Lipopolysaccharid

Milligramm

Minuten 


\begin{tabular}{|c|c|}
\hline $\mathrm{ml}$ & Milliliter \\
\hline $\mathrm{mm}$ & Millimeter \\
\hline $\mathrm{mM}$ & millimolar \\
\hline$\mu l$ & Mikroliter \\
\hline$\mu \mathrm{m}$ & Mikrometer \\
\hline MMST & Mini-Mental-Status-Test \\
\hline MRT & Magnetresonanztomographie \\
\hline $\mathrm{NaCl}$ & Natriumchlorid \\
\hline $\mathrm{NaOH}$ & Natriumhydroxid \\
\hline OPSI & overwhelming-post-splenectomy-infection \\
\hline PCR & Polymerase-Kettenreaktion \\
\hline PET & Positronen-Emissions-Tomographie \\
\hline $\mathrm{pg}$ & Pikogramm \\
\hline rpm & Umdrehungen pro Minute \\
\hline S. pneumoniae & Streptococcus pneumoniae \\
\hline SP3 & S. pneumoniae-Typ-3-Stamm \\
\hline TBE & Tris(hydroxymethyl)-aminomethan-Borat- \\
\hline & Ethylendiamintetraessigsäure-Puffer \\
\hline $\mathrm{Tg}^{+}$ & transgene Mäuse der Tg2576-Mauslinie \\
\hline $\mathrm{Tg}^{-}$ & nicht-transgene Mäuse der Tg2576-Mauslinie \\
\hline Tris & Tris(hydroxymethyl)-aminomethan \\
\hline z.B. & zum Beispiel \\
\hline ZNS & Zentralnervensystem \\
\hline ZTE & Zentrale Tierexperimentelle Einrichtung \\
\hline
\end{tabular}




\section{Inhaltsverzeichnis}

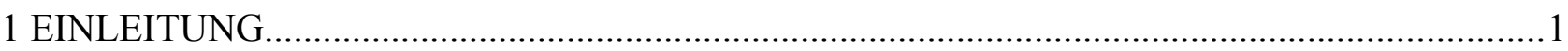

1.1 Neurodegenerative Erkrankungen und Infektionen....................................................... 1

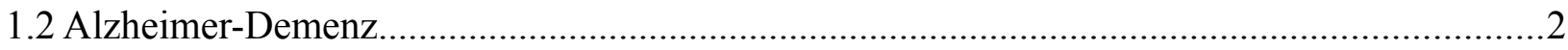

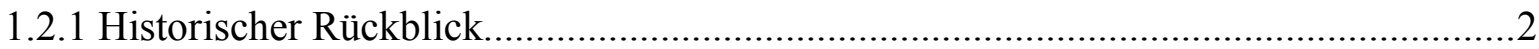

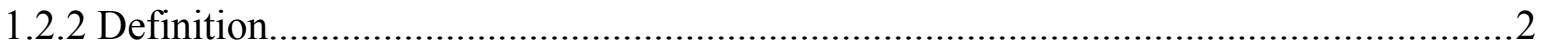

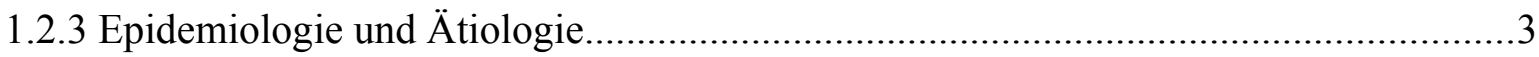

1.2.4 Pathogenese

1.2.4.1 Morphologische Veränderungen im ZNS......................................................4

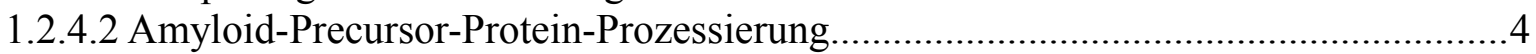

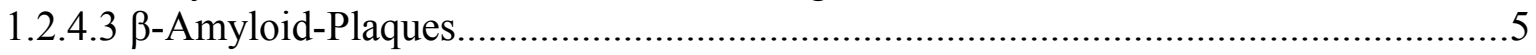

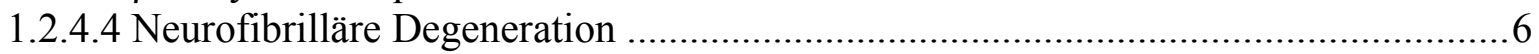

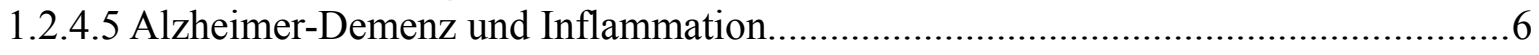

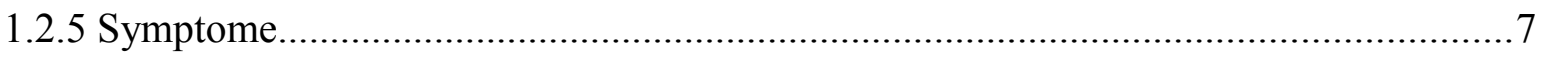

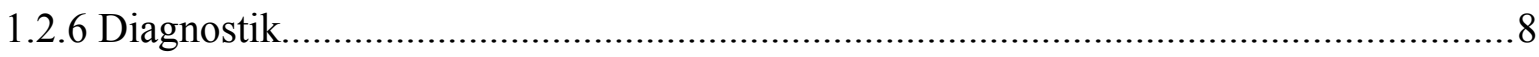

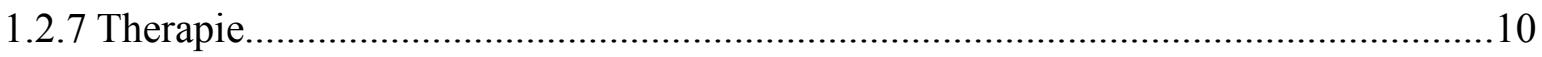

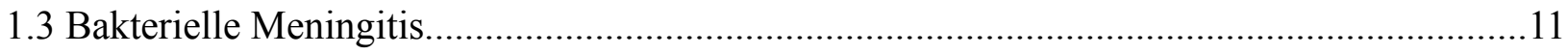

1.3.1 Epidemiologie und klinisches Bild................................................................. 11

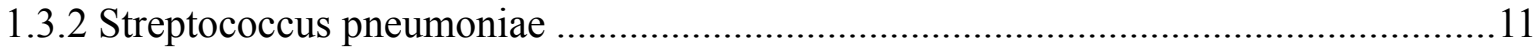

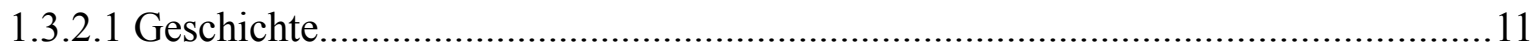

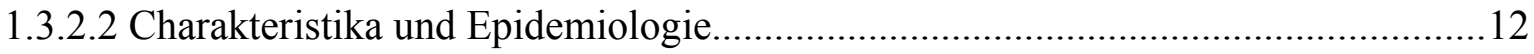

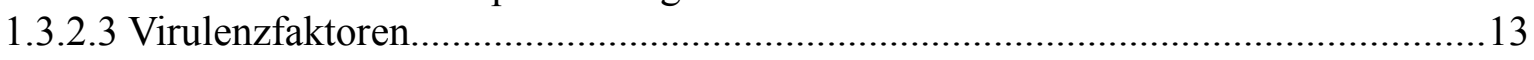

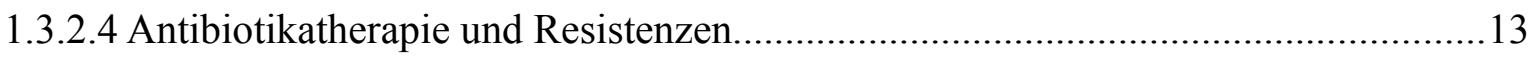

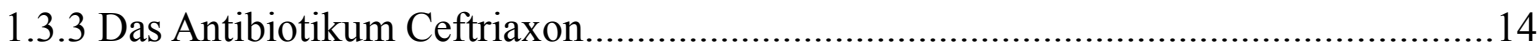

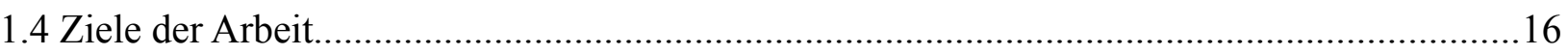

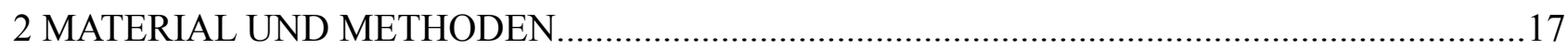

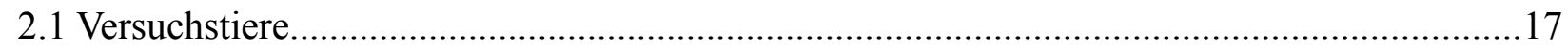

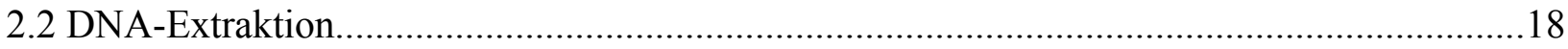

2.3 Genotypisierung mittels Polymerase-Kettenreaktion........................................................ 19

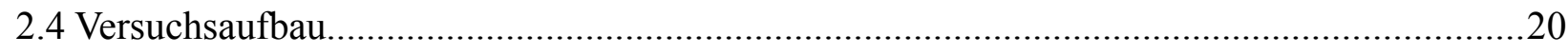

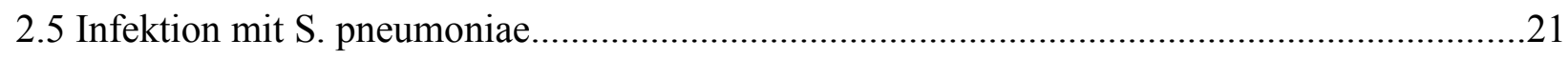

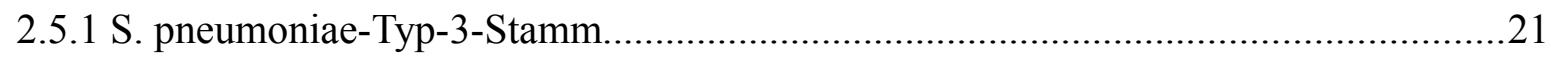

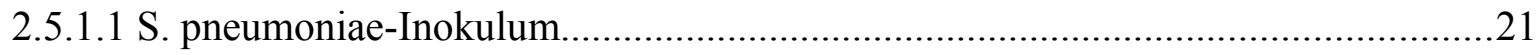

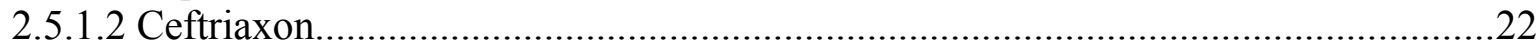

2.5.1.3 intrazerebrale Infektion mit S. pneumoniae-Typ-3-Stamm................................22

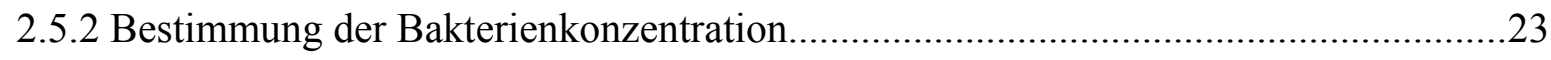

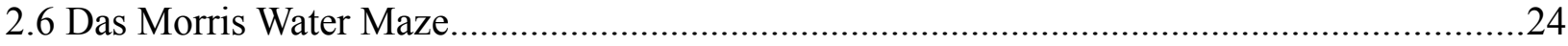

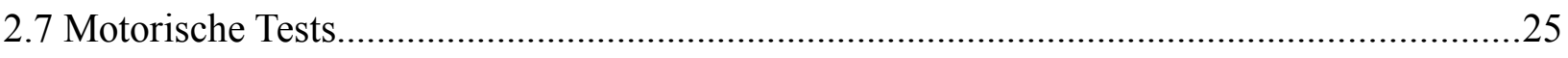

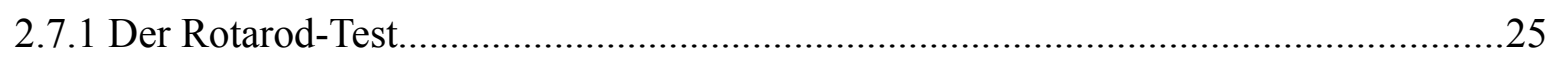

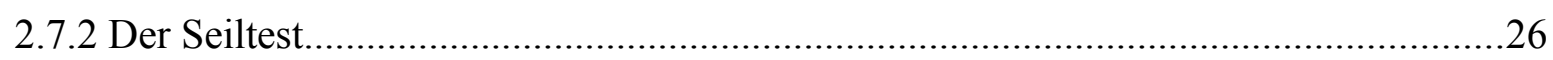

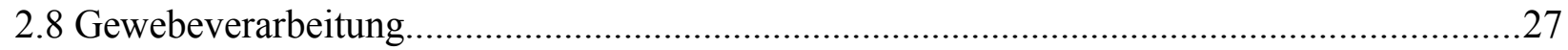

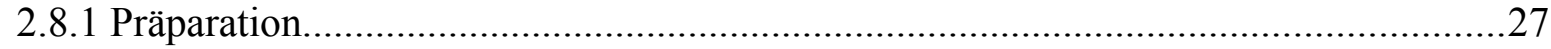




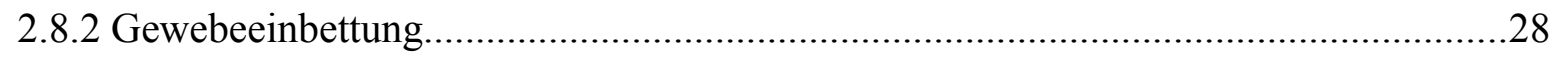

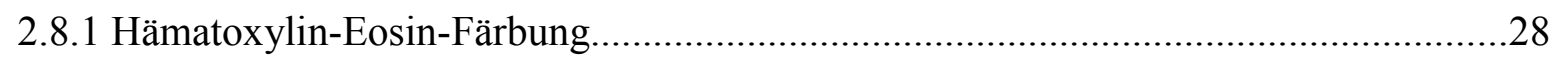

2.8.2 Enzyme-Linked Immunosorbent Assay ..........................................................29

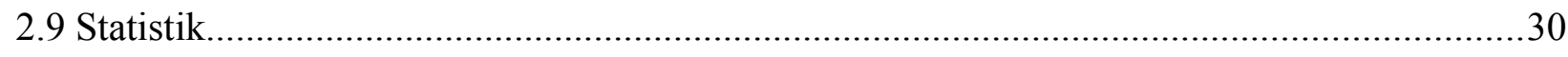

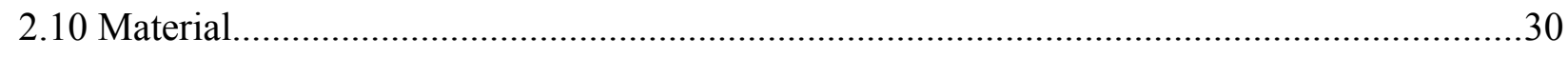

2.10.1 Reagenzien, Chemikalien und Lösungen........................................................ 30

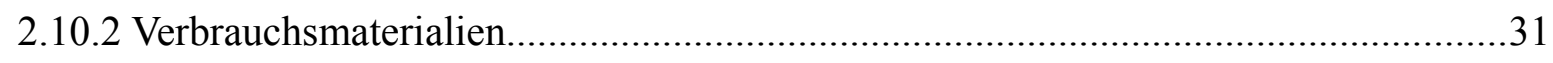

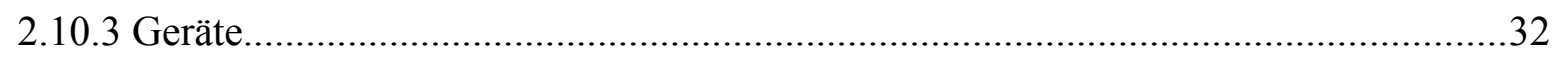

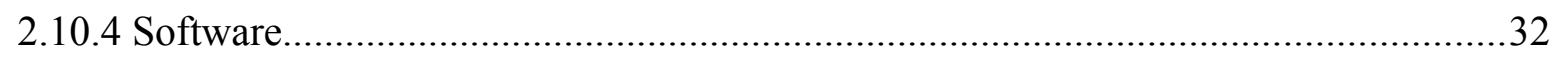

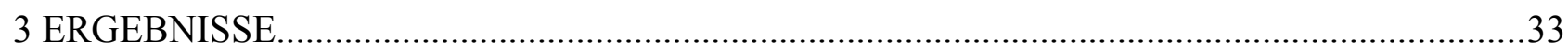

3.1 Vergleich zwischen transgenen und nicht-transgenen Mäusen des Stammes Tg2576 (vor

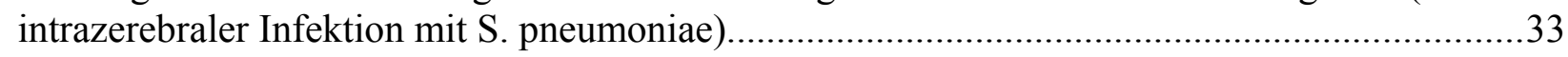

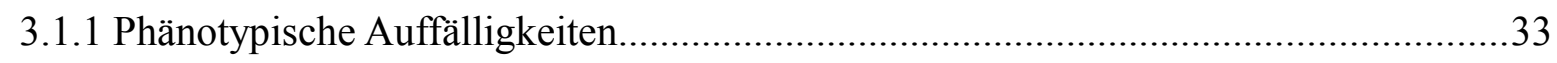

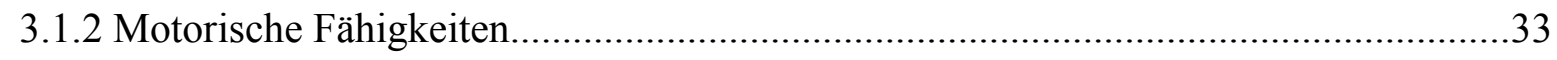

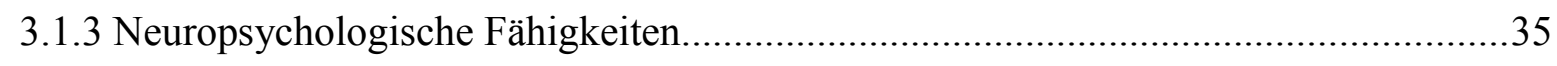

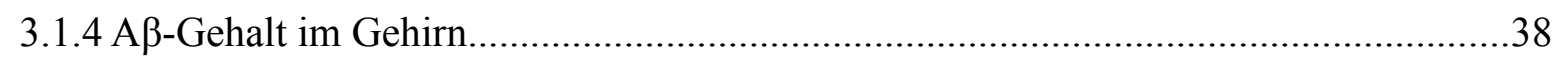

3.2 Empfindlichkeit der transgenen und nicht-transgenen Mäuse des Stammes Tg2576 auf eine

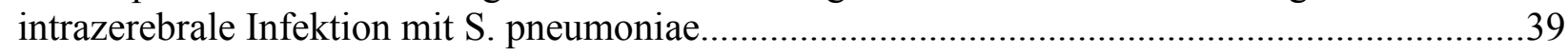

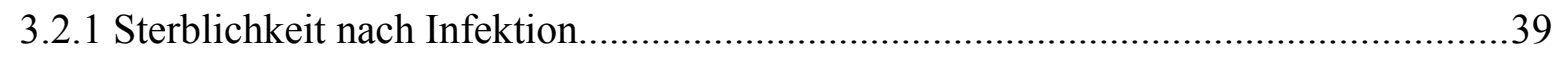

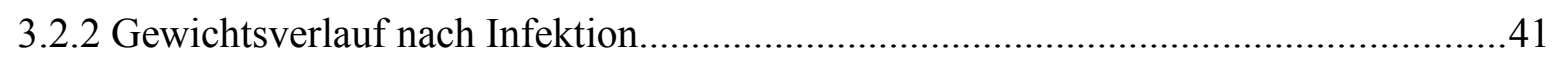

3.2.3 Bakterienlast im ZNS und Entzündungszeichen im Gehirn.....................................42 3.3 Einfluss einer intrazerebralen Infektion mit S. pneumoniae auf den Krankheitsverlauf bei transgenen Mäusen des Stammes Tg2576 ........................................................................43

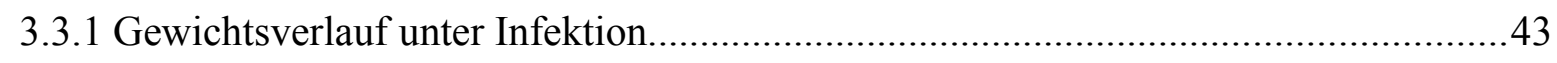

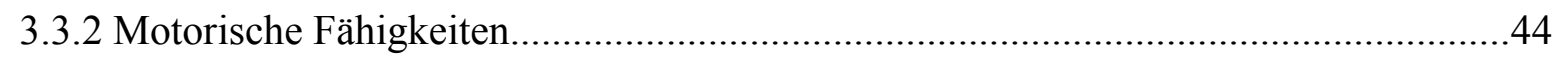

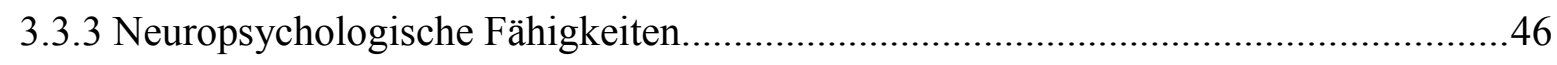

3.3.4 A $\beta$-Gehalt im Gehirn am Ende des Versuches......................................................49

3.3.5 A $\beta$-Gehalt im Verlauf der Infektion.................................................................... 51

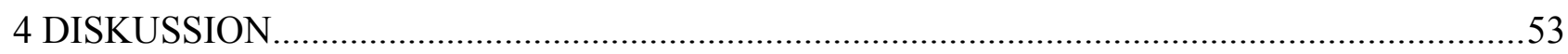

4.1 Vergleich zwischen transgenen und nicht-transgenen Mäusen des Stammes Tg2576 (vor intrazerebraler Infektion mit S. pneumoniae) .......................................................................53

4.2 Empfindlichkeit der transgenen und nicht-transgenen Mäuse des Stammes Tg2576 auf eine intrazerebrale Infektion mit S. pneumoniae.......................................................................55

4.3 Einfluss einer intrazerebralen Infektion mit S. pneumoniae auf transgene Mäuse des

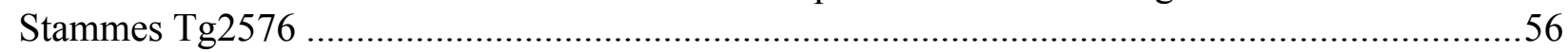

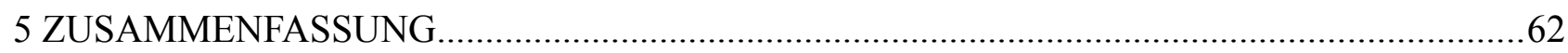

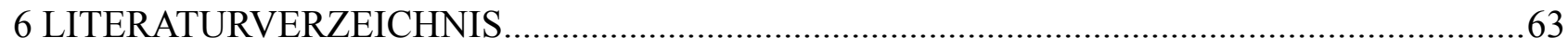




\section{EINLEITUNG}

\subsection{Neurodegenerative Erkrankungen und Infektionen}

Entzündliche Prozesse spielen eine Rolle bei der Pathogenese neurodegenerativer Erkrankungen (Aloisi 2001, Raivich und Banati 2004). So finden sich aktivierte Mikroglia, die der Hauptbestandteil der angeborenen Immunantwort im Zentralnervensystem (ZNS) sind, in Gehirnen von Patienten mit Alzheimer-Demenz (AD) (Van Everbroeck et. al 2004, Kim und de Vellis 2005), Parkinson (Mc Geer PL et al. 1998, Mc Geer PL und Mc Geer EG 2004) und amyotropher Lateralsklerose (ALS) (Turner et al. 2004). Das angeborene Immunsystem ist durch die neurodegenerative Erkrankung schon aktiviert („primed“) (Godoy et al. 2008, Nguyen et al. 2002).

Studien an Patienten ohne Demenzerkrankung deuten darauf hin, dass systemische Entzündungen zum Nachlassen der kognitiven Fähigkeiten und zu einer Reduktion des Hippokampusvolumens führen können (Yaffe et al. 2004, Marsland et al. 2008). Weitere Untersuchungen lassen vermuten, dass häufig durchgemachte systemische Entzündungen das Risiko an AD zu erkranken erhöhen (Engelhart et al 2004, Tan et al. 2007, Bermejo et al. 2008, Bonotis et al. 2008). Das Voranschreiten von neurodegenerativen Erkrankungen während und nach einer durchgemachten Infektion wurde beobachtet, und Infektionen können für das Auslösen einer akuten Exazerbation verantwortlich gemacht werden (Perry et al. 2007). Systemische Infektionen sind assoziiert mit einer Abnahme kognitiver Fähigkeiten von AD-Patienten, die auch nach überstandener Infektionserkrankung weiterhin bestehen bleiben können (Holmes et al. 2003). Weiterhin ist der Verlust von mnestischen Funktionen nach Infektionen zu nennen. Zwillingsstudien bei $A D$ belegen einen früheren Ausbruch der Erkrankung, wenn einer der Zwillinge zuvor an einer systemischen Infektion gelitten hat (Nee und Lippa 1999).

In Tierexperimenten wurde die Ausschüttung von zytotoxischen Mediatoren gefunden, die im Rahmen einer systemischen Infektion mit Lipopolysacchariden (LPS) ausgeschüttet werden, das Immunsystem zusätzlich aktivieren und somit den Prozess der neuronalen Degeneration im Prionen-Modell verstärken (Cunningham et al. 2008, Cunningham et al. 2005). Studien an ALS-Mäusen zeigen eine Exazerbation der Erkrankung und einen Untergang von Neuronen nach LPS-Applikation (Nguyen et al. 2004). Dies konnte auch für die experimentelle autoimmune Enzephalitis (EAE) bei Infektion mit S. pneumoniae 
gezeigt werden (Herrmann et al. 2006). Die klinische Verschlechterung der Grunderkrankung bei gleichzeitiger Aktivierung von Mikroglia durch endogene/exogene Substanzen, welche zu einer zusätzlichen Ausschüttung von inflammatorischen Zytokinen führen, scheinen den neurodegenerativen Prozess zu verstärken.

\subsection{Alzheimer-Demenz}

\subsubsection{Historischer Rückblick}

Alois Alzheimer (1864-1915), ein deutscher Psychiater und Neuropathologe aus Marktbreit am Main, beschrieb erstmalig 1906 auf einer Fachtagung in Tübingen das Krankheitsbild der Demenz vom Alzheimer-Typ.

Die Patientin Auguste Deter, welche sich seit 1901 in Alzheimers Behandlung im Psychiatrischen Klinikum Frankfurt am Main befand, zeigte das charakteristische Bild dieser degenerativen Hirnerkrankung. Nach ihrem Tod 1906 untersuchte Alzheimer mikroskopisch das Gehirn der Patientin und fand neben zugrunde gegangenen Nervenzellen Eiweißablagerungen, die er als sogenannte Plaques beschrieb (Stertz 1953).

Die offizielle Namensgebung dieser Erkrankung geht auf den Psychiater Emil Kraepelin zurück. Im Jahre 1910 benannte Kraepelin in der achten Ausgabe seines Werkes „Lehrbuch der Psychiatrie“ diese Demenzform nach ihrem Erstbeschreiber Alois Alzheimer (Möller und Graeber 1998).

\subsubsection{Definition}

Die Alzheimer-Demenz (AD, Synonyme: Demenz vom Alzheimer-Typ, Morbus Alzheimer, Alzheimer's Disease) ist eine neurodegenerative Hirnerkrankung des höheren Lebensalters, die zur klinischen Krankheitsausbildung der Demenz infolge einer Hirnatrophie führt. Langsam zunehmende Gedächtnis- und Orientierungsstörungen sind typische neuropsychologische Symptome der AD. Im Verlauf zeigen sich häufig depressive Verstimmung sowie Probleme in der Bewältigung des Alltagslebens.

Charakteristisch, jedoch nicht pathognomonisch, sind mikroskopische 
Fibrillenveränderungen, sogenannte Tangles, und Amyloid-Plaques, die sich in der gesamten Hirnrinde finden lassen (Jellinger und Bancher 1996).

\subsubsection{Epidemiologie und Ätiologie}

Die AD ist die häufigste neurodegenerative Erkrankung, wobei in Deutschland ca. 1 Million und weltweit ca. 25 Millionen Menschen erkrankt sind (Eckert 2005, Bickel 2001, Qiu et al. 2009). Das hauptsächliche Erkrankungsalter liegt im 7. und 8. Lebensjahrzehnt. Die Prävalenz der Gesamtbevölkerung liegt bei ca. 1\%, wobei diese Zahl bei den über 80 Jährigen auf 30\% ansteigt (Böcker et al. 2008). Die durchschnittliche Lebenserwartung nach Ausbruch der Erkrankung liegt bei 7 bis 8 Jahren, kann jedoch auch mehrere Jahrzehnte betragen. Herauszustellen ist, dass nicht die Erkrankung selbst, sondern die Folgen einer Bettlägerigkeit, wie z.B. Aspiration, mangelnde Nahrungs-/ Flüssigkeitsaufnahme, Wundinfektion, Pneumonie und Nierenversagen, Gründe für das Versterben der Patienten sind. Es liegt keine geschlechtsspezifische Prädisposition vor. Jedoch erkranken Frauen in der Regel häufiger an der AD als Männer. Dieser Umstand ist mit dem höheren Anteil von Frauen in der Erkrankungsaltersgruppe zu erklären (Fillit et al. 2002).

Aufgrund der sich weltweit verändernden Altersstruktur wird für das Jahr 2030 eine erhebliche Zunahme der Erkrankung bis auf 60 Millionen Fälle weltweit vermutet. Die daraus resultierenden sozioökonomischen Kosten sind enorm, wenn man bedenkt, dass die Pflege eines einzigen Alzheimerpatienten in der Bundesrepublik Deutschland ca. 44000 Euro pro Jahr kostet (Hallauer et al. 2000). Eine möglichst frühe Diagnose der Erkrankung wäre hinsichtlich der therapeutischen Behandlung ausgesprochen wichtig und auch aus ökonomischer Sicht vorteilhaft, weil ein früher Behandlungsbeginn möglicherweise den Zeitpunkt der erhöhten Pflegebedürftigkeit hinauszögern könnte und dadurch die Pflegekosten gesenkt würden. Um die Lebensqualität der Patienten zu verbessern und die resultierenden Kosten zu senken, gibt es intensive Forschungen, welche die Therapie und Früherkennung der AD verfeinern sollen. 


\subsubsection{Pathogenese}

\subsubsection{Morphologische Veränderungen im ZNS}

Bei der Alzheimerkrankheit findet man eine Atrophie der Hirnrinde, die besonders die Frontal-, Temporal- und Parietallappen betrifft. Im fortgeschrittenen Stadium kann diese Atrophie auch auf die Marklager übergehen. Histopathologisches Korrelat der AD ist der Untergang von Neuronengruppen. So findet sich auf subkortikaler Ebene häufig ein Untergang des Nucleus basalis Meynert, welcher über cholinerge Fasern in die Großhirnrinde projiziert (Schliebs und Arendt 2006, Geula et al. 2008). Besonders ist das noradrenerge System des Locus coeruleus betroffen, dessen aufsteigende Bahnen aus dem Nucleus raphe dorsalis unter anderem in den Hippokampus und den Neokortex ausstrahlen. Veränderungen in diesen Systemen können die nicht kognitiven Beschwerden der Patienten erklären. Mikroskopische Veränderungen im frontalen und temporoparietalen Assoziationskortex sowie im entorhinalen Kortex und im Hippokampus mit Abnahme der Synapsendichte stehen im Zusammenhang mit Einbußen der kognitiven Leistungen (Reitz et al. 2009, Ondrejcak et al. 2010).

Das Auftreten von extrazellulären Proteinablagerungen in Form von $\beta$-Amyloid-Plaques und intrazellulären Fibrillenveränderungen, sogenannten Tangles, stellt einen Stimulus für die Aktivierung von Mikroglia, Freisetzung von Komplementfaktoren und Ausschüttung von Entzündungsmediatoren dar (Akiyama et al. 2000).

\subsubsection{Amyloid-Precursor-Protein-Prozessierung}

Das Amyloid-Vorläuferprotein (APP, Synonym: Amyloid Precursor Protein) ist ein Transmembranprotein, das von vielen Zellentypen des Organismus gebildet wird und zahlreiche Aufgaben in Vorgängen der Neuroprotektion, der synaptischen Transmission, des axonalen Transports, des Neuritenwachstums und der Signaltransduktion besitzt (Evin und Weidemann 2002, Aslan und Ozben 2004, Mattson et al. 1993, Zhou et al. 2007).

Das Gen, dieses Proteins ist auf Chromosom 21 lokalisiert. Untersuchungen an DownSyndrom-Patienten (Patienten mit Trisomie 21) ergaben einen Zusammenhang zwischen AD und dieser genetischen Erkrankung, da Trisomie 21 unweigerlich zur AD-Pathologie führt (Lott und Head 2001). Das Protein kommt in verschiedenen Isoformen vor (APP 695, 
APP 751 und APP 770), wobei APP 695 ausschließlich in Neuronen gebildet wird (Mills und Reiner 1999).

APP 695 kann auf 2 Arten posttranslational prozessiert werden. Hierbei wird ein amyloidgener und ein nicht-amyloidgener Weg unterschieden. Bei diesem Vorgang sind Proteasen, sogenannte Sekretasen beteiligt, die APP hydrolytisch an verschiedenen Stellen spalten können (Sisodia 1992, Esch et al. 1990).

Der überwiegende Teil des membranständigen Proteins wird mithilfe der $\alpha$-Sekretase und anschließend durch die $\gamma$-Sekretase in lösliche, nicht pathogene Peptide gespalten. Die $\alpha-$ Sekretase schneidet dabei in der $\beta$-Amyloid-Domäne des APP, wodurch kein pathogenes $\beta$-Amyloid $(A \beta)$ entstehen kann. Im alternativen Weg übernimmt die $\beta$-Sekretase die Aktivität der $\alpha$-Sekretase. Hierbei entstehen im Zusammenspiel mit der $\gamma$-Sekretase 38 bis 42 Aminosäuren lange Peptide (z.B. $A \beta$ 1-38, $A \beta$ 1-40, $A \beta$ 1-42) (Haass und Selkoe 2007). Etwa $90 \%$ der gebildeten $A \beta$-Peptide sind 40 Aminosäuren lang ( $A \beta$ 1-40), nur ein kleiner Teil von etwa $10 \%$ besteht aus 42 Aminosäuren (Aß 1-42) (Zimmermann et al. 2005).

Hierbei ist besonders entscheidend, in welchem Verhältnis die längere zur kürzeren Peptidvariante gebildet wird. Es konnte gezeigt werden, dass $A \beta$ 1-42 im Gegensatz zu $A \beta$ 1-40 viel stärker zu Amyloidablagerungen neigt. Dies ist auf die erhöhte Lipophilie dieses Peptides zurückzuführen (Kawahara 2004). Durch forcierte $\alpha$-Sekretasetätigkeit wird ein signifikanter Rückgang der Aß-Formationen erreicht (Buxbaum et al. 1993).

\subsubsection{3 $\beta$-Amyloid-Plaques}

Dem Protein $A \beta$ kommt eine wichtige Rolle in der Pathogenese der $A D$ zu. A $A$-Plaques sind Ablagerungen einer Reihe von Substanzen in der extrazellulären Grundsubstanz des Kortex und des Hippokampus sowie in der Basalmembran zerebraler Blutgefäße (Bauer et al. 1995, Mulder und Terwel 1998, Smith 2000). Sie enthalten hauptsächlich A . Die pathogenetischen Zusammenhänge zwischen den Aß-Plaques und der AD konnten bis heute nicht sicher geklärt werden (Selkoe 2001).

Durch die Tätigkeit der $\mathrm{y}$-Sekretase können unterschiedliche Varianten des unlöslichen $A \beta$-Peptides entstehen. Die $\gamma$-Sekretase ist ein Proteinkomplex, der aus Präsenilin und zahlreichen weiteren Proteinen (Nicastrin, Aph1 und Pem-2) gebildet wird. Das Präsenilin1-Gen liegt auf Chromosom 14, wohingegen das Präsenilin-2-Gen auf Chromosom 1 lokalisiert ist. Mutationen in den Präsenilin-Genen beeinflussen die räumliche 
Konfiguration des Proteinkomplexes und folglich die Arbeitsweise der $\mathrm{Y}$-Sekretase, wodurch neurotoxisches $A \beta$ 1-40 und $A \beta$ 1-42 entstehen kann (Suzuki et al. 1994).

\subsubsection{Neurofibrilläre Degeneration}

Auch intrazelluläre Neurofibrillenbündel gelten als neurohistopathologische Marker der AD, obgleich sie im hohen Lebensalter ebenso im Gehirn von klinisch gesunden Menschen und auch bei anderen Hirnerkrankungen auftreten können. Sie sind in Neuriten und im neuronalen Perikaryon lokalisiert und enthalten im Wesentlichen pathologisch verändertes Tau-Protein und Mikrotubulifragmente. Als Bestandteil des neuronalen Zytoskeletts sind Mikrotubuli von Bedeutung für die Stabilität und Funktion der Nervenzellen. An die Mikrotubuli sind sogenannte Mikrotubuli-assoziierte Proteine angelagert. Zu diesen gehört auch Tau, ein Phosphoprotein, das den wichtigsten Bestandteil der Neurofibrillenbündel darstellt. Bei der AD erfolgt eine abnorme Hyperphosphorylierung des Tau-Proteins, das dadurch nicht mehr an Mikrotubuli bindet. Diese werden somit instabil und akkumulieren als paarige helikale Filamente. Dies führt zur Entstehung von Neurofibrillenbündeln, welche als „neurofibrilläre tangles“ bezeichnet werden. Die größte Anzahl von Neurofibrillenbündeln ist bei der $A D$ in den Hirnarealen mit der stärksten neuronalen Degeneration zu finden (Bauer et al. 1995, Myers und Goate 2001, Richard und Amouyel 2001, Selkoe 2001).

\subsubsection{Alzheimer-Demenz und Inflammation}

Auch inflammatorische Geschehen spielen eine erhebliche Rolle bei der Entstehung von neurodegenerativen Erkrankungen. So lässt sich beispielsweise in Gehirnen von ADPatienten eine Aktivierung von Mikroglia, den wichtigsten immunologisch wirksamen Zellen im ZNS, finden (Aloisi 2001, Raivich und Banati 2004).

Nach der Mikroglia-Dysfunktion-Hypothese nach Streit haben Mikroglia in gesunden Gehirnen protektive Funktionen, deren Hauptaufgabe in der Gewährleistung der neuronalen Vitalität und Funktionalität liegt (Streit 2002). Ein wichtiger Aspekt der mikroglialen Schutzfunktion ist demnach die Regulation des Abbaus von anfallendem $A \beta$. Dysfunktionen führen zu einer Anreicherung und Akkumulation von $A \beta$ mit Ausbildung der 
spezifischen Plaquestrukturen (Streit 2004).

Weiterhin findet man Entzündungsreaktionen in unmittelbarer Nähe der abgelagerten Plaques mit Erhöhung der Zytokinaktivität (insbesondere Interleukin-1 $\beta$, Interleukin-6 und Tumor-Nekrose-Faktor- $\alpha$ ), lokaler Akute-Phase-Reaktion und einer Aktivierung der Komplementkaskade. Diese immunologischen Reaktionen verursachen möglicherweise eine Schädigung der Nervenzellen und führen so zu einer Verstärkung der pathologischen Prozesse (In't Veld et al. 2001, McGeer EG et al. 2001). Grund zu dieser Annahme liefern auch Forschungen mit antiinflammatorischen Substanzen, die einen protektiven Einfluss auf dieses Entzündungsgeschehen haben sollen (Lee et al. 2010).

\subsubsection{Symptome}

Die ersten Anzeichen der AD äußern sich in recht unspezifischen Symptomen wie Kopfschmerzen, Schwindel und allgemeiner Leistungsschwäche. In diesem Stadium ist eine konkrete Diagnosestellung sehr schwierig .

Frühe Zeichen, die eine Erkrankung vom Alzheimer-Typ vermuten lassen, sind Gedächtnisstörungen und Wortfindungsstörungen. Diese können mehr oder weniger stark ausgeprägt sein, verschlimmern sich jedoch im Laufe der Erkrankung erheblich.

Die kognitiven Einbußen sind vor allem im Rahmen des Kurzzeitgedächtnisses zu finden, wohingegen das Langzeitgedächtnis lange intakt bleibt. Das Aufnehmen und Verarbeiten von neuen Informationen bereitet den Patienten erhebliche Schwierigkeiten. An Ereignisse, die lange in der Vergangenheit geschehen sind, können sich Erkrankte erstaunlich lange erinnern.

Die Patienten werden vergesslich und verlieren den Überblick selbst über sehr vertraute Situationen und Aufgaben. Mit der Reduktion der Merkfähigkeit stellen sich nach und nach Probleme bei der Bewältigung des alltäglichen Lebens, beispielsweise bei der regelmäßigen Einnahme von Medikamenten, ein.

Das Frühsymptom der Wortfindungsstörung kann nach einiger Zeit in Echolalie, Perservationen bis hin zu Neologismen gipfeln. Im neurologischen Status sind die Patienten meist weder zeitlich noch örtlich, seltener auch zur eigenen Person nicht vollkommen orientiert. Weitere neuropsychologische Symptome sind bilaterale Apraxie, Aphasie, Akalkulie und Alexie. In der körperlichen Untersuchung findet man oft leichte Reflexdifferenzen. Pathologische Hand- und Mundgreifreflexe sind häufig auslösbar. 
Bei den nicht kognitiven Störungen sind Antriebsmangel und Verstimmungszustände bis hin zur Depression zu nennen. Diesen Symptome wird jedoch häufig weniger Beachtung geschenkt, obgleich sie auf eine Therapie verhältnismäßig gut ansprechen. Affektlabilität mit Aggressivität, selbst gegen Bezugspersonen, sowie Erregungszustände bis hin zu Wahngedanken mit paranoiden Ideen und Halluzinationen wurden beschrieben (Lykouras und Gournellis 2011). Die Erkrankung führt schließlich zu Demenz, schwerster Invalidität und folglich zu Pflegebedürftigkeit.

Differentialdiagnostisch ist die $A D$ von anderen Demenzformen und der vaskulären Enzephalopathie abzugrenzen, die infolge von zerebralen Multiinfarkten ebenfalls zur Demenz führen kann (Böcker et al. 2008).

\subsubsection{Diagnostik}

Eine eindeutige Diagnose ist bei der AD zur Zeit leider erst nach dem Tod durch die histochemische Untersuchung des Gehirns möglich. Das Zusammenspiel aus klinischen, laborchemischen, bildgebenden sowie neuropsychologischen und neurophysiologischen Untersuchungen bildet die Grundlage der Diagnosefindung zu Lebzeiten. Da die Symptome und Veränderungen der Erkrankung in frühen Stadien sehr unspezifisch sind, ist eine klare Diagnosestellung hier oftmals schwierig.

Die klinische Diagnose wird nach den Kriterien der International Statistical Classification of Diseases 10, und des Diagnostic and Statistical Manual of Mental Disorders (DSM-IV) der American Psychiatric Association gestellt; laut DSM-IV wird eine Gedächtnisstörung plus mindestens eines der neurologischen Symptome Aphasie, Apraxie, Agnosie oder Störungen der Exekutivfunktionen zur Diagnosestellung verlangt. Die Diagnose kann erst nach Ausschluss anderer Demenzursachen gestellt werden (Pull 1995). Das heißt, die kognitiven Defizite dürfen nicht durch andere Erkrankungen des ZNS, welche progrediente Defizite in Gedächtnis oder Kognition verursachen (z.B. zerebrovaskuläre Erkrankung, Morbus Parkinson und Morbus Huntington), durch systemische, als Demenzursache bekannte Erkrankungen (z.B. Hypothyreoidismus, Vitamin-B12-Mangel, HumanImmunodeficiency-Virus (HIV)-Infektion) oder durch die länger anhaltende Wirkung einer Substanz (z.B. Alkohol) erklärbar sein (Geldmacher und Whitehouse 1997, Vicioso 2002).

Der verbreitetste neuropsychologische Test ist der Mini-Mental-Status-Test (MMSE, Synonym: Mini-Mental-State-Examination) nach Folstein, welcher zur Einschätzung des 
Ausmaßes der Demenz angewendet wird. Dabei wird die kognitive Leistungsfähigkeit bzw. Beinträchtigung anhand einer 30-Punkte-Skala bewertet. Folgende Punkteeinteilung hat sich hierbei etabliert:

- 0-11 schwere Demenz

- 12-18 mittelschwere Demenz

- 19-23 leichte Demenz

- 24-26 kognitive Beeinträchtigung

- 27-30 unbeeinträchtigte Leistungsfähigkeit (Folstein et al. 1975).

Im Uhren-Test nach Shulman wird der Patient gebeten, eine bestimmte Uhrzeit in eine von inm selbst angefertigte Uhrenskizze unter Berücksichtigung des Minuten- und Stundenzeigers einzuzeichnen. Es handelt sich hierbei um eine Screening-Methode zur Prüfung der Visuokonstruktion (parietale Funktion) und des Problemlösens (frontale Funktion) (Shulman et al. 1993).

Daneben findet die apparative Diagnostik zunehmend Anwendung. In der Computertomographie (CT) und der Magnetresonanztomographie (MRT) finden sich, je nach Stadium, Volumenminderungen über der gesamten Hirnrinde mit Betonung des medialen Temporallappens. Es besteht jedoch kein eindeutiger Zusammenhang zwischen Ausmaß der Atrophie und klinischen Leistungseinschränkungen. Die PositronenEmissions-Tomographie (PET) kann Veränderungen des Glucosemetabolismus vor allem in temporalen und parietalen Regionen zeigen. Mit Hilfe der PET ist es möglich, ohne Histologie die AD mit hoher Sicherheit von der Lewy-Körperchen-Demenz abzugrenzen (Lehéricy et al. 2007, Mosconi et al. 2007).

Bei den invasiven Techniken ist die Liquordiagnostik zu nennen. Hierbei liegt das Augenmerk auf dem Tau-Protein, dem APP und den Amyloid-Peptiden. Man findet eine Erniedrigung des $A \beta$ 1-42, während die Gesamtkonzentration von $A \beta$ (gemessen an der Konzentration von $A \beta$ 1-40) nahezu unverändert bleibt. Durch den Untergang von Neuronen reichert sich Tau-Protein im Liquor an. Sehr spezifisch für die AD ist das Auftreten von phosphoryliertem Tau-Protein im Liquor (Andreasen et al. 2003). Untersuchungen des Liquors bezüglich $A \beta$, des Tau-Proteins und des phospho-TauProteins stellen zur Zeit die beste und validierteste Möglichkeit dar, um die AD von anderen Demenzformen abzugrenzen (Marksteiner et al. 2007). Aktuellere Studien über 
diese Biomarker machen zwar Fortschritte bezüglich der Frühdiagnostik der AD und zeigen Tendenzen, haben jedoch noch keinen Einzug in die klinische Arbeitsweise gefunden (Mattsson et al. 2009).

\subsubsection{Therapie}

Derzeit ist keine kausale Therapie vorhanden, lediglich symptomatische Behandlung kann angeboten werden.

Der Mangel an Acetylcholin scheint eine wichtige Rolle für die Entstehung der kognitiven Symptome zu spielen. Aus diesem Grund werden Cholinesterase-Hemmstoffe (Donepezil, Rivastigmin, Galantamin), die das Vorhandensein des Acetylcholin im synaptischen Spalt zeitlich verlängern, eingesetzt. Der Prozess des kognitiven Abbaus kann somit verlangsamt werden. Vitamin E kann aufgrund seines leicht neuroprotektiven Effektes ergänzend hinzugefügt werden. Vom Einsatz von Benzodiazepinen wird aufgrund ihrer paradoxen Wirkung bei älteren Patienten und ihrer Kumulationstendenz abgeraten bzw. wird bei der Behandlung mit diesen Substanzen eine engmaschige Überwachung empfohlen. Bei Depressivität können Serotonin-Wiederaufnahme-Hemmer verabreicht werden. Aufgrund ihrer anticholinergen Wirkung sind trizyklische Antidepressiva kontraindiziert (Grossberg 2005, Soto et al. 2007). Sinnvoll sind ferner eine Bewegungstherapie sowie ein maßvolles Training der verbleibenden geistigen Funktionen. Dabei ist jedoch darauf zu achten, dass der Patient nicht überfordert wird. Der Erhalt der geistigen Aktivität des Erkrankten durch maßvolles Training verzögert das Auftreten eines demenziellen Syndromes signifikant. Das Aufstellen von Orientierungshilfen, wie Warnschilder und Kalender, kann den Betroffenen helfen, sich in ihrer eigenen Wohnung zurechtzufinden und das alltägliche Leben zu bestreiten. Selbsthilfegruppen, in denen sich die Patienten über ihre Probleme und Sorgen austauschen, werden ebenfalls angeboten. Des Weiteren ist das Training der Angehörigen, die den Patienten in der häuslichen Betreuung unterstützen sollen, ein wichtiger Bestandteil der Therapie (Hüll und Voigt-Radloff 2008). 


\subsection{Bakterielle Meningitis}

\subsubsection{Epidemiologie und klinisches Bild}

Die bakterielle Meningitis bei Kleinkindern und Erwachsenen wird am häufigsten durch Streptococcus pneumoniae (S. pneumoniae) verursacht (Dagan 2000). Weitere häufige Erreger sind Neisseria meningitidis, Haemophilus influenzae und Listeria monocytogenes (Williams und Nadel 2001). Durch Pneumokokken verursachte Meningitiden besitzen hohe Letalitätsraten. Trotz wirksamer Antibiotikatherapie versterben bis zu 20-30\% aller Patienten mit einer Pneumokokkenmeningitis. Bis zu $40-50 \%$ aller Patienten leiden unter

Spätfolgen, wie z.B. kognitiven Einschränkungen, Lern- und Gedächtnisschwierigkeiten, epileptischen Anfällen, Paresen und Hörstörungen (Bohr et al. 1984, Durand et al. 1993, Pfister et al. 1993).

Die Symptome reichen von Kopf- und Nackenschmerzen, Meningismus-Zeichen, ReizÜberempfindlichkeit, Fieber, Übelkeit, Erbrechen bis hin zu epileptischen Anfallsleiden (Stevenson 1973, Koedel et al. 2002).

Von erheblicher prognostischer Bedeutung ist der rasche und gezielte Einsatz von Antibiotika. Jedoch konnte in den vergangenen 4 Jahrzehnten trotz intensiver Forschung auf dem Gebiet der antibakteriellen Therapie keine signifikante Verbesserung der Morbiditäts- und der Mortalitätsrate erzielt werden (Durand et al. 1993).

\subsubsection{Streptococcus pneumoniae}

\subsubsection{Geschichte}

Ihren Namen haben die Streptokokken Billroth zu verdanken, der sie im Jahre 1874 erstmals nach ihrem Ketten-ähnlichen Erscheinungsbild unter dem Mikroskop beschrieb. Der US-Amerikaner Sternberg und der französische Wissenschaftler Pasteur isolierten 1881 nahezu zeitgleich und unabhängig voneinander Pneumokokken (Sternberg 1881). Ein Jahr später zeigte Friedländer einen klinischen Zusammenhang zwischen dem Bakterium S. pneumoniae und der Lungenentzündung (Friedländer 1882). 1885 gelang es Fränkel an der Charité Berlin, den Erreger erstmals in Reinkultur zu züchten und seine 
Pathogenität an der Maus unter Beweis zu stellen (Henrichsen 1999).

\subsubsection{Charakteristika und Epidemiologie}

S. pneumoniae (Synonym: Pneumokokken, Diplococcus pneumoniae) zählt zur Gattung der Streptokokken. Das Bakterium ist ein Gram-positives Stäbchen, welches Katalasenegativ ist und fakultativ anaerob wachsen kann.

Unter einem Wachstumsoptimum von $37^{\circ} \mathrm{C}$ und $5-10 \%$ iger $\mathrm{CO}_{2}$-Atmosphäre lassen sich S. pneumoniae auf Blutagar anzüchten. Sie besitzen die Fähigkeit zur a-Hämolyse. Aufgrund ihrer fehlenden Eigenschaft zur $\beta$-Hämolyse werden sie nach der BrownKlassifikation in die Gruppe der nicht $\beta$-hämolysierenden Streptokokken eingeteilt (Facklam 2002). Im Gegensatz zur $\beta$-Hämolyse werden bei der $\alpha$-Hämolyse die Erythrozytenwände nicht geschädigt und bleiben damit weitestgehend intakt (Gibson et al. 1999). Somit kann kein Hämoglobin $(\mathrm{Hb})$ austreten und in die Umgebung diffundieren. Bei der $\alpha$-Hämolyse wird das $\mathrm{Hb}$ im Inneren der Erythrozyten zu Biliverdin reduziert, welches als grünlich verfärbter Hof um die Bakterienkolonie imponiert. Dieser Vorgang wird auch als Vergrünung bezeichnet (Facklam 2002, Murdoch 1998).

Makroskopisch imponiert S. pneumoniae als kleine, runde, kuppelförmige und schleimig aussehende Kolonie. Des Weiteren werden Optochin-Sensitivität und Galle-Löslichkeit als Identifikationskriterium für S. pneumoniae genutzt (Mundy et al. 1998).

Die für den Menschen pathogenen Stämme bilden eine schützende Polysaccharidkapsel aus, sie werden als „smooth“ bezeichnet. Für den Menschen apathogene Stämme ohne umhüllende Kapsel bezeichnet man hingegen als „rough“ (Thompson und Eisenstein 1975). Von dieser Polysaccharidkapsel sind bisher 90 unterschiedliche Serotypen identifiziert worden (Bentley et al. 2006).

Im Menschen kommt S. pneumoniae häufig als Kommensale der Schleimhäute des oberen Respirationstraktes vor und ist auf der Bindehaut der Augen zu finden. Weltweit gehört die durch S. pneumoniae verursachte Pneumokokkenpneumonie zu einer der häufigsten bakteriell verursachten Infektionskrankheiten. Darüber hinaus ist $S$. pneumoniae gehäuft Ursache der Otitis media des Kleinkindes, der Meningitis sowie der Pneumonie älterer Menschen und immunkompromittierter Patienten, wie z.B. HIVPatienten. Weiterhin können Pneumokokken Arthritiden und Peritonitiden verursachen (Rubins et al. 1993). Bei splenektomierten Patienten ist das „overwhelming-post- 
splenectomy-infection“ (OPSI)-Syndrom in ca. $80 \%$ der Fälle durch S. pneumoniae verursacht (Lucas 1991). Insgesamt sterben in der Bundesrepublik Deutschland jährlich ca. 12000 Menschen an den Folgen einer Pneumokokkeninfektion (Mielke und Stück 2004).

\subsubsection{Virulenzfaktoren}

Der wichtigste Virulenzfaktor der pathogenen S. pneumoniae stellt die Polysaccharidkapsel dar. Die Hauptfunktion der Kapsel besteht in der Inhibition des wirtseigenen Phagozytosesystems. Einen weiteren Virulenzfaktor stellt das vom Bakterium gebildete, porenbildende Toxin Pneumolysin dar (Rubins et al. 1996, Bonev et al. 2001). Dieses Enzym wird bei der Lyse von S. pneumoniae freigesetzt, kann aber durch manche Stämme auch frei sezerniert werden (Balachandran et al. 2001). Pneumolysin hat zum einen die Eigenschaft, Zellen zu lysieren, gleichzeitig ist es in der Lage, das Immunsystem des Wirtes zu aktivieren und so eine Entzündungsreaktion hervorzurufen. Die Freisetzung von Pneumolysin kann beispielsweise beim Einsatz von zellwandsynthesehemmenden Antibiotika oder Nährstoffmangel auftreten (Cockeran et al. 2002, Mitchell 2000). Die Hyaluronat-Lyase, ein weiterer Virulenzfaktor, erleichtert die Infektion des Wirtes durch Abbau der extrazellulären Matrix des Gewebes. Abschließend sind zwei Neuraminidasen (Neuraminidase 1, Neuraminidase 2) zu nennen, welche die Zellen des Wirtes durch Spaltung von Oberflächenglykanen schädigen (Lock et al. 1988 a, Lock et al. 1988 b).

\subsubsection{Antibiotikatherapie und Resistenzen}

Mittel der Wahl zur Therapie von Pneumokokkeninfektionen ist Penicillin, alternativ können Cephalosporine der 3. Generation oder Erythromycin verabreicht werden (Herbert und Dörries 2005). Allerdings nimmt weltweit die Häufigkeit der Antibiotika-resistenten Stämme zu. Gemäß Hoban et al. waren 1999 22\% der Pneumokokken in Europa resistent gegenüber Penicillin und 25\% gegenüber Erythromycin bei steigender Tendenz (Hoban et al. 2001). Reinert et al. stellten fest, dass 24,6\% europäischer S. pneumoniae-Isolate Penicillin-unempfindlich sind (Reinert et al. 2005). Diese Entwicklung beruht auf Modifikationen im Genom des Erregers. Dabei werden die Penicillin-Bindeproteine so 
verändert, dass eine geringere Affinität und Empfindlichkeit gegenüber den Penicillinen entsteht (Tomasz und Munoz 1995). Festgehalten sei an dieser Stelle, dass der inadäquate Einsatz von Antibiotika zu einer Verschlimmerung der Resistenzentwicklung führt. So ist beispielsweise vom alleinigen Einsatz von Makroliden bei der Therapie von S. pneumoniae-Infektionen abzuraten. So sind in Deutschland über 15\% (Reinert et al. 2002), in Spanien und den USA sogar bis zu 35\% (Sokol 2001) der S. pneumoniae-Isolate resistent gegen diese Antibiotikaklasse. In Europa beläuft sich die Resistenz gegenüber Makrolidantibiotika im Mittel auf 28,6\% (Reinert et al. 2005). Zusammenhänge in der Häufigkeit der Verordnung von Makroliden zur Therapie von Infektionskrankheiten und der zunehmenden Resistenz von Pneumokokken gegen diese Antibiotikagruppe konnten wissenschaftlich belegt werden. Dies ist beunruhigend, wenn man bedenkt, dass Makrolide häufig zur Therapie von Infektionen der oberen Atemwege eingesetzt werden (Pihlajamäki et al. 2001).

\subsubsection{Das Antibiotikum Ceftriaxon}

Ceftriaxon ist ein Cephalosporinantibiotikum der 3. Generation mit breitem Wirkspektrum (Bergan 1987). Es gehört wie Penicillin zu den $\beta$-Lactamantibiotika, die eine bakterizide Wirkung besitzen (Adu und Armour 1995). Ceftriaxon besitzt neben Cefotaxim im grampositiven Bereich das größte Wirkspektrum aller 3.-Generations-Cephalosporine und deckt gleichzeitig ein großes Spektrum gramnegativer Keime ab (Klein und Cunha 1995). Der Eliminationsweg geschieht etwa zu gleichen Teilen über Niere und Leber. Ceftriaxon besitzt eine besonders lange Elimationshalbwertzeit von ca. 8 Stunden, sodass es möglich ist, Ceftriaxon nur einmal pro Tag parenteral zu verabreichen (Brogden und Ward 1988, Frenkel 1988).

Die Wirkungsweise von Ceftriaxon entspricht der der Penicilline, wobei der $\beta$-Lactamring, der ein gemeinsames Strukturmerkmal darstellt, für die bakterizide Wirkung wichtig ist. Wie bei allen Cephalosporinen sind die Angriffsorte von Ceftriaxon die Peptidoglykansynthetasen (Mureinsynthetasen), die verschiedene konstruktive Funktionen beim Aufbau der Bakterienzellwand haben. Der $\beta$-Lactamring, welcher dem Substrat der Mureinsynthetasen strukturverwandt ist, blockiert durch Acylierung des Enzyms den Aufbau der schützenden Bakterienzellwand. Da Mureinsynthetasen im menschlichen Organismus nicht vorhanden sind, sind $\beta$-Lactamantibiotika relativ gut verträglich (Rosin 
und Henschler 1996). Sie können daher in hohen Dosen, ohne Wechselwirkungen zu verursachen verabreicht werden. Nebenwirkungen, wie beispielsweise epileptische Anfälle, treten nach intrathekaler Applikation deutlich häufiger als nach intravenöser Gabe auf. $\beta$-Lactamantibiotika erreichen nach intravenöser Gabe niedrige Konzentrationen in der Cerebrospinalflüssigkeit. Dieser Umstand ist durch ihre hydrophile Struktur und ihre hohe Affinität zu einer Protonen-Auswärtspumpe, welche der Penetration in die Cerebrospinalflüssigkeit entgegen wirkt, bedingt. Auch in entzündeten Bereichen des ZNS, etwa infolge einer Meningitis, ist ihre Anreicherung im Vergleich zu anderen Antibiotikaklassen wie z.b. Fluorchinolone eher gering. 3.-Generations-Cephalosporine besitzen ein ideales Aktivitätsspektrum, um ambulant erworbene Meningitiden zu behandeln, und sind dafür auch zugelassen (Nau et al. 2010, Roberts und Lipman 2009, Prasad et al. 2007).

Ceftriaxon und allgemein Cephalosporine wirken nur auf wachsende, nicht jedoch auf ruhende Keime. Dieser Umstand erklärt, warum es bei zu kurzer Anwendung der Therapie nicht zum kompletten Absterben der Bakterien, sondern zu Rezidiven kommen kann (Estler 2000). 


\subsection{Ziele der Arbeit}

Der klinisch-neurologische und neuropsychologische Status von Patienten, die an einer neurodegenerativen Erkrankung, wie Alzheimer-Demenz, Morbus Parkinson oder Amyotropher Lateralsklerose, leiden, verschlechtert sich häufig durch begleitende bakterielle Infektionen. Ein genaueres Verständnis dieses klinisch beobachteten Phänomens ist die Voraussetzung für die Entwicklung verbesserter Therapieansätze.

In Vorarbeiten unserer Arbeitsgruppe führte eine einmalige systemische Infektion mit S. pneumoniae zu einer Verschlechterung des klinischen Zustandes von Mäusen mit EAE (Mausmodell der MS). In vitro bewirkten $A \beta$ und bakterielle Toll-like-Rezeptor-Agonisten eine synergistische Aktivierung von Mikrogliazellen. Wiederholte systemische S. pneumoniae-Infektionen mit anschließender antibiotischer Behandlung hatten allerdings keinen Einfluss auf den Krankheitsbeginn und -verlauf der AD, des Morbus Parkinson und der ALS im Mausmodell. Die S. pneumoniae-Meningitis führte bei Wildtypmäusen zu einer Verschlechterung der neuropsychologischen Fähigkeiten.

Ziel der vorliegenden Arbeit war es, den Einfluss einer einmaligen intrazerebralen Infektion mit S. pneumoniae mit anschließender antibiotischer Behandlung auf Tg2576-Mäuse (Alzheimer-Modell) zu untersuchen. Es sollten insbesondere folgende Fragen beantwortet werden:

1. Ist der verwendete Versuchsaufbau in der Lage, einen klinischen Unterschied zwischen nicht-transgener und transgener Population der Tg2576-Mauslinie aufzuzeigen?

2. Gibt es Unterschiede bezüglich der Empfindlichkeit auf eine intrazerebrale Infektion mit S. pneumoniae zwischen nicht-transgener und transgener Population der Tg2576-Mauslinie?

3. Beeinflusst eine intrazerebrale Infektion mit S. pneumoniae den Verlauf der AD und die Konzentration von A $\beta$ im Gehirn bei transgenen Tg2576-Mäusen? 


\section{MATERIAL UND METHODEN}

\subsection{Versuchstiere}

Die tierexperimentellen Untersuchungen wurden an 11 bis 14 Monate alten Mäusen des Stammes Tg2576 durchgeführt. Die Genehmigung für die Experimente wurde nach positivem Votum der Tierschutzkommission der Medizinischen Fakultät der Universität Göttingen von der Bezirksregierung Braunschweig, Niedersachsen erteilt.

Wasser und Nahrung wurden den Tieren ad libitum zur Verfügung gestellt. Die Versuchstiere wurden während der tierexperimentellen Versuche 3 mal wöchentlich gewogen. Bei einem Gewichtsverlust über $15 \%$ des Ausgangswertes wurden die Tiere aus tierschutzrechtlichen Gründen durch zervikale Dislokation getötet.

Gehalten wurden die Mäuse Geschlechter-getrennt in Gemeinschaftskäfigen zu maximal 7 Tieren bei konstant $20^{\circ} \mathrm{C}$ und einer relativen Luftfeuchte von $55 \%$. Auf die Einhaltung des Tag/Nachtzyklus wurde geachtet. Mit Beginn der neuropsychologischen Tests wurden die Tiere in Einzelkäfige umgesetzt. Aufgefallen ist, dass vor allem die männlichen Tiere gegenüber ihren Artgenossen steigendes aggressives Verhalten zeigten und daher schon vor Versuchsbeginn vereinzelt werden mussten. Insgesamt wurden 77 transgene Mäuse $\left(\mathrm{Tg}^{+}\right)$und 19 nicht-transgene Mäuse $\left(\mathrm{Tg}^{-}\right)$verwendet. Zur Unterscheidung wurden die Tiere in den ersten 2 Wochen nach Geburt durch Ohrmarkierungen gekennzeichnet. Die dadurch gewonnenen Biopsate wurden zur Genotypisierung mittels PolymeraseKettenreaktion (PCR) zum Nachweis des humanen Amyloid-Vorläuferprotein (hAPP, Synonym: human Amyloid Precursor Protein)-695-Gens verwendet.

Der Tg2576-Mäusestamm wurde 1995 von Dr. K. Hsiao, Minnesota entwickelt und beschrieben (Hsiao et al. 1995, Hsiao et al. 1996). Die Mäuse tragen in ihrem Genom die Sequenz für das hAPP 695 mit der Doppelmutation Lys670-Asn und Met671-Leu (k670n, m671I), gefunden in einer schwedischen Familie mit früh beginnender AD, unter Kontrolle des Promotors für das Prion-Protein-Gen vom Hamster (Tg(hAPP695.k670nm671I)2576).

Der Stamm Tg2576 wurde freundlicherweise von Prof. Dr. med. R. Schliebs aus dem Paul-Flechsig-Institut für Hirnforschung, Universität Leipzig, zur Verfügung gestellt. 
Gehalten und neu verpaart wurden die Mäuse in der Zentralen Tierexperimentellen Einrichtung (ZTE) der Universitätsmedizin Göttingen. Die F1-Generation der C57BL/6 / SJL-Mäuse wurde rückgekreuzt mit C57BL/6-Tieren, und es entstanden in der F2Generation Individuen, bei denen das humane APP, verglichen mit endogenem Maus-APP, um das Fünffache überexprimiert ist (Hsiao et al. 1996). Das humane $A \beta$ ist bei diesen Tieren von Geburt an nachweisbar, zuerst in löslicher Form und vom 8. bis 10. Lebensmonat an als Thioflavin-S-positive Aß-Plaqueablagerungen, die ab ca. dem 15. Monat progressiv akkumulieren. Weibliche Mäuse können bis zu dreimal mehr Plaques ausbilden als männliche Artgenossen (Callahan et al. 2001). Die Mutation im APP-Gen hat keine Auswirkung auf die Lernfähigkeit junger 3 Monate alter Mäuse, jedoch lassen sich erhebliche Defizite in der Gedächtnisleistung von 9-10 Monate alten Tg2576-Mäusen im Vergleich zu nicht-transgenen Mäusen finden (Hsiao et al. 1996).

\subsection{DNA-Extraktion}

Das zu untersuchende Material für die Genotypisierung der Mäuse wurde im Alter von 2 Wochen im Rahmen der Nummerierung mittels Ohrmarkierungen gewonnen. In der Vorbereitung der DNA-Extraktion wurde Tail-Lysis-Puffer bestehend aus $100 \mathrm{mM}$ Tris(hydroxymethyl)-aminomethan (Tris), $5 \mathrm{mM}$ Ethylendiamintetraacetat (EDTA), $200 \mathrm{mM}$ $\mathrm{NaCl}$ und 1\%iges SDS angesetzt. Die Biopsate wurden in 1,5 ml EppendorfReaktionsgefäßen (E-Cups) mit $350 \mu$ l Tail-Lysis-Puffer und $20 \mu$ l Proteinase K überführt. Anschließend wurden die Proben bei $56^{\circ} \mathrm{C}$ für 5-6 Stunden geschüttelt. Nach 5 minütiger Zentrifugation bei $20000 \times g$ wurde der Überstand in ein neues E-Cup überführt, mit $350 \mu \mathrm{l}$ Isopropylalkohol aufgefüllt und vermischt. Im folgenden Arbeitsschritt wurden die Proben über einen Zeitraum von $10 \mathrm{~min}$ bei 20000 x g zentrifugiert. Der entstandene Überstand wurde verworfen. Die gewonnenen Pellets wurden in $350 \mu \mathrm{l} 70 \%$ igem Ethanol gewaschen. Die Proben wurden nun nochmals über 5 min bei $20000 \times g$ zentrifugiert. Der hieraus resultierende Überstand wurde abgegossen, und die nun entstandenen Pellets wurden bei Raumtemperatur getrocknet. Im Anschluss wurde jedes Pellet in $100 \mu$ doppelt destilliertem Wasser (Aqua bidest.) gelöst. Die Proben wurden bei $-20^{\circ} \mathrm{C}$ aufbewahrt. 


\subsection{Genotypisierung mittels Polymerase-Kettenreaktion}

\section{Hintergrund:}

Die PCR ist ein Verfahren, um DNA in vitro zu vervielfältigen. Der Begriff Kettenreaktion beschreibt dabei die Tatsache, dass das Produkt vorheriger Zyklen Ausgangsstoff für den folgenden Zyklus ist und somit eine exponentielle Vervielfältigung bestimmter DNAAbschnitte erfolgt. Bei jedem Zyklus müssen die DNA-Stränge durch Erhitzen auf ca. $95^{\circ} \mathrm{C}$ in Einzelstränge aufgespalten werden. Für den Vorgang der Vervielfältigung wurde früher eine aus Escherichia coli (E. coli) gewonnene Polymerase eingesetzt. Diese ist jedoch nicht hitzestabil und muss daher bei jedem Zyklus neu zugegeben werden, was diese Labormethode zunächst sehr kostspielig und zeitintensiv machte. Eine entscheidende Verbesserung des Verfahrens war die Entdeckung einer hitzestabilen aus dem Bakterium Thermus aquaticus gewonnenen Polymerase. Die sogenannte Taq-Polymerase muss nicht bei jedem Zyklus neu zugesetzt werden, was den Arbeitsablauf wesentlich vereinfacht (Saiki et al 1988). Zur qualitativen Auswertung werden die gewonnenen DNAFragmente auf ein Agarosegel aufgetragen und gelelektrophoretisch aufgetrennt.

\section{Durchführung:}

Zunächst wurde der Mastermix angesetzt. Dieser beinhaltet pro Probe jeweils 0,5 $\mu$ ler Primer 1501 -1503 (1501: 5`- AAG CGG CCA AAG CCT GGA GGG TGG AAC CA -3”; 1502: $5^{`}$ - GTG GAT AAC CCC TCC CCC AGC CTA GAC CA -3`, 1503: $5{ }^{`}$ - CTG ACC ACT CGA CCA GGT TCT GGG T -3`), 0,5 $\mu$ l Desoxyribonukleosidtriphosphat (dNTP), 2,5 $\mu$ l Puffer-Lösung, 6,21 $\mu$ l Aqua bidest. und 0,69 $\mu$ l Dimethylsulfoxid (DMSO). Anschließend wurden pro Probe 0,1 $\mu$ l Taq-Polymerase und $2 \mu$ der zu untersuchenden DNA hinzugefügt. Analog zur Proben-DNA wurde auch mit der Positiv- $\left(\mathrm{Tg}^{+}\right)$, der NegativKontrolle ( $\mathrm{Tg}^{-}$) sowie einer Nullprobe (Aqua dest.) verfahren. Alle Arbeitsschritte geschahen auf Eis. Anschließend wurden die Ansätze in einen Thermocycler überführt und amplifiziert $\left(95^{\circ} \mathrm{C}\right.$ für $3 \mathrm{~min}, 95^{\circ} \mathrm{C}$ für 40 sek, $54^{\circ} \mathrm{C}$ für 30 sek, $72^{\circ} \mathrm{C}$ für $\left.1 \mathrm{~min}\right)$. Dieser Zyklus wurde 35mal wiederholt.

Zur Herstellung des Agarose-Gels wurden $2 \mathrm{~g}$ Agarose mit $75 \mathrm{ml}$ Tris(hydroxymethyl)aminomethan-Borat-Ethylendiamintetraessigsäure-Puffer in einem Erlenmeyerkolben vermischt, bis zum Aufkochen in der Mikrowelle erhitzt und nach Zugabe von 2,5 $\mu$ l Ethylbromid in eine Gel-Ausgießform überführt. In das noch flüssige 
Agarose-Gel wurde nun ein Kamm, welcher die Taschen für die einzelnen Proben vorgibt, eingeführt. Nach diesem Arbeitsschritt wurde alles bei Raumtemperatur bis zur Verfestigung abgekühlt, und der Kamm wurde wieder entfernt.

Im Folgenden wurde das Agarose-Gel in eine mit TBE gefüllte Elektrophoresekammer befördert. Die Geltaschen wurden mit je 11,5 $\mu$ l Probe befüllt. Die Elektrophorese erfolgte bei 120 Volt für 45 min. Zur Bestimmung der Basenpaarlänge wurde $2 \mu 100$ bp-Marker verwendet. Schlussendlich wurden die Banden im Agarose-Gel mit UV-Licht sichtbar gemacht und fotographiert.

\subsection{Versuchsaufbau}

Der Versuch begann mit einer initalen Trainingsphase über 3 Tage, in der die motorischen und neuropsychologischen Tests eingeübt wurden. Anschließend wurde zum Zeitpunkt 0 die Infektion durchgeführt. In den nächsten 5 Tagen wurde eine Antibiose verabreicht (1. Antibiose an Tag 1; letzte Antibiose an Tag 6). Die Tiere wurden nach Infektion über einen Zeitraum von 31 Tagen mit unterschiedliche Methoden zu unterschiedlichen Zeitpunkten getestet. Die Experimente bestanden aus:

1. Morris Water Maze (siehe auch Kapitel 2.6)

2. Seiltest (siehe auch Kapitel 2.7.1)

3. Rotarod-Test (siehe auch Kapitel 2.7.2).

Nach 31 Tagen wurde der Versuch beendet. Alle Mäuse wurden, wie in Kapitel 2.1 beschrieben, getötet und anschließend präpariert (siehe auch Kapitel 2.8.1)(siehe auch Abb. 1). 


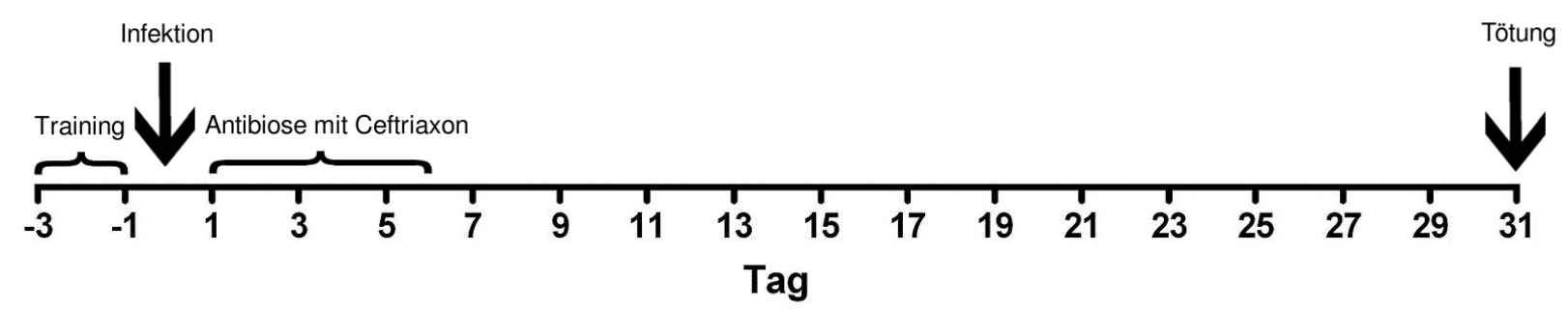

Abb. 1: Versuchsaufbau. Tag -3 bis -1 : Trainingsabschnitt; Tag 0: intrazerebrale Infektion; Tag 1 bis Tag 6 Antibiose mit Ceftriaxon; Tag 1 bis Tag 31: Testphase (Morris Water Maze, Seiltest, Rotarod-Test); Tag 31: Tötung und Präparation

\subsection{Infektion mit S. pneumoniae}

\subsubsection{S. pneumoniae-Typ-3-Stamm}

Für die Infektion wurde ein S. pneumoniae-Typ-3-Stamm verwendet, der ursprünglich von einem Patienten mit Meningitis isoliert wurde. Dieser Stamm wurde freundlicherweise von Prof. Dr. med. M.G. Täuber aus dem Institut für Infektionskrankheiten der Universität Bern, Schweiz zur Verfügung gestellt. Die Bakterien wurden initial über eine Passage im Kaninchen vermehrt. Danach wurden sie auf Blutagar angezüchtet, in isotone Kochsalzlösung $(\mathrm{NaCl})$ überführt und bei $-80^{\circ} \mathrm{C}$ aufbewahrt.

\subsubsection{S. pneumoniae-Inokulum}

Die Keimzahl des Inokulums betrug $4 \times 10^{9}$ Kolonie-bildende-Einheiten (CFU, Synonym: Colony Forming Units $/ \mathrm{ml}$. Nach dem Auftauen wurden die Bakterien mit $0,9 \% \mathrm{NaCl}$ auf eine Konzentration von ca. 1 × $10^{6} \mathrm{CFU} / \mathrm{ml}$ verdünnt. Die Infektion erfolgte intrazerebral auf die in Kapitel 2.5.1.3 beschriebene Art und Weise. Zur Virulenzkontrolle der Erreger wurden zusätzlich 4 Kontrollmäuse infiziert, welche später nicht antibiotisch behandelt wurden. Des Weiteren wurde zur Erregerkontrolle von der verwendeten Infektionslösung eine Verdünnungsreihe angefertigt, diese anschließend auf Blutagar ausplattiert und über 24 Stunden im Brutschrank bei $37^{\circ} \mathrm{C}$ inkubiert. Dabei ergab sich eine durchschnittliche Erregerkonzentration von $8.83 \times 10^{3} \mathrm{CFU} / \mathrm{ml}$. 


\subsubsection{Ceftriaxon}

Eine Ampulle $(1 \mathrm{~g})$ Ceftriaxon wurde in $10 \mathrm{ml}$ Aqua ad iniectabilia vollständig gelöst. Die Lösung $(100 \mathrm{mg} / \mathrm{ml})$ wurde in E-Cups aliquotiert und bei $-20^{\circ} \mathrm{C}$ aufbewahrt. Nach dem Auftauen wurde die Ceftriaxon-Lösung mit $0,9 \% \mathrm{NaCl}$ auf $10 \mathrm{mg} / \mathrm{ml}$ verdünnt, und der Maus wurde gewichtsadaptiert $10 \mu \mathrm{l} / \mathrm{g}$ Körpergewicht (KG) subkutan injiziert. Dies entspricht einer Ceftriaxonmenge von $100 \mathrm{mg} / \mathrm{kg} \mathrm{KG}$.

\subsubsection{3 intrazerebrale Infektion mit S. pneumoniae-Typ-3-Stamm}

Die Anästhesie der Mäuse erfolgte durch intraperitoneale Injektion (Einwegnadel, 24 Gauge) von $100 \mathrm{mg} / \mathrm{kg} \mathrm{KG} \mathrm{Ketamin} \mathrm{und} 10 \mathrm{mg} / \mathrm{kg} \mathrm{KG}$ Xylazin. Nachdem festgestellt wurde, dass die Mäuse frei von Reaktionen auf Umweltreize waren, wurde mit der intrazerebralen Injektion begonnen. Hierbei wurde die Infektionsgruppe mit $10 \mu$ 0,9\%iger $\mathrm{NaCl}$-Lösung, welche S. pneumoniae Typ 3 enthielt, infiziert. Im Mittel wurden die Mäuse mit $8.83 \times 10^{3} \mathrm{CFU}$ beimpft. Zur genauen Lokalisation der Einstichstelle wurde die Strecke zwischen Ohr und Auge gedrittelt. Am Übergang zwischen vorderem und mittleren Drittel wurde eingestochen. Hierfür wurde eine Einwegnadel (24 Gauge) mit einem speziellen Aufsatz verwendet, der sicherstellte, dass die Injektion nur auf oberflächliche Strukturen des rechten Vorderhirns beschränkt blieb. Der Kontrollgruppe wurde auf gleiche Weise 10 $\mu \mathrm{l}$ isotone Kochsalzlösung verabreicht. (Wellmer et al. 2000). Insgesamt wurden $77 \mathrm{Tg}^{+}-$ und 19 Tg-Mäuse diesem Prozedere unterzogen (siehe Tabelle 1).

\begin{tabular}{|l|l|l|}
\hline Applizierte Substanz & Genotyp & Tierzahl am Anfang des Versuches \\
\hline S. pneumoniae & $\mathrm{Tg}^{+}$ & 47 \\
\hline $\mathrm{NaCl}$ & $\mathrm{Tg}^{+}$ & 30 \\
\hline S. pneumoniae & $\mathrm{Tg}^{-}$ & 12 \\
\hline $\mathrm{NaCl}$ & $\mathrm{Tg}^{-}$ & 7 \\
\hline
\end{tabular}

Tabelle 1: Gruppengröße der Versuche mit S. pneumoniae-Infektion / NaCl-Injektion bei $\mathrm{Tg}^{+}-$ und Tg-Mäusen. Angegeben ist die Anzahl der Tiere, die applizierte Substanz und der Genotyp der Tiere. 
Die sensitivsten Zeichen einer Meningitis waren Lethargie, Bewegungslosigkeit und Gewichtsverlust. Später zeigten sich bei der Meningitisgruppe Opisthotonus bis hin zu epileptischen Anfällen (Nau et al. 1999). 22 Stunden nach der Infektion wurde mit der Antibiose begonnen. Benutzt wurden $100 \mathrm{mg} / \mathrm{kg} \mathrm{KG}$ Ceftriaxon, welches über 5 Tage alle 12 Stunden subkutan (Einwegnadel, 24 Gauge) appliziert wurde.

\subsubsection{Bestimmung der Bakterienkonzentration}

Von allen Mäusen, die mit S. pneumoniae beimpft wurden und die in der Akutphase der Infektion starben bzw. getötet werden mussten, wurde das Kleinhirngewebe zur Bestimmung der Keimzahl ausplattiert. Hierfür wurde das Kleinhirngewebe mithilfe eines Homogenisators in $500 \mu \mathrm{l} 0,9 \% \mathrm{NaCl}$ zerkleinert und anschließend vermischt. Das verwendete Inokulum wurde ebenfalls ausplattiert, um festzustellen wie viele Bakterien geimpft wurden. Hierbei wurde vom verwendeten Inokulum bzw. vom Kleinhirnhomogenat eine serielle 1 : 10 Verdünnung in 8 Schritten durchgeführt (siehe Abb. 2).

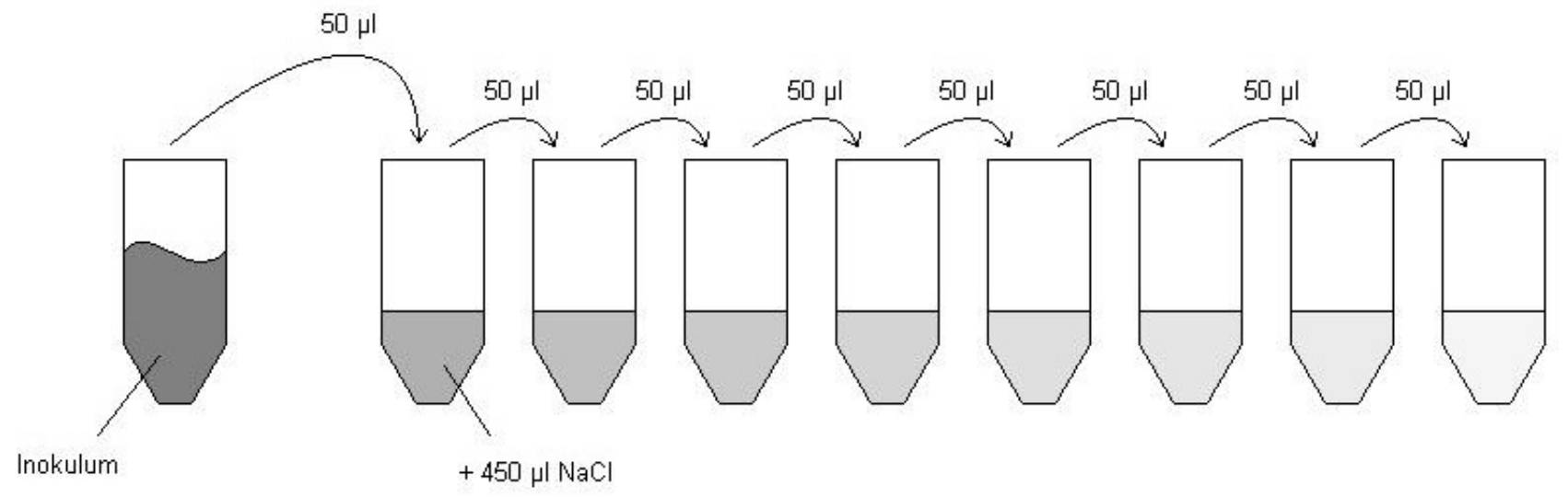

Abb. 2: Verdünnungsreihe für das Inokulum.

Von jedem Verdünnungsschritt wurden $10 \mu \mathrm{l}$ entnommen und auf eine Kochblutagarplatte aufgetragen. Die Platte wurde für 24 Stunden im Brutschrank bei $37^{\circ} \mathrm{C}$ inkubiert. Die gewachsenen Kolonien wurden ausgezählt und die CFU/ml bestimmt. Dadurch konnte die Bakterienlast der zugeführten Infektionslösung bzw. im Kleinhirngewebe bestimmt werden. 


\subsection{Das Morris Water Maze}

\section{Hintergrund:}

Das Morris Water Maze (Synonym: Morris-Wasserlabyrinth) beschreibt ein tierexperimentelles Verfahren zur Durchführung von Verhaltensexperimenten bei Nagetieren. Ziel des Versuches ist es, dass das Versuchstier eine durchsichtige, unter der Wasseroberfläche versteckte Plattform findet. Die äußeren visuellen Einflüsse werden hierbei gleich gehalten, damit sich der Nager im Water Maze orientieren kann. Das Tier wird immer an der gleichen Stelle im Labyrinth positioniert, wobei auch die Plattform immer am selben Ort steht.

Vor allem Defizite im räumlichen Denken und in der Merkfähigkeit von Nagern können somit aufgedeckt werden. Der Vorteil des Morris Water Maze gegenüber herkömmlichen Labyrinthen ist die Tatsache, dass es keine lokalen, sondern nur globale Landmarken gibt und der natürliche Fluchtreflex der Tiere einen hohen Motivationsfaktor darstellt (Morris 1984).

\section{Durchführung:}

Verwendet wurde ein weißes, rundes Becken mit einem Durchmesser von $104 \mathrm{~cm}$ und einer Höhe von $35 \mathrm{~cm}$. Die Wassertemperatur lag konstant bei $22^{\circ} \mathrm{C}$. Die Plattform befand sich $1 \mathrm{~cm}$ unter der Wasseroberfläche und war daher für die Mäuse nicht sichtbar. In jedem Durchlauf hatten die Mäuse 90 sek Zeit, um die versteckte Plattform zu finden. Bei Nichterreichen wurden sie nach Ablauf der Zeit für 30 sek auf der Plattform platziert. Aufgezeichnet wurde dies mithilfe einer über dem Becken befestigten Kamera, welche an einen Computer angeschlossen war. Hierfür wurde die Software Videomot 2.0 von TSESystems verwendet. Ausgewertet wurde hiermit die Zeit, welche zum Erreichen der Plattform benötigt wird, die zurückgelegte Gesamtstrecke und die durchschnittliche Schwimmgeschwindigkeit der Mäuse (Wellmer et al 2000, Ebert et al. 2010).

Bestandteil des Versuches war ein Trainingsabschnitt, der sich über 3 Tage vor der Infektion erstreckte, in welchem jede Maus täglich 6 Wiederholungen absolvieren musste. Am Tag der Infektion wurde vor Injektion der 1. Lauf, welcher 3 Wiederholungen beinhaltete, durchgeführt. Die Intervalle zwischen den Läufen wurden auf 7 Tage festgelegt (pro Lauf 3 Wiederholungen) und über einen Zeitraum von 27 Tagen durchgeführt. Am Tag 29 wurde die Plattform im Becken an eine andere Stelle versetzt 
und es wurde analog zum Trainingsabschnitt über 3 Tage mit je 6 Wiederholungen pro Tag getestet (siehe Abb. 3).

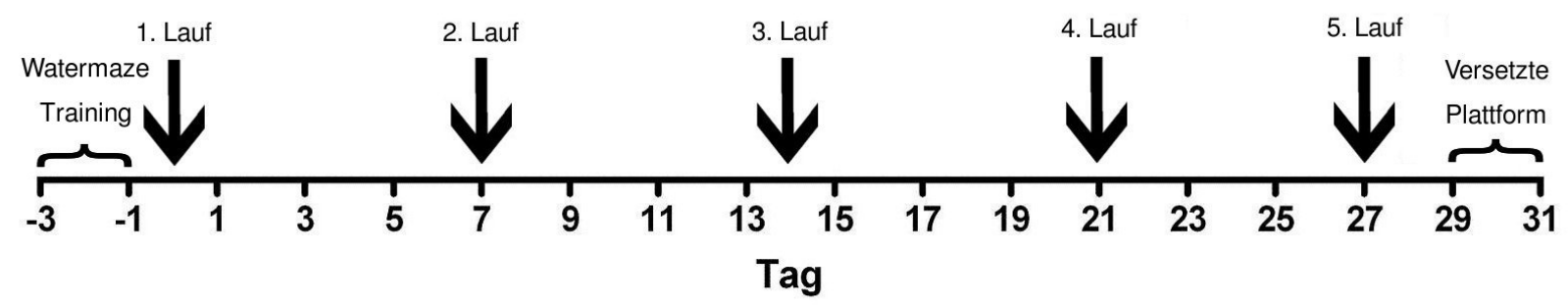

Abb. 3: Versuchsanordnung Water Maze. Tag -3 bis -1: Trainingsabschnitt; Tag 0, 7, 14, 21, 27 : jeweilige Läufe; Tag 29 bis 31: Water Maze mit versetzter Plattform

Da die Zeiten bis zum Erreichen der Plattform im Water Maze individuell zwischen jeder Wiederholung stark variieren können, wurde der Median der Ergebnisse der Trainingstage, der einzelnen Läufe und der Testtage mit versetzter Plattform von jeder Maus bestimmt.

\subsection{Motorische Tests}

\subsubsection{Der Rotarod-Test}

Motorische Koordination und Balanceeigenschaften können mit dem Rotarod-Test überprüft werden (Jones und Roberts 1968). Benutzt wurde das Rotarod-System der Firma Neuroscience. Die Maus wurde bei diesem Verfahren auf einen rotierenden Zylinder gesetzt und musste stetig in Bewegung bleiben, um nicht abzustürzen. Der Zylinder bewegte sich anfangs langsam mit einer Geschwindigkeit von 4 Umdrehungen pro Minute (rpm). Die Geschwindigkeit wurde kontinuierlich bis zu einem Maximum von 40 rpm gesteigert. Nach 300 sek Testung wurde der Versuch vom Versuchsleiter beendet. Notiert wurde die Zeit, bis die Maus sich nicht mehr auf dem rotierenden Zylinder halten konnte (min. 0 sek, max. 300 sek).

Der Rotarod-Test wurde in den ersten 3 Tagen jeweils einmal täglich eingeübt. Anschließend wurde er einmal pro Woche durchgeführt (siehe Abb. 4). 


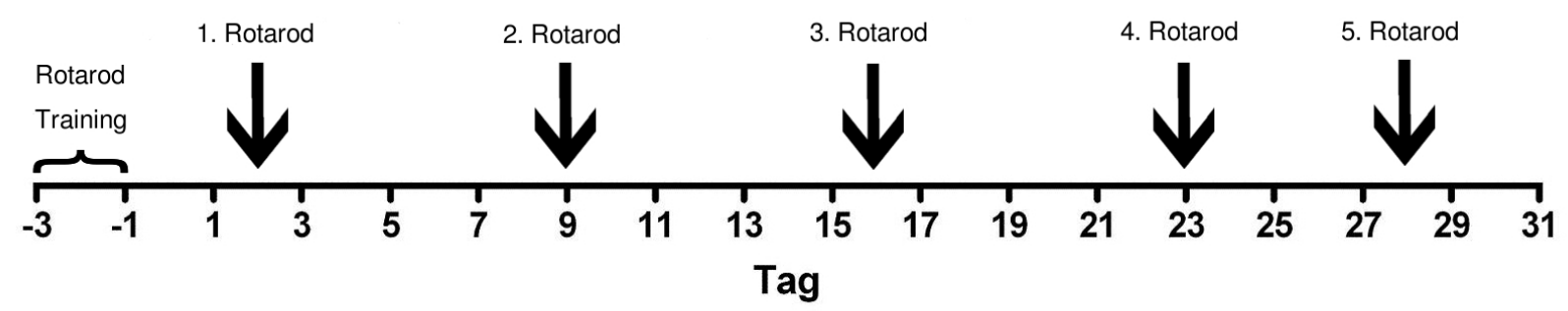

Abb. 4: Versuchsanordnung Rotarod-Test. Tag -3 bis -1 Trainingsabschnitt, Tag 2, 9, 16, 23, 28 : einzelne Testtage

\subsubsection{Der Seiltest}

Der Seiltest wird verwendet, um die motorischen Eigenschaften und das Koordinationsverhalten von Mäusen zu beurteilen. Hierzu wurde ein $60 \mathrm{~cm}$ langes, in einer Höhe von $60 \mathrm{~cm}$ gespanntes Seil mit einem Durchmesser von $1 \mathrm{~mm}$ verwendet (Miquel und Blasco 1978). An beiden Enden des Seils befand sich eine Plattform, welche die Maus über das Seil erreichen konnte. Die Maus wurde mit den Vorderläufen hängend in der Mitte des Seil platziert. Nun hatte die Maus 60 sek Zeit, um eine der beiden Plattformen am Ende des Seils zu erreichen (Wellmer et al. 2000).

Es wurden Wertungspunkte entsprechend der Tabelle 2 vergeben.

\begin{tabular}{|l|l|l|l|}
\hline \multicolumn{2}{|l|}{$\begin{array}{l}\text { Maus schafft es, eine Plattform innerhalb von } 60 \\
\text { sek zu erreichen. }\end{array}$} & $\begin{array}{l}\text { Maus schafft es nicht, eine Plattform innerhalb } \\
\text { von } 60 \text { sek zu erreichen. }\end{array}$ \\
\hline $\begin{array}{l}\text { Zeit bis zum Erreichen } \\
\text { der Plattform [sek] }\end{array}$ & Wertung & $\begin{array}{l}\text { Zeit, welche die Maus } \\
\text { am Seil hängt [sek] }\end{array}$ & Wertung \\
\hline 0 bis 6 & 0 & mehr als 60 & 10 \\
\hline 7 bis 12 & 1 & 59 bis 54 & 11 \\
\hline 13 bis 18 & 2 & 53 bis 48 & 12 \\
\hline 19 bis 24 & 3 & 47 bis 42 & 13 \\
\hline 25 bis 30 & 4 & 41 bis 36 & 14 \\
\hline 31 bis 36 & 5 & 35 bis 30 & 15 \\
\hline 37 bis 42 & 6 & 29 bis 24 & 16 \\
\hline 43 bis 48 & 7 & 23 bis 18 & 17 \\
\hline 49 bis 59 & 8 & 17 bis 12 & 18 \\
\hline 59 bis 60 & 9 & 11 bis 6 & 19 \\
\hline & & unter 6 & 20 \\
\hline
\end{tabular}


Tabelle 2: Vergabe der Wertungspunkte beim Seiltest (Wellmer et al. 2000).

Um Verletzungen beim Sturz zu vermeiden, wurde der Boden mit weichem Material abgepolstert. Miquel und Blasco haben herausgefunden, dass ältere Mäuse im Vergleich zu jungen Artgenossen erhebliche Defizite bei der Bewältigung dieser Aufgabe haben und insgesamt mehr Zeit benötigen (Miquel and Blasco 1978).

Der Seiltest wurde in den ersten 3 Tagen jeweils einmal täglich eingeübt. Anschließend wurde er einmal pro Woche durchgeführt (siehe Abb. 5).

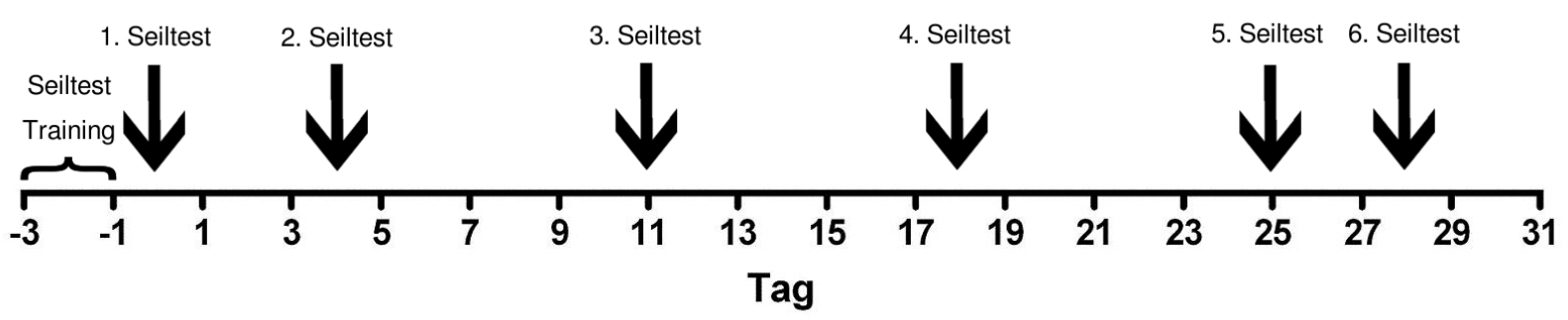

Abb. 5: Versuchsanordnung Seiltest. Tag -3 bis -1 Trainingsabschnitt, Tag 1, 4, 11, 18, 25, 28 : einzelne Testtage

\subsection{Gewebeverarbeitung}

Die Gehirne der getöteten bzw. gestorbenen Mäuse wurden zur histologischen Evaluation bzw. zur Durchführung des Enzyme-Linked Immunosorbent Assay (ELISA) wie nachfolgend beschrieben bearbeitet.

\subsubsection{Präparation}

Das ZNS der Mäuse wurde möglichst schonend unter Lösung des umgebenden Knochenund Weichteilmantels mittels Präparationsschere, Skalpell und Präparationspinzette freigelegt. Das Gehirn wurde samt meningealer Strukturen aus der Schädelgrube gelöst, und die rechte Hemisphäre wurde von der linken Hemisphäre samt Kleinhirnhälften getrennt. Das gewonnene rechte Kleinhirn wurde zur Bestimmung der Bakterienzahl genutzt (siehe Kapitel 2.5.2). Die rechte Großhirnhemisphäre wurde in 4\%iger FormalinLösung fixiert, bei $4^{\circ} \mathrm{C}$ aufbewahrt, in Paraffinharz eingebettet und anschließend für die 
histologische Evaluation verwendet. Der linke Teil des Gehirns wurde in Kleinhirn und Großhirn geteilt. Die linke Großhirnhemisphäre wurde mittig in einen vorderen und einen hinteren Teil aufgetrennt. Beide Teile wurden bei $-80^{\circ} \mathrm{C}$ gelagert und für die Proteinextraktion verwendet.

\subsubsection{Gewebeeinbettung}

Die Entfernung des Formalins aus den Gewebestücken geschah durch zweistündiges Waschen mit $\mathrm{H}_{2} \mathrm{O}$. Die Einbettung in Paraffinharz erfolgte vollautomatisch über 16 Stunden in einem Einbettautomat. Die von Paraffin durchtränkten Gewebestücke wurden anschließend an der Eingießstation in ein Gießschälchen gelegt, mit heißem Paraffin übergossen und zu einem Paraffinblock verarbeitet, wobei die Einbettkassette den Blockträger bildete. Nach dem Abkühlen des Paraffinblockes wurden mithilfe eines Mikrotoms $3 \mu \mathrm{m}$ dünne Schnitte hergestellt, in $40^{\circ} \mathrm{C}$ warmem Wasserbad gestreckt und auf einen Objektträger übertragen.

\subsubsection{Hämatoxylin-Eosin-Färbung}

\section{Hintergrund}

Die HE-Färbung ist eine Routinefärbemethode in der Histologie. Sie basiert auf dem Zusammenspiel der färbenden Eigenschaften der beiden namensgebenden Substanzen, Hämatoxylin und Eosin.

Der natürliche Farbstoff Hämatoxylin muss erst in Hämalaun aufbereitet werden, um seine färbenden Eigenschaften auszubilden. Hämalaun färbt alle basophilen Strukturen wie z.B. Zellkern und endoplasmatisches Retikulum blau.

Eosin ist ein synthetischer saurer Farbstoff und färbt alle acidophilen bzw. basischen (eosinophilen) Strukturen rot, was vor allem die Zellplasmaproteine umfasst.

\section{Durchführung}

Zum Entparaffinieren wurden die Schnitte 3 mal für $10 \mathrm{~min}$ in Xylol eingelegt. Anschließend wurden die Schnitte in absteigender Ethanolkonzentration in 4 Etappen $(100 \%, 96 \%, 70 \%, 50 \%)$ für je 3 min rehydriert. Im Folgenden wurde mit Aqua dest. gespült. Die Schnitte wurden 5 - 10 min in Mayers Hämalaunlösung gefärbt und 10 min 
unter fließendem Aqua dest. gebläut. Anschließend wurde 5 min in Eosin G unter Zugabe von Eisessig gegengefärbt. In einer aufsteigenden Alkohol-Xylol-Reihe $(2 \times 2$ min $70 \%$, 95\%, 100\% Ethanol, $3 \times 3 \mathrm{~min}$ Xylol) wurden die Schnitte entwässert und danach in Kunstharz eingedeckelt.

\subsubsection{Enzyme-Linked Immunosorbent Assay}

\section{Hintergrund}

Der Enzyme-Linked Immunosorbent Assay (ELISA) ist ein Immunoassay, mit dem es möglich ist, eine Antigenkonzentration anhand eines Substratumsatzes zu bestimmen. Im Gegensatz zum Radioimmunoassay basiert die Konzentrationsbestimmung nicht auf einer Radioaktivitätsmessung, sondern auf einer enzymatischen Farbreaktion. Mit dem ELISA ist es möglich, Konzentrationen von Proteinen und Viren, aber auch Konzentrationen von Toxinen, Hormonen und Pestiziden zu bestimmen (Avrameas 1969).

Der Name besagt, dass eine Komponente (entweder Antigen oder Antikörper) an einer festen Phase absorbiert ist. Nun werden Antigen oder Antikörper mit einem Enzym markiert, welches in der Lage ist, eine Farbreaktion zu katalysieren. Dies äußert sich üblicherweise in einem Farbumschlag, der quantitativ bestimmt werden kann (Engvall und Perlman 1971).

\section{Durchführung}

Folgende ELISAs wurden durchgeführt:
1. $A \beta 1-40$
2. $A \beta 1-42$

Als Ausgangsmaterial dienten Stücke der linken Großhirnhemisphäre der Mäuse. Die Proteine wurden entsprechend den Angaben des Herstellers extrahiert. Bestandteil der Proteinextraktion waren die Sonifikation der Gewebestücke und die Inkubation im mitgelieferten Lysis-Puffer. Durch anschließende Zentrifugation wurde das lösliche A $\beta$ vom unlöslichen $A \beta$ getrennt. Der gewonnene Überstand enthielt das zu untersuchende lösliche $A \beta$. Das unlösliche $A \beta$ in Form eines Pellet wurde durch Zugabe von Ameisensäure in Lösung gebracht. Nach Zentrifugation und Verwendung des 
entstandenen Überstandes konnte auch das unlösliche $A \beta$ mit Hilfe des ELISA quantifiziert werden. Bestimmt wurde somit die Konzentration von löslichem und unlöslichen A 1 1-40 / 1-42 mit den ELISA-Kits entsprechend den Protokollen des Herstellers.

\subsection{Statistik}

Für die statistischen Auswertungen und die graphischen Darstellungen wurde die GraphPad Prism 4.0 Software verwendet. Parametrische Daten wurden als Mittelwerte \pm Standardabweichungen und nicht-parametrische Daten als Mediane (25./75. Perzentile) angegeben. Zwei Gruppen parametrischer Daten wurden mit dem Student's t-test bzw. mehrere Gruppen mit der Analysis of variance (ANOVA) mit Bonferroni-Korrektur verglichen. Zwei Gruppen nicht-parametrischer Daten wurden mit dem Mann-Whitney Utest verglichen. Zum Vergleich der Verlaufskurven der klinischen Scores, der Seiltest- und Rotarod-Test-Leistungen sowie der Water Maze-Zeiten, -Strecken und -Geschwindigkeiten von infizierten Mäusen und $\mathrm{NaCl}-M a ̈ u s e n$ wurden die Flächen unter den Kurven (AUC; Areas under the curve) mit Hilfe des Mann-Whitney U-tests verglichen. P-Werte $<0,05$ wurden als statistisch signifikant betrachtet.

\subsection{Material}

\subsubsection{Reagenzien, Chemikalien und Lösungen}

- Ceftriaxon

- Natriumchlorid-Lösung

- PBS

- dNTP Set, Molecular Biology Grade

- GoTaq DNA Polymerase

- PCR-Puffer

- Agarose Electrophoresis Grade
Rocephin; Hoffmann-LaRoche, Grenzach-Wyhlen

Delta Select, Pfullingen

Biochrom AG, Berlin

Fermentas Life Science, Vilnius, Litauen

Promega Gmb, Madison, WI, USA

Promega Gmb, Madison, WI, USA Invitrogen Life Technologies, Berlin 
- O'RangeRulerTM 100bp DNA-Ladder, ready-to-use

- Tris

- EDTA

- $\mathrm{NaCl}$

- SDS

- Proteinase K, recombinant, PCR Grade

- Ethanol

- DMSO

- TBE

- Ketamin

- Xylazin

- Formalin

- $\mathrm{KMnO}_{4}$

- $\mathrm{K}_{2} \mathrm{~S}_{2} \mathrm{O}_{5}$

- Oxalsäure

$-\mathrm{NaOH}$

- $\mathrm{H}_{2} \mathrm{O}_{2}$

- Essigsäure
Fermentas Life Science, Vilnius, Litauen

Merck, Darmstadt

Merck, Darmstadt

Merck, Darmstadt

Merck, Darmstadt

Roche Applied Science, Mannheim

Merck, Darmstadt

Merck, Darmstadt

Merck, Darmstadt

Hoffmann-LaRoche, Grenzach-

Wyhlen

Hoffmann-LaRoche, Grenzach-

Wyhlen

Merck, Darmstadt

Merck, Darmstadt

Merck, Darmstadt

Merck, Darmstadt

Merck, Darmstadt

Merck, Darmstadt

Merck, Darmstadt

\subsubsection{Verbrauchsmaterialien}

- $2 \mathrm{ml}-, 5 \mathrm{ml}-, 10 \mathrm{ml}-S p r i t z e n$

- 1-ml-Insulinspritzen

- Einbettkassetten

- E-Cups

- Pipettenspitzen

- Einwegkanülen
Braun, Melsungen

Braun Melsungen

KABE Labortechnik, Nümbrecht

Eppendorf, Hamburg

Eppendorf, Hamburg

Braun, Melsungen 
- Kochblutagar-Platten

- ELISAAß 1-40/1-42

- $10 \mathrm{ml}-$, 50ml-Tube

\subsubsection{Geräte}

- Zentrifuge

- Vortexer

- Thermocycler

- Elektrophoresekammer

- UV-Kontaktlampe

- Brutschrank

- Präparationsschere

- Präparationspinzette

- Skalpell

- Einbettautomat

- $\quad$ Eingießstation

- $\quad$ Multi-plate reader

- $\quad$ Pipetten

- $\quad$ Mikroskop BX51TF

- $\quad$ Sonifikator UW 2070

- Rotarod-System

\subsubsection{Software}

- $\quad$ GraphPad Prism 4.0

- $\quad$ Videomot 2.0
Mikrobiologie, Göttingen

The Genetics Company, Schlieren, Schweiz

Sarstedt, Nümbrecht

Eppendorf, Hamburg

IKA® Labortechnik, Staufen

Biometra, Göttingen

Amersham Pharmacia Biotech,

Nümbrecht

Vetter $\mathrm{GmbH}$, Wiesloch

Biometra, Göttingen

Aesculap, Tuttlingen

Aesculap, Tuttlingen

Aesculap, Tuttlingen

Leica Vertrieb $\mathrm{GmbH}$, Bensheim

Shandon, Frankfurt

Tecan, Crailsheim

Eppendorf, Hamburg

Olympus, Hamburg

Bandelin electronic, Berlin

Neuroscience Inc, Tokyo, Japan
GraphPad Software, San Diego, CA, USA

TSE-Systems, Bad Homburg 


\section{ERGEBNISSE}

\subsection{Vergleich zwischen transgenen und nicht-transgenen Mäusen des Stammes Tg2576 (vor intrazerebraler Infektion mit S. pneumoniae)}

\subsubsection{Phänotypische Auffälligkeiten}

Die phänotypischen Unterschiede zwischen den beiden Gruppen zeigten sich bei 11-14 Monaten alten transgenen $\left(\mathrm{Tg}^{+}\right)$und nicht-transgenen ( $\left.\mathrm{Tg}^{-}\right)$Mäusen der Tg2576-Mauslinie im Ausgangsgewicht am Anfang des Versuches. Hier waren die $\mathrm{Tg}^{+}$-Mäuse signifikant leichter als die Tg-Mäuse $\left(25,58 \pm 4,414 \mathrm{~g}\right.$ für $\mathrm{Tg}^{+}$vs. $30,02 \pm 4,831 \mathrm{~g}$ für $\left.\mathrm{Tg} ; \mathrm{P}=0,0002\right)$ (siehe Abb. 6). Bis auf diesen Unterschied konnten keine Differenzen in Bezug auf Erscheinungsbild, Farbe oder Gestalt festgestellt werden.

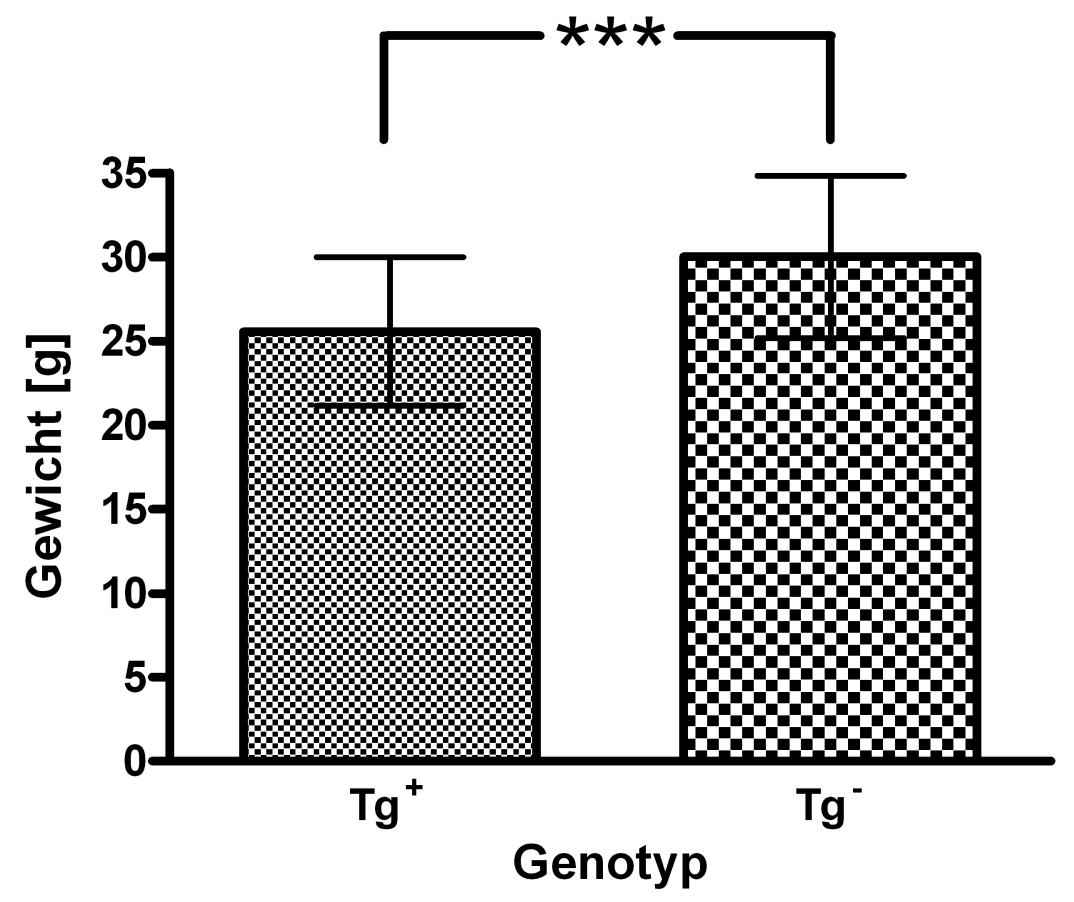

Abb. 6: Ausgangsgewichte der $\mathrm{Tg}^{+}-$vs. $\mathrm{Tg}^{-}-$Mäuse zu Beginn des Versuches. Angegeben ist das Gewicht in g. Dargestellt sind Mittelwerte und Standardabweichung des Gewichts in g. Die $\operatorname{Tg}^{+}$-Mäuse $(n=77)$ sind signifikant leichter als die Tg-Mäuse $(n=19)\left({ }^{* * *} P<0,001\right)$.

\subsubsection{Motorische Fähigkeiten}

Um die motorischen Fähigkeiten der Mäuse vor Infektion zu evaluieren, wurden der 
Rotarod-Test und der Seiltest verwendet. In der Trainingsphase wurden die beiden motorischen Tests entsprechend dem Versuchsaufbau durchgeführt (siehe auch Kapitel 2.7).

Die motorische Leistung der $\mathrm{Tg}^{+}$-Mäuse im Rotarod-Test war signifikant schlechter als die der Tg-Mäuse, das heißt sie konnten sich nicht so lange auf dem rotierenden Zylinder halten [Area under the curve (AUC, sek x Tag): 420,5 (336,5 / 554,3) für Tg ${ }^{+}$-Mäuse vs. 558,0 (482,0 / 600,0) für Tg-Mäuse; $P=0,0018$ ] (siehe Abb. 7).
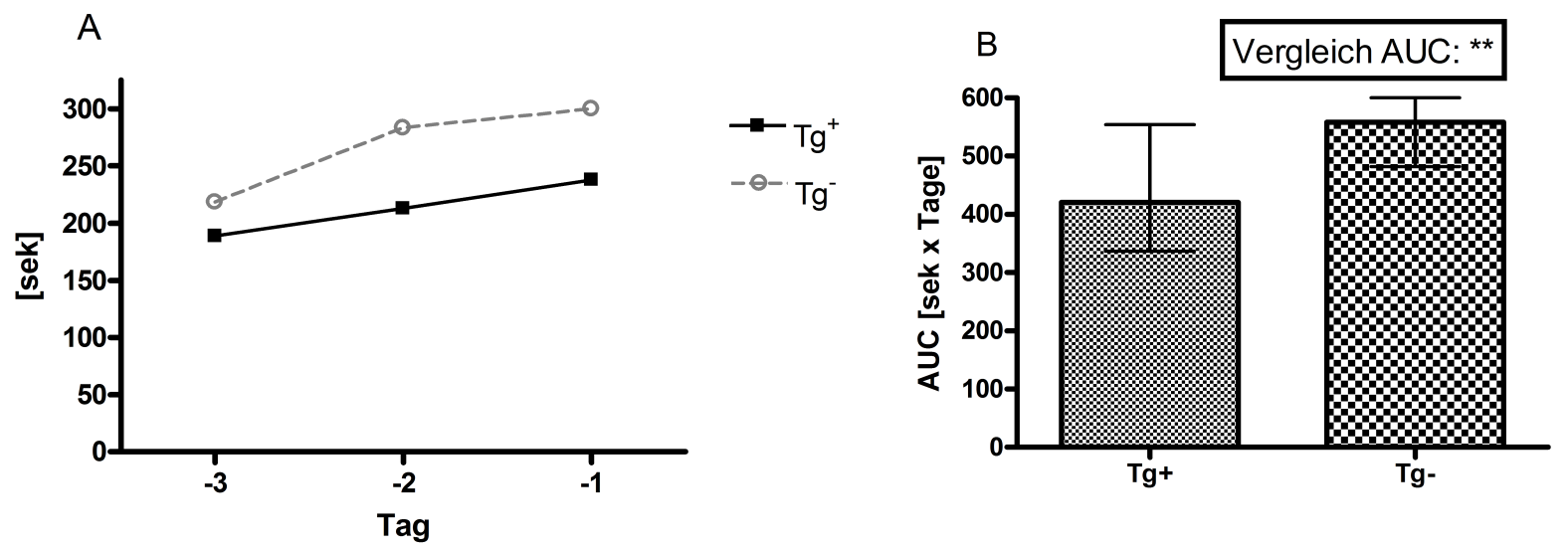

\begin{abstract}
Abb. 7: Motorische Leistung der $\mathrm{Tg}^{+}-$vs. Tg-Mäuse im Rotarod-Test in der Trainingsphase sowie graphische Darstellung der AUC.

A: Dargestellt sind die Mediane der Verweildauer der Mäuse auf dem rotierenden Zylinder in sek.

B: Angegeben sind die Mediane und 25./75. Perzentile der AUC.

Die $\mathrm{Tg}^{+}$-Mäuse $(\mathrm{n}=77$ ) erreichten im Rotarod-Test niedrigere Zeitwerte als die Tg-Mäuse $(\mathrm{n}=19)$.

Die AUC war signifikant unterschiedlich zuungunsten der $\mathrm{Tg}^{+}$-Mäuse ( $\left.{ }^{* *} P<0,01\right)$.
\end{abstract}

Im Seiltest fand sich ein statistisch signifikanter Unterschied zwischen den beiden Versuchsgruppen zugunsten der Tg-Mäuse [AUC (Score x Tag): 27,00 (22,00 / 30,00) Tg+-Mäuse vs. 30,00 (27,50/30,00) Tg-Mäuse; P = 0,04] (siehe Abb. 8). 

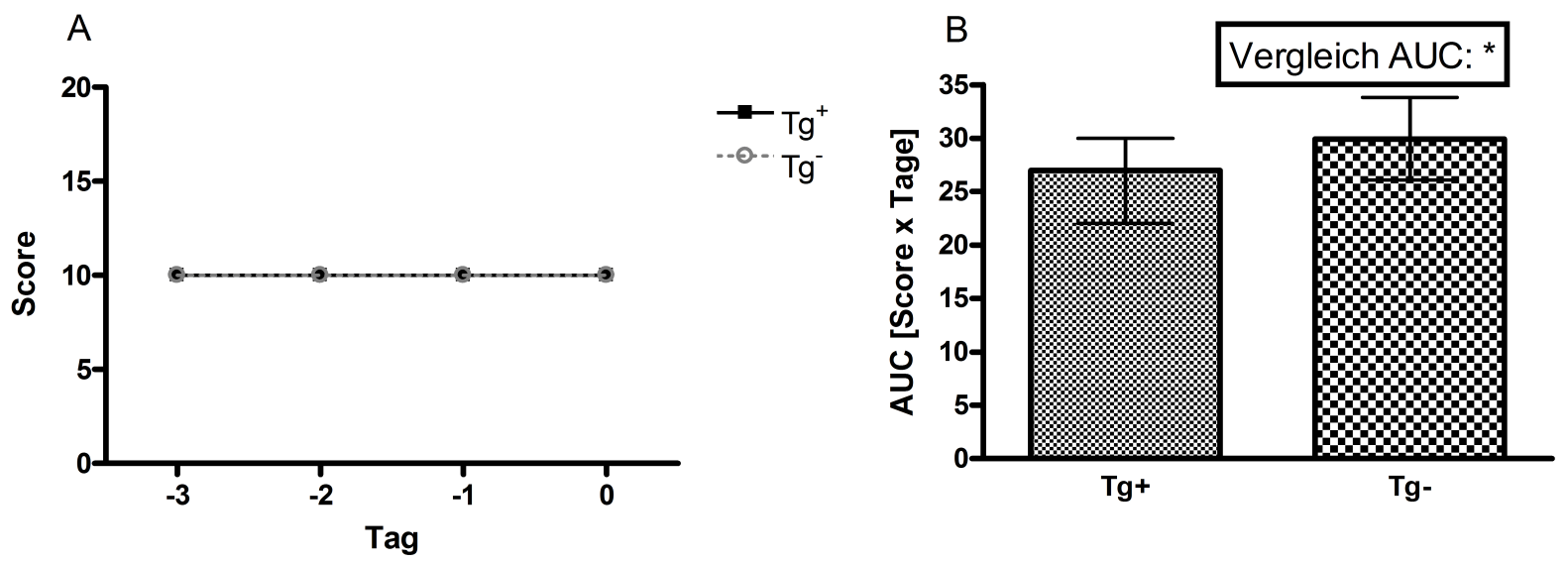

Abb. 8: Motorische Leistung der $\mathrm{Tg}^{+}$vs. Tg-Mäuse im Seiltest in der Trainingsphase sowie graphische Darstellung der AUC.

A: Dargestellt sind die Mediane der Scores der einzelnen Versuchszeitpunkte.

B: Angegeben sind die Mediane und 25./75. Perzentile der AUC.

Die $\mathrm{Tg}^{+}$Mäuse $(n=77)$ hatten im Median den gleichen Score wie $\operatorname{Tg}^{-}$-Mäuse $(n=19)$, welcher statistisch signifikant niedriger für die $\operatorname{Tg}^{+}$Mäuse war $\left({ }^{*} P<0,05\right)$.

\subsubsection{Neuropsychologische Fähigkeiten}

Die neuropsychologischen Fähigkeiten wurden mit Hilfe des Morris Water Maze getestet. Hierbei wurde die Zeit, welche bis zum Erreichen der versteckten Plattform benötigt wurde, gestoppt. Wie in Abb. 9 dargestellt, brauchten die $\mathrm{Tg}^{+}$-Mäuse (ausgenommen Zeitpunkt -3) länger, um die Plattform zu finden, und zeigten geringere Verbesserungsschritte in den einzelnen Trainingsabschnitten als die Tg-Mäuse. Die AUC (sek x Tag) unterschied sich nicht signifikant zwischen den beiden Gruppen [167,1 (110,9 / 233,2) für $\mathrm{Tg}^{+}$vs. 151,1 (61,46 / 203,1) für Tg; P = 0,0839]. 

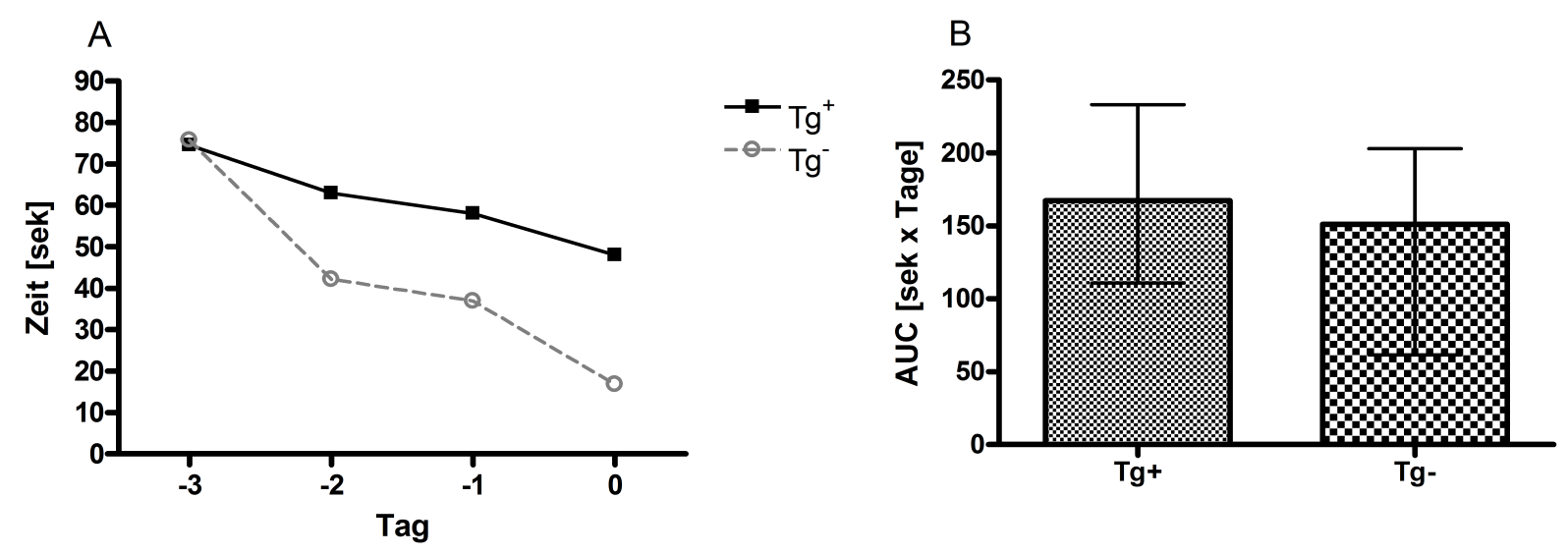
Abb. 9: Morris Water Maze (Zeit) der $\mathrm{Tg}^{+}$vs. $\mathrm{Tg}^{-}-$Mäuse in der Trainingsphase sowie graphische Darstellung der AUC.

A:Dargestellt sind die Mediane der Zeiten an den jeweiligen Versuchstagen, welche benötigt wurden, um die versteckte Plattform zu finden.

B: Angegeben sind die Mediane und 25./75. Perzentile der AUC.

Die $\mathrm{Tg}^{+}$-Mäuse $(n=77)$ zeigen geringere Verbesserungsschritte in den einzelnen Testtagen als die Tg-Mäuse $(n=19)$.

Weiterhin wurde die Strecke gemessen, welche die Mäuse bis zum Erreichen der Plattform oder bis zum Abbruch des Durchlaufs durch den Versuchsleiter (Zeit > 90 sek) zurücklegten. Hierbei legten die $\mathrm{Tg}^{+}$-Mäuse signifikant mehr Strecke zurück als die $\mathrm{Tg}^{-}$ Mäuse [AUC (cm x Tag): 2407 (1685 / 3184) für $\mathrm{Tg}^{+}$vs. 1445 (888,4 / 1910) für Tg; P < 0,0001] (siehe Abb. 10). 

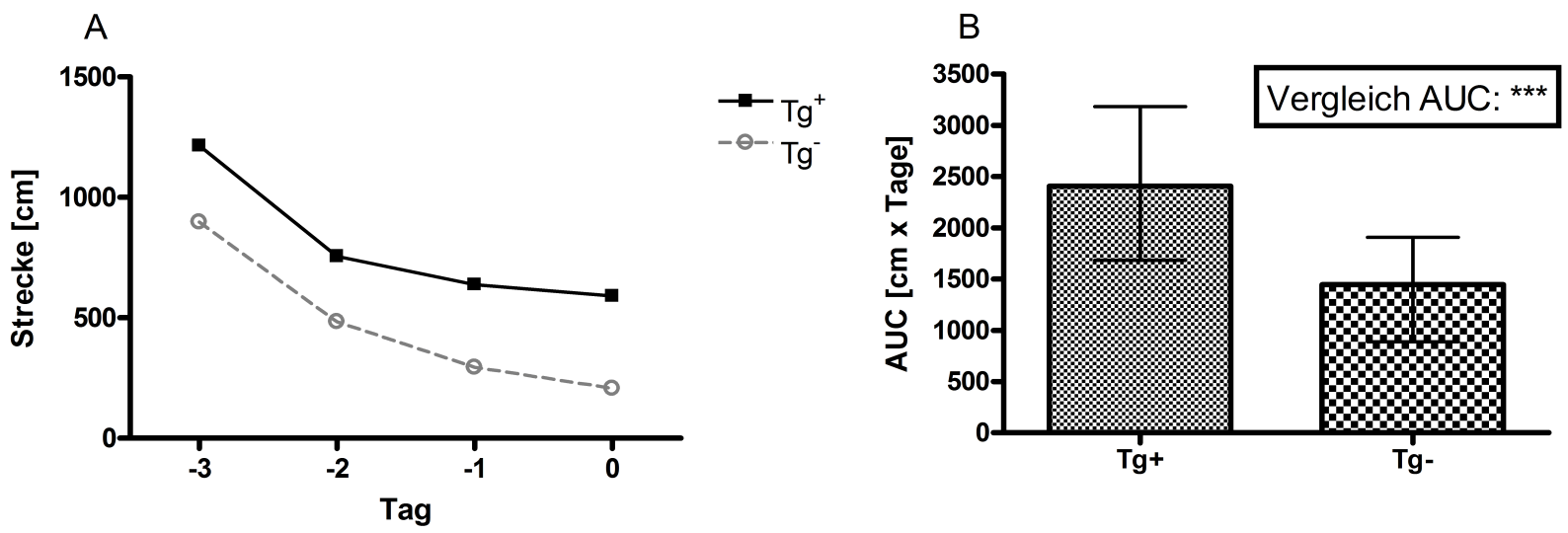

Abb. 10: Morris Water Maze (Strecke) der $\mathrm{Tg}^{+}$vs. $\mathrm{Tg}^{-}-$Mäuse in der Trainingsphase sowie graphische Darstellung der AUC.

A: Dargestellt ist der Median der zurückgelegten Strecken an den einzelnen Versuchstagen.

B: Angegeben sind die Mediane und 25./75. Perzentile der AUC.

Die $\mathrm{Tg}^{+}-$Mäuse $(\mathrm{n}=77)$ legten auf ihrer Suche nach der Plattform signifikant mehr Strecke zurück als die $\operatorname{Tg}^{-}$-Mäuse $(n=19)\left({ }^{* * *} P<0.001\right)$.

Die durchschnittliche Schwimmgeschwindigkeit der Mäuse wurde berechnet. Hier zeigte sich kein signifikanter Unterschied zwischen den beiden Gruppen [AUC (cm/s x Tag): $52,44(39,93 / 63,94)$ für $\mathrm{Tg}^{+}$vs. 45,23 $(27,47 / 56,10)$ für Tg; $\left.\mathrm{P}=0,1181\right]$ (siehe Abb. 11). 

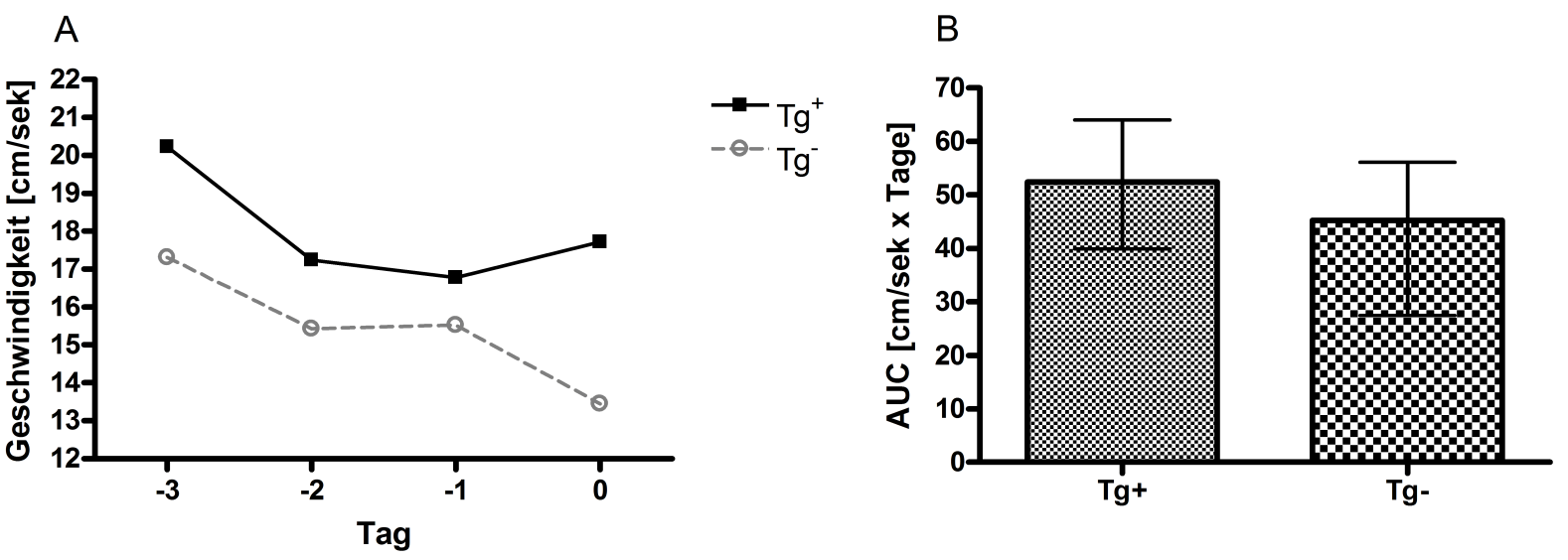

Abb. 11: Morris Water Maze (Geschwindigkeit) der $\mathrm{Tg}^{+}-\mathrm{vs}$. $\mathrm{Tg}^{-}-$Mäuse in der Trainingsphase sowie graphische Darstellung der AUC.

A: Dargestellt ist der Median der Geschwindigkeit der Versuchstage.

B: Angegeben sind die Mediane und 25./75. Perzentile der AUC.

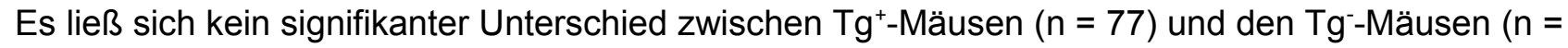
19) finden $(P=0,1181)$. Es zeigte sich allerdings ein Trend zugunsten der Tg-Mäuse.

\subsubsection{Aß-Gehalt im Gehirn}

Das Gehirngewebe wurde nach dem Tod der Mäuse gewonnen und aufgearbeitet (siehe hierzu Kapitel 2.8). Mithilfe von ELISAs wurde die Konzentrationen von löslichem A (140 und 1-42) im Gehirn bestimmt. Für folgende Auswertung wurden die Mäuse verwendet, die mit $\mathrm{NaCl} 0,9 \%$ behandelt worden waren.

Es fand sich ein signifikanter Unterschied zwischen den $\mathrm{Tg}^{+}$und $\mathrm{Tg}^{-}$-Mäusen für beide $\mathrm{A} \beta$ Formen. Dabei hatten die $\mathrm{Tg}^{+}$-Mäuse durchweg höhere Aß-Gehalte als die Tg-Mäuse. Der $A \beta$ 1-40-Gehalt betrug in der Gruppe der Tg+-Mäuse $(n=30)$ 236,7 \pm 122,2 pg/ml vs. 7.892 $\pm 4,682 \mathrm{pg} / \mathrm{ml}$ in der Tg-Mäuse $(\mathrm{n}=7)(\mathrm{P}<0,0001)$. Bei der Bestimmung des $A \beta$ 1-42Gehaltes fanden sich Konzentrationen von 211,9 \pm 153,3 pg/ml bei den $\mathrm{Tg}^{+}$-Mäusen vs. $90,47 \pm 30,41$ pg/ml in der Gruppe der Tg-Mäuse $(P=0,0464)$ (siehe Abb. 12). 

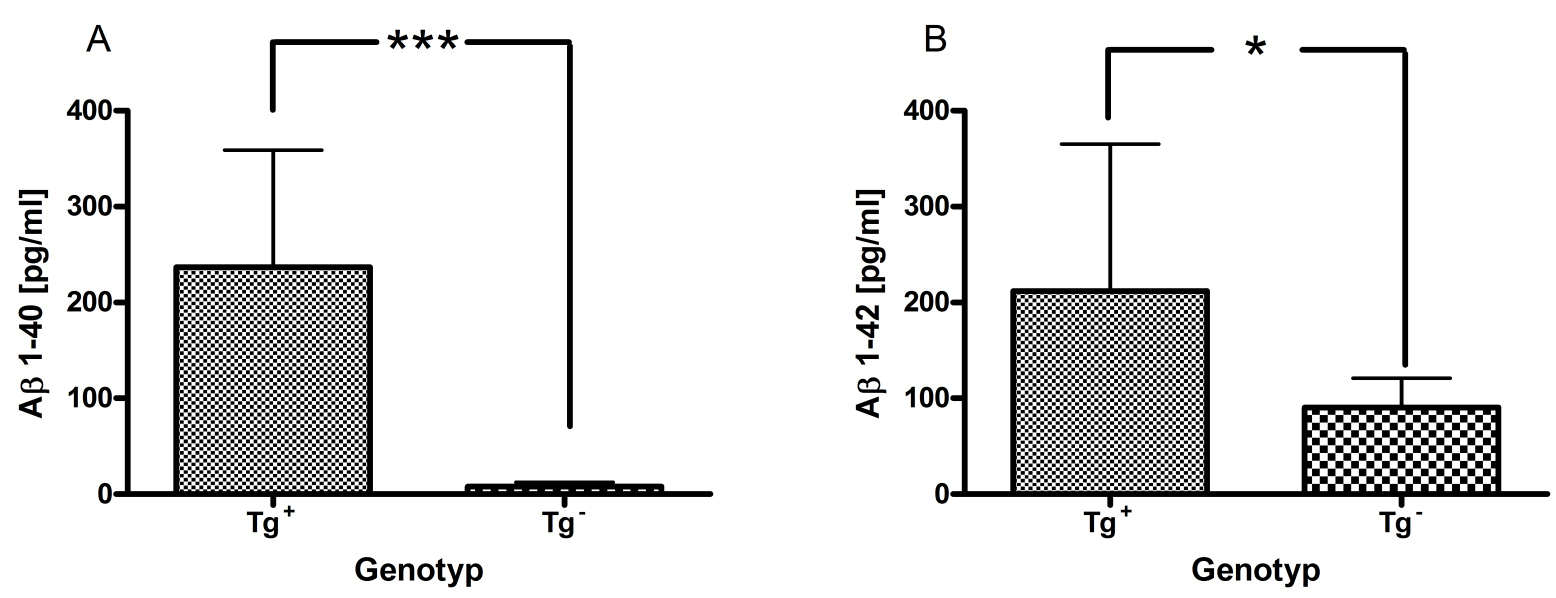

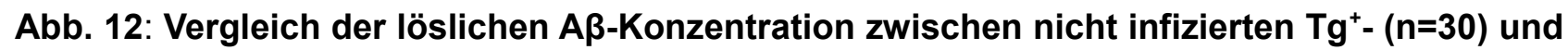
Tg$^{-}-(n=7)$ Mäusen. Dargestellt sind die Mittelwerte \pm Standardabweichungen der A $\beta$-Gehalte in $\mathrm{pg} / \mathrm{ml}$ A: lösliches $\mathbf{A} \boldsymbol{\beta}$ 1-40: Während bei den $\mathrm{Tg}^{+}-$Mäusen eine hohe $A \beta-K o n z e n t r a t i o n ~ a u f f i e l$, waren bei den $\mathrm{Tg}^{-}-$Mäusen nahezu kein lösliches $A \beta 1-40$ zu messen ( $\left.{ }^{* * *} P<0,0001\right)$ B: lösliches A $\beta$ 1-42: Die Tg+-Mäuse hatten signifikant größere Mengen lösliches A $\beta$ 1-42 als die Tg־-Mäuse im Gehirn ( $\left.{ }^{*}<<0,05\right)$.

\subsection{Empfindlichkeit der transgenen und nicht-transgenen Mäuse des Stammes Tg2576 auf eine intrazerebrale Infektion mit $S$. pneumoniae}

\subsubsection{Sterblichkeit nach Infektion}

Am Ende des Versuches waren mehr als doppelt so viele Mäuse der transgenen Gruppe infolge der Infektion mit $S$. pneumoniae verstorben als bei der nicht-transgenen Gruppe [ca. $53 \%$ bei $\mathrm{Tg}^{+}$vs. $25 \%$ bei Tg-]. Die Sterblichkeit der Mäuse, welchen $\mathrm{NaCl}$ verabreicht

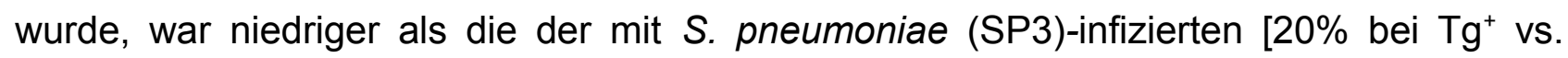
14,29\% bei $\left.\mathrm{Tg}^{-}\right]$(siehe Tabelle 4). 


\begin{tabular}{|l|l|l|l|l|}
\hline Genotyp & $\begin{array}{l}\text { Applizierte } \\
\text { Substanz }\end{array}$ & $\begin{array}{l}\text { Tierzahl am Anfang } \\
\text { des Versuches }\end{array}$ & $\begin{array}{l}\text { Tierzahl am } \\
\text { Ende des } \\
\text { Versuches }\end{array}$ & $\begin{array}{l}\text { Während des } \\
\text { Versuches } \\
\text { verstorben }\end{array}$ \\
\hline Tg $^{+}$ & $\begin{array}{l}\text { S. pneumoniae } \\
\text { (SP3) }\end{array}$ & 47 & $22(46,81 \%)$ & $25(53,19 \%)$ \\
\cline { 2 - 5 } & $\mathrm{NaCl}$ & 30 & $24(80 \%)$ & $6(20 \%)$ \\
\hline $\mathrm{Tg}^{-}$ & $\begin{array}{l}\text { S. pneumoniae } \\
\text { (SP3) }\end{array}$ & 12 & $9(75 \%)$ & $3(25 \%)$ \\
\cline { 2 - 5 } & $\mathrm{NaCl}$ & 7 & $6(85,71 \%)$ & $1(14,29 \%)$ \\
\hline
\end{tabular}

Tabelle 4: Sterblichkeiten der Mäuse mit S. pneumoniae-Infektion / NaCl-Injektion bei $\mathrm{Tg}^{+}$ und Tg-Mäusen. Angegeben ist die Anzahl der Tiere am Anfang und Ende des Versuches und die Anzahl der während des Versuches verstorbenen Tiere.

Betrachtet man den Verlauf der Sterblichkeit über den gesamten Versuch, so fällt auf, dass die größte Sterblichkeit während der akuten Infektionsphase auftrat (siehe Abb. 13).
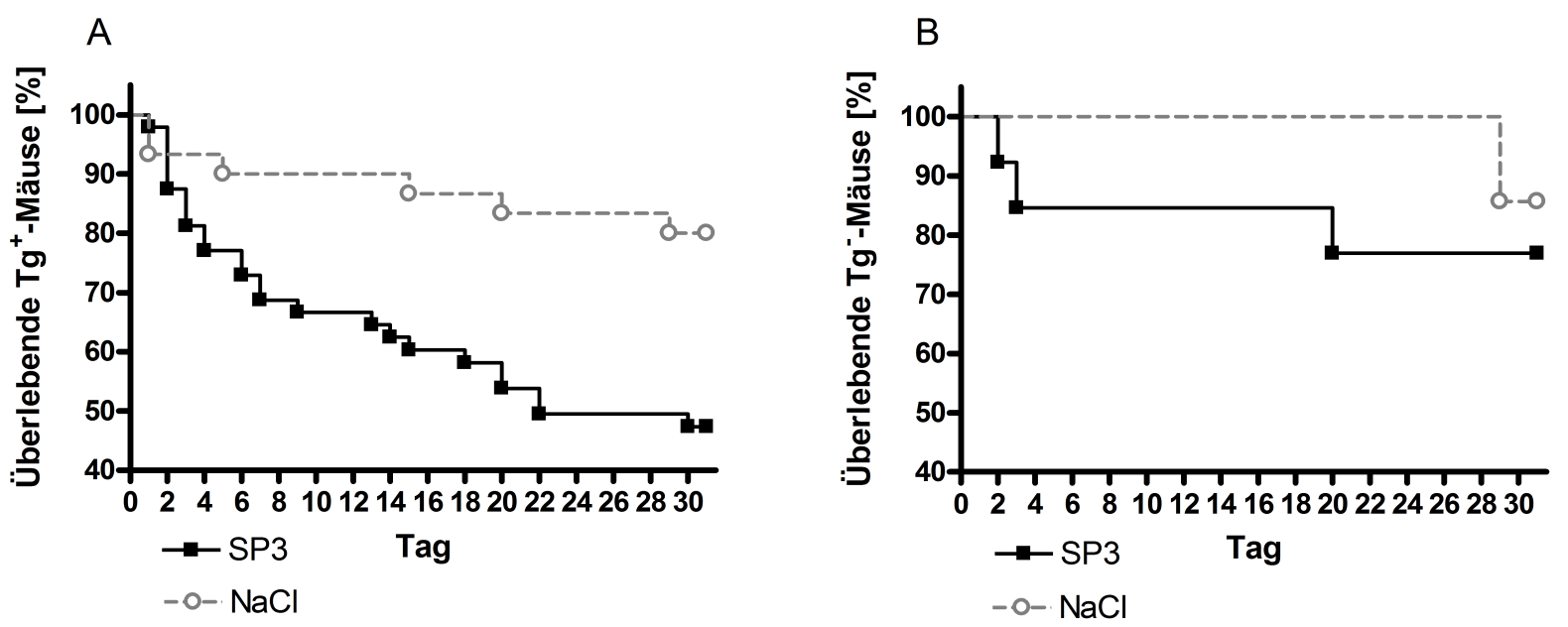

Abb. 13: Kaplan-Meier-Kurve der infizierten und nicht-infizierten $\mathrm{Tg}^{+}$- und $\mathrm{Tg}^{-}$-Mäuse über den gesamten Versuch. Dargestellt ist der Prozentsatz der überlebenden Mäuse über die Zeit. SP3 = mit S. pneumoniae Typ 3 infizierte Mäuse, $\mathrm{NaCl}$ : mit $0,9 \%$ iger $\mathrm{NaCl}$ behandelte Kontrollmäuse A: für $\mathbf{T g}^{+}$-Mäuse: Zu erkennen ist eine erhebliche Sterblichkeit der SP3-infizierten Mäuse gegenüber der Kontrollgruppe, ganz besonders im Zeitraum unmittelbar nach der Infektion. B: für Tg-Mäuse: Auch hier findet sich eine erhöhte Sterblichkeit in der akuten Infektionsphase. Allerdings überleben bis zum Ende des Versuches prozentual mehr SP3-Mäuse als dies für die $\mathrm{Tg}^{+}$-Mäuse der Fall ist. 


\subsubsection{Gewichtsverlauf nach Infektion}

Wie in Kapitel 2.5.1.3 bereits beschrieben, ist die Gewichtsabnahme ein valides Zeichen für das Durchmachen einer akuten Infektion. Das Gewicht der $\mathrm{Tg}^{+}$- und $\mathrm{Tg}^{-}$-Mäuse zu Beginn des Versuchs unterschied sich signifikant. Das Gewichtsminimum bei den $\mathrm{Tg}^{+}-$ Mäusen wurde am 3. Tag post infectionem erreicht. Sie zeigten im Vergleich zum Infektionstag ( $\operatorname{Tag} 0$ ) eine signifikante Gewichtsabnahme um 10,57\% des Ausgangsgewichtes $[26,67 \pm 3,738 \mathrm{~g}$ an Tag 0 vs. $23,85 \pm 3,621$ an Tag 2; $P=0,0150]$. Bei den nicht-transgenen Mäusen wurde das Gewichtsminimum unter der Infektion am Tag 4 erreicht. Die Gewichtsabnahme betrug gegenüber dem Gewicht an Tag 0 8,36\% [31,21 $\pm 5,028 \mathrm{~g}$ an Tag 0 vs. 28,6 \pm 4,944 $\mathrm{g}$ an Tag 3; $\mathrm{P}=0,2831]$. Das Gewicht der Tiere beider Gruppen stieg unter der antibiotischen Therapie und Erholung von der Infektion wieder an. Der Gewichtsverlauf über den gesamten Versuch zeigte kontinuierlich niedrigere Gewichtswerte bei den $\mathrm{Tg}^{+}-$Mäusen gegenüber den $\mathrm{Tg}^{-}-$Mäusen (siehe Abb. 14). 


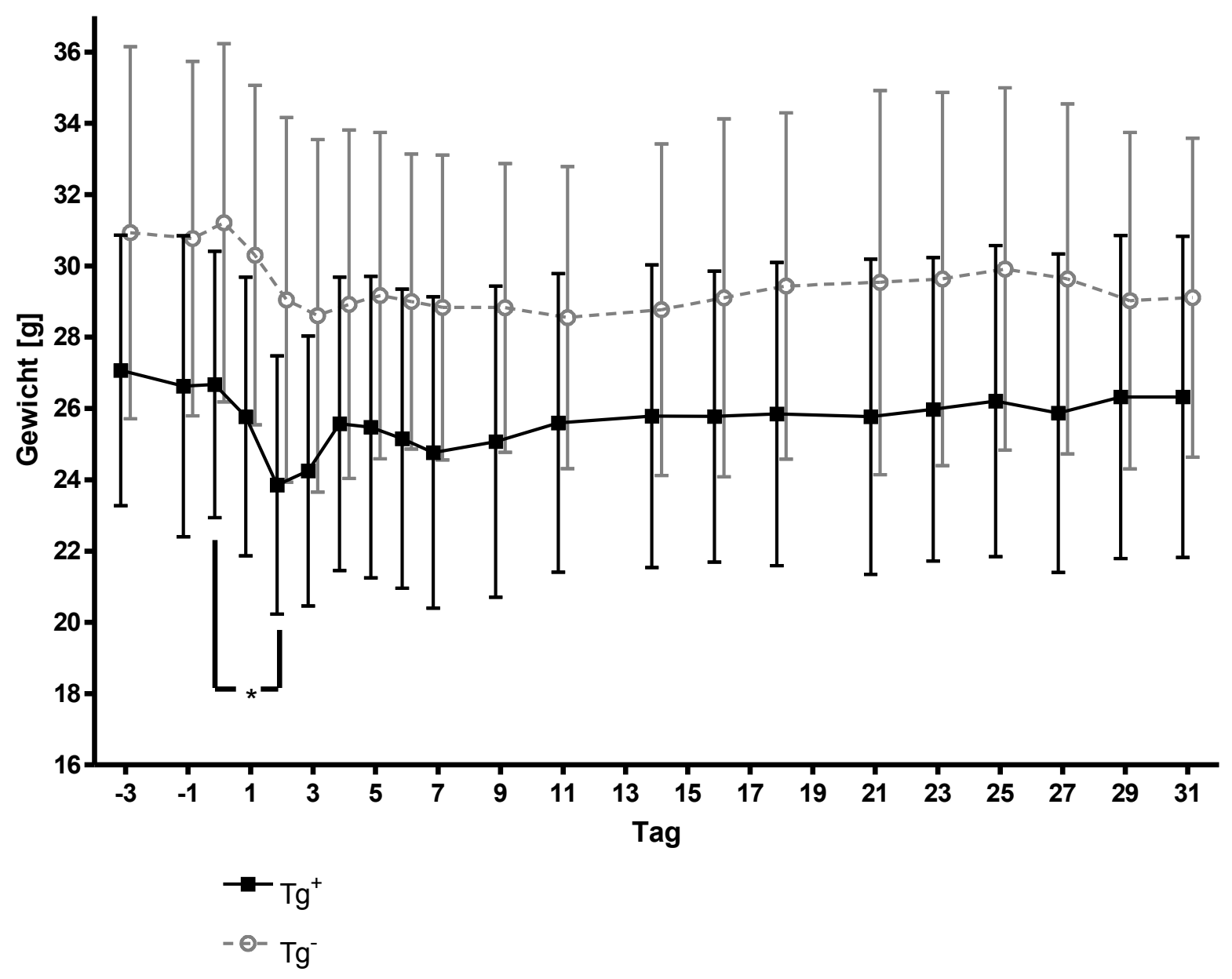

Abb. 14: Gewichtsverlauf der überlebenden S. pneumoniae-infizierten $\mathrm{Tg}^{+}-(\mathrm{n}=22)$ und $\mathrm{Tg}^{-}-$ ( $n=9)$ Mäuse über den ganzen Versuchszeitraum. Dargestellt sind die Mittelwerte \pm Standardabweichungen der Gewichte in g. Zu erkennen ist eine deutliche Gewichtsabnahme in der Infektionsphase $\left({ }^{*} \mathrm{P}<0,05\right)$. Nach antibiotischer Behandlung stiegen die Gewichtswerte wieder an.

\subsubsection{Bakterienlast im ZNS und Entzündungszeichen im Gehirn}

Um zu zeigen, dass die Beimpfung mit S. pneumoniae in einer Dosis geschehen war, welche ohne antibiotische Therapie letal verlaufen wäre, wurden neben den Versuchstieren auch 4 transgene Kontrollmäuse des Stammes Tg2576 mit infiziert. Diese wurden keiner antibiotischen Therapie mit Ceftriaxon unterzogen und waren alle am 2. Tag nach Infektion verstorben bzw. mussten aus tierschutzrechtlichen Bestimmungen getötet werden. Beim Ausplattieren der Kleinhirne auf Blutagarplatten ließen sich im Mittel $1.83 \mathrm{x}$ $10^{9} \mathrm{CFU} / \mathrm{ml}$ bestimmen. Die Kleinhirne der Versuchsmäuse, welche während der 
Antibiosephase verstorben sind, wurden ebenfalls ausplattiert. Hier ließen sich niedrigere Bakterienlasten als bei den 4 Kontrollmäusen ohne Antibiose finden. Ab dem 3. Tag nach Antibiose ließen sich keine Bakterien im Kleinhirn mehr anzüchten.

Die histologische Aufarbeitung der Gehirne mittels HE-Färbung aller während des Versuches gestorbenen Mäuse ergab entzündliche Veränderungen der Meningen und des Kortex bei der Infektionsgruppe. Diese Veränderungen konnten bis zum 9. Tag nach Infektion nachgewiesen werden. Schnitte von später verstorbenen Mäusen zeigten keine entzündlichen Infiltrate mehr. Bei der Gruppe, welche lediglich mit 0,9\%iger NaCl-Lösung infiziert wurde, ließen sich diese Veränderungen nicht finden. Es konnten hier keine Unterschiede zwischen $\mathrm{Tg}^{+}$- und $\mathrm{Tg}^{-}-$Mäusen festgestellt werden.

\subsection{Einfluss einer intrazerebralen Infektion mit S. pneumoniae auf den Krankheitsverlauf bei transgenen Mäusen des Stammes Tg2576}

\subsubsection{Gewichtsverlauf unter Infektion}

Über die einzelnen Versuchstage wurde das Gewicht der Mäuse der Infektionsgruppe (SP3, mit S. pneumoniae Typ 3 infiziert) und der Kontrollgruppe ( $\mathrm{NaCl}$, mit 0,9\%iger $\mathrm{NaCl}$ Lösung beimpft) bei $\mathrm{Tg}^{+}$-Mäusen verfolgt. Hierbei zeigte sich ein nahezu gleiches Ausgangsgewicht der beiden Gruppen [27,06 \pm 3,794 g SP3 vs. 26,95 \pm 4,285g NaCl, $\mathrm{P}=$ 0,9221]. Nach Infektion mit S. pneumoniae zeigte sich eine signifikante Gewichtsabnahme [Abfall um 10,57\% des Ausgangsgewichtes, Minimum an Tag 2 post infectionem] (siehe Abb. 15). Das Gewicht der NaCl-Mäuse blieb hingegen gleich. Nach antibiotischer Therapie stieg das Gewicht der SP3-Mäuse bis zum Versuchsende fast auf den Wert des Ausgangsgewichts wieder an. 


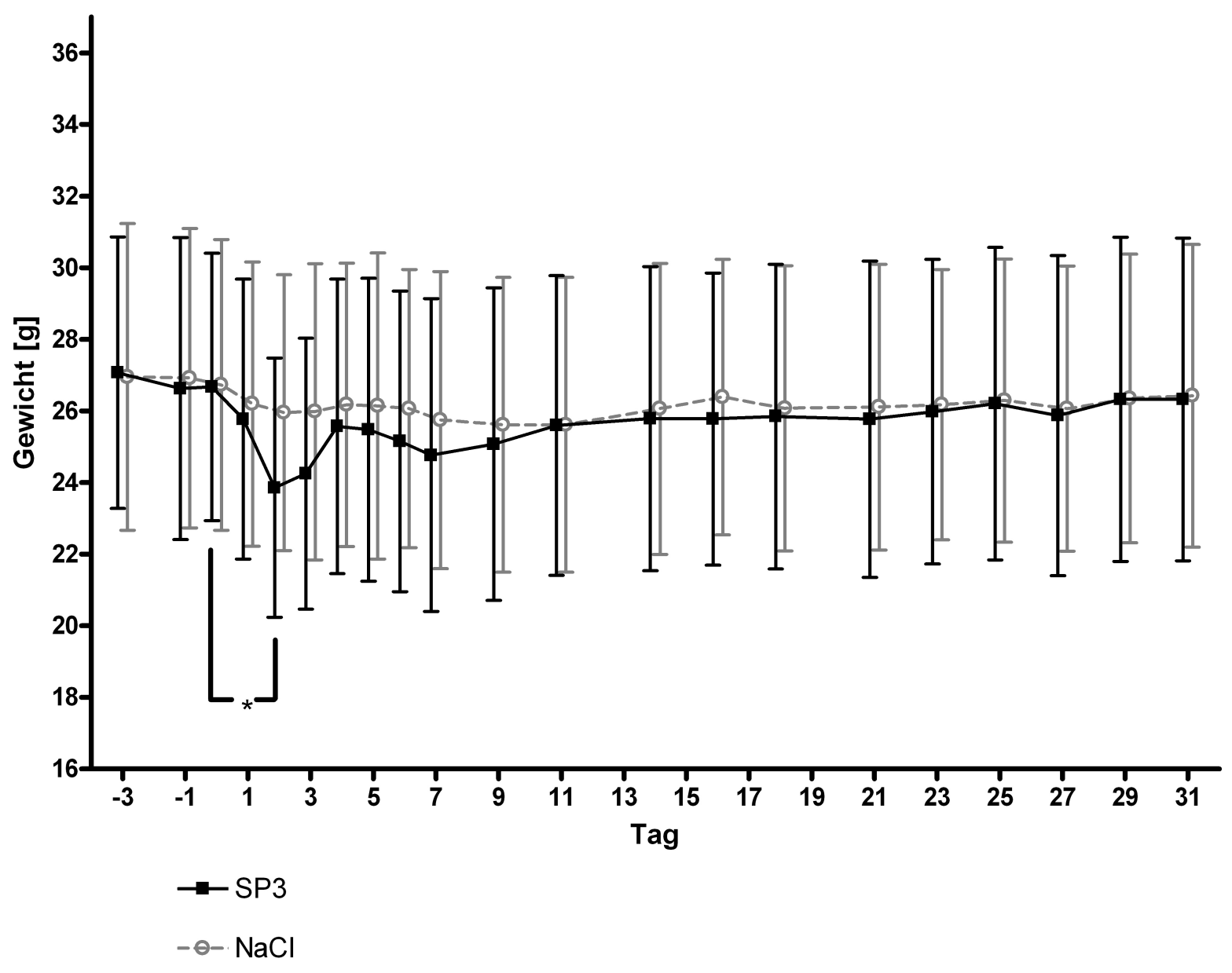

Abb. 15: Gewichtsverlauf der $\mathrm{Tg}^{+}-$Mäuse der SP3- $(n=22)$ und NaCl-Gruppe $(n=24)$ über den gesamten Versuchszeitraum. Dargestellt sind die Mittelwerte \pm Standardabweichungen der Gewichte in g. Im Gegensatz zur NaCl-Gruppe fand bei den mit SP3 infizierten Mäusen zwischen Tag 0 und Tag 2 eine signifikante Gewichtsabnahme unter Infektion statt ( $\left.{ }^{*}<<0,05\right)$. Das Gewicht stieg am Ende des Versuches fast wieder auf den Ausgangswert an.

\subsubsection{Motorische Fähigkeiten}

Die motorischen Fähigkeiten zwischen Infektions- und Kontrollgruppe wurden mithilfe des Rotarod-Tests und des Seiltests evaluiert. Hierbei wurde entsprechend dem Versuchsaufbau verfahren (siehe auch Kapitel 2.7).

Bezüglich der motorischen Leistungen im Rotarod-Test zeigte sich bei Vergleich der AUC (sek x Tag) der beiden Gruppen kein signifikanter Unterschied zwischen NaCl- und SP3Gruppe [AUC: 7817 (5994 / 8535) für SP3 vs. 8299 (6837/ 8961) für NaCl; P = 0,2182]. In der Trainingsphase verbesserten sich beide Gruppen gleich schnell und erreichten an Tag 
-1 fast die gleiche Zeit im Rotarod-Test. Auffällig ist jedoch, dass die SP3-Mäuse in der Infektionsphase (Tag 2) deutlich niedrigere Zeiten auf dem Rotarod absolvierten als ihre nicht-infizierten Artgenossen. Dieser Unterschied blieb auch nach abgeschlossener antibiotischer Therapie bestehen und wurde an Tag 9 signifikant $(P=0,045)$. Die Leistung der Tiere beider Gruppen im Rotarod-Test näherte sich im weiteren Versuchsverlauf wieder an und zeigte ab Tag 16 kaum noch Differenzen zwischen den beiden Gruppen (siehe Abb. 16).

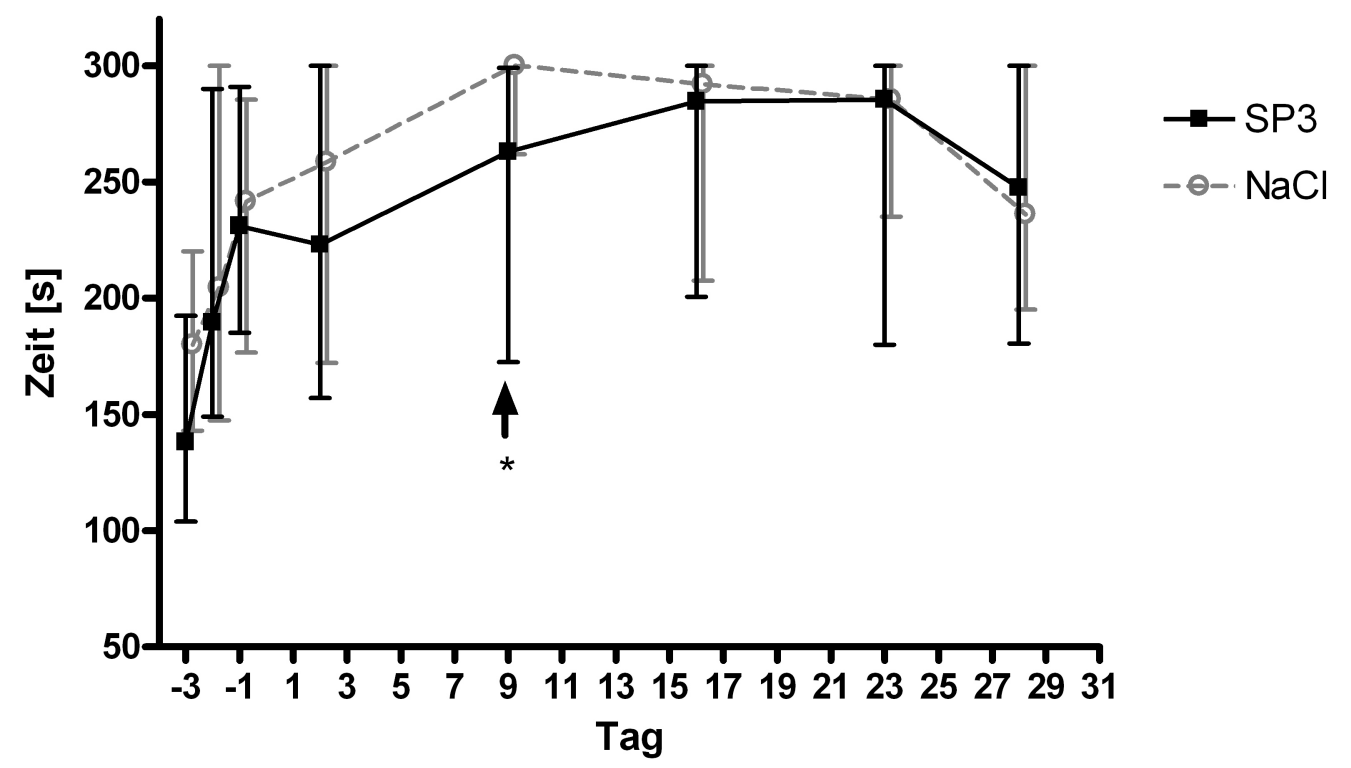

Abb. 16: Motorische Leistung im Rotarod-Test der SP3- $(n=22)$ und NaCl-Gruppe $(n=24)$ für $\mathrm{Tg}^{+}$-Mäuse über den gesamten Versuchszeitraum. Angegeben sind die Mediane \pm 25./75. Perzentile in sek. An Tag 2 und 9 schafften die SP3-Mäuse weniger Zeit auf dem Rotarod als die $\mathrm{NaCl}-$ Mäuse $\left({ }^{*} \mathrm{P}<0,05\right)$. Dieser Unterschied war an den folgenden Testtagen nicht mehr festzustellen.

Zwischen den beiden Gruppen zeigte sich kein signifikanter Unterschied bezüglich der motorischen Leistung im Seiltest [AUC (Score x Tag): 306,3 (208,5 / 310,0) für SP3 vs. 247,3 (162,0 / 299,5) für NaCl; P = 0,0664] (siehe Abb. 17). 


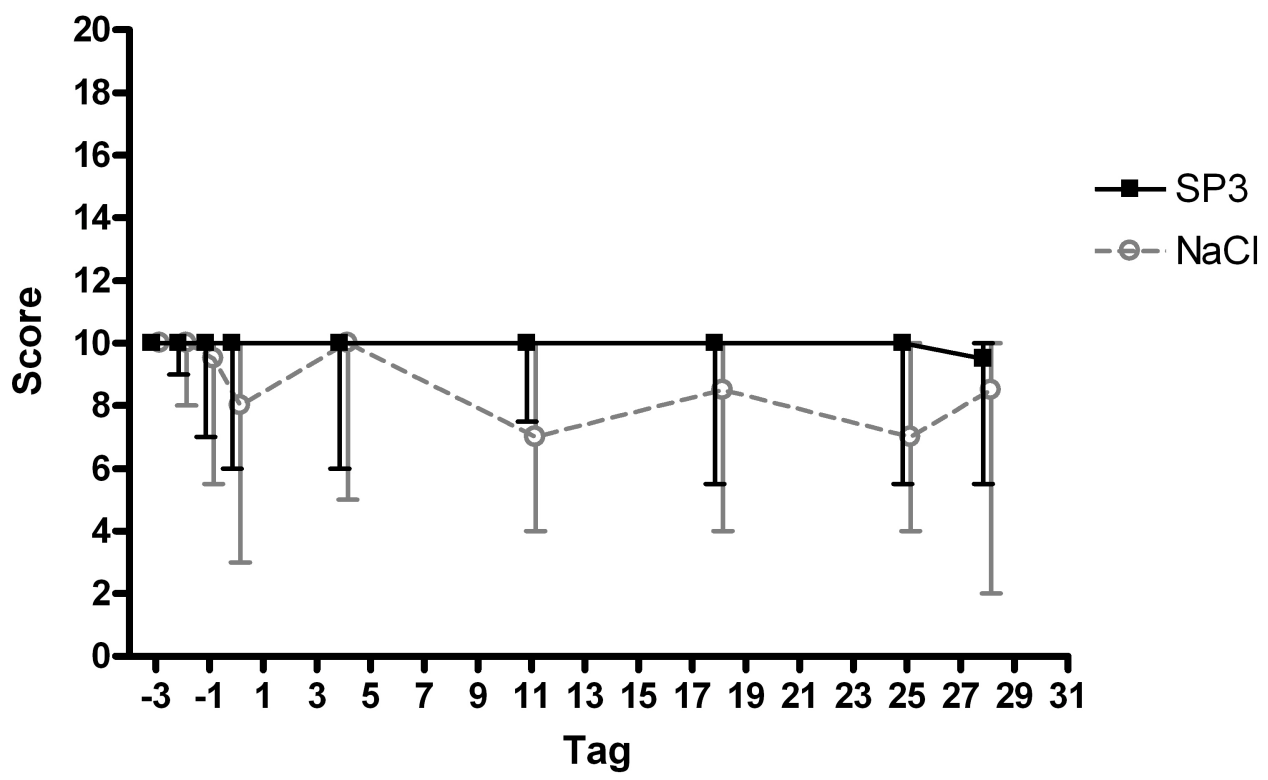

Abb. 17: Seiltest der SP3- $(n=22)$ vs. NaCl-Gruppe $(n=24)$ bei $\mathrm{Tg}^{+}-$Mäusen über den gesamten Versuchszeitraum. Angegeben sind die Mediane $\pm 25 . / 75$. Perzentile des Scores der einzelnen Versuchszeitpunkte. Es fand sich kein signifikanter Unterschied zwischen den beiden Gruppen.

\subsubsection{Neuropsychologische Fähigkeiten}

Der Morris Water Maze ist ein tierexperimenteller Versuchsaufbau, mit welchem es möglich ist, neuropsychologische Fähigkeiten von Mäusen zu bewerten. In Kapitel 4.1 konnte gezeigt werden, dass der verwendete Versuchsaufbau in der Lage ist, klinische Unterschiede zwischen transgenen und nicht transgenen Mäusen des Stammes Tg2576 aufzudecken.

Im Morris Water Maze wurde die Zeit, welche bis zum Erreichen der Plattform vergangen ist, aufgezeichnet. In der Trainingsphase (Tag -3 bis 0 ) zeigten sich keine Unterschiede im Lernverhalten zwischen den beiden Versuchsgruppen [AUC (sek x Tag): 162,6 $(103,4 / 225,1)$ für SP3 vs. 158,8 $(102,5 / 220,4)$ für NaCl; $P=0,8863$ ]. Am Tag 0 war zwar ein großer Unterschied zwischen den beiden Gruppen zugunsten der Kontrollgruppe zu erkennen, welcher jedoch keine statistische Signifikanz erreichte $[63,61(25,58 / 88,51)$ sek für SP3 vs.28,38 (15,88/83,05) sek für NaCl; P = 0,2061]. In der Postinfektionsphase (Tag 7 bis 27) zeigte sich ebenfalls kein signifikanter Unterschied der Water-Maze-Zeiten 
zwischen den beiden Gruppen [AUC (sek x Tag): 1168 (798,2/1606) SP3 vs. 1163 $(637,5 / 1528) \mathrm{NaCl} ; P=0,6285]$. Am Tag 29 wurde die versteckte Plattform umgestellt und bis zum Ende des Versuchs (Tag 31) an diesem Ort belassen. Es zeigten sich fast identische Werte für die beiden Versuchsgruppen in der Bewältigung dieser neuen Aufgabe [AUC, 145,2 $(53,89 / 165,1)$ für SP3 vs. 131,2 $(61,11 / 162,6)$ für $\mathrm{NaCl} ; \mathrm{P}=0.9825$ ] (siehe Abb. 18).

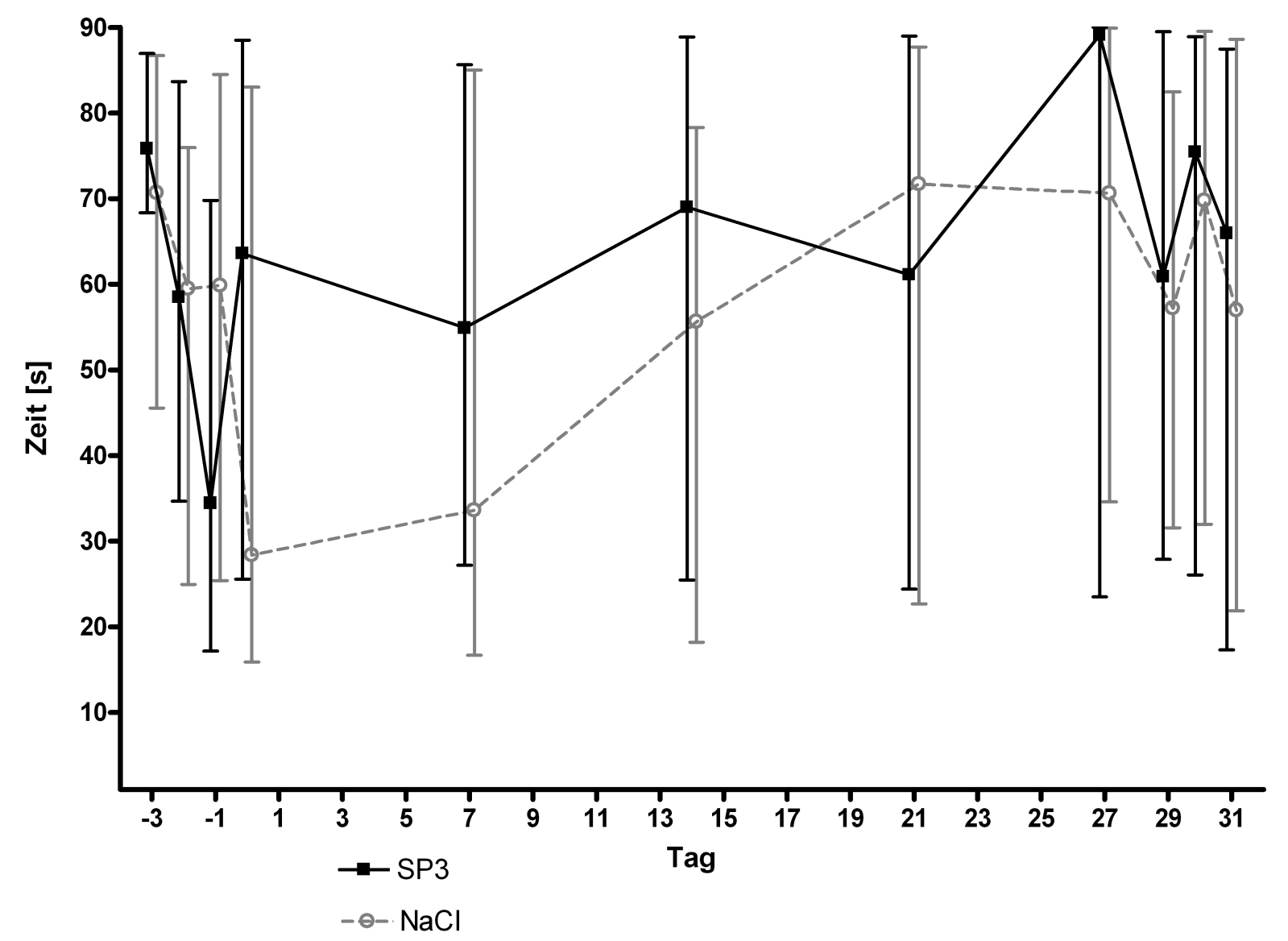

Abb. 18: Erreichte Zeiten im Morris Water Maze von SP3-infizierten $(n=22)$ und nicht infizierten ( $n=24$ ) $\mathrm{Tg}^{+}$-Mäusen über den gesamten Versuchszeitraum Dargestellt sind die Mediane und 25./75. Perzentile der benötigten Zeit zum Finden der Plattform in sek zu den einzelnen Versuchszeitpunkten. Es lassen sich keine signifikanten Unterschiede zwischen den beiden Gruppen in der Trainingsphase, der Infektions-/Postinfektionsphase sowie im Versuchsabschnitt mit der versetzten Plattform finden.

Bei der Auswertung der Strecke über den gesamten Versuchszeitraum ergaben sich keine signifikanten Differenzen zwischen SP3- und der NaCl-Gruppe [AUC (cm x Tag), 30079 
(16446/39117) für SP3 vs. 23799 (16289/30299) für NaCl; P = 0,2484]. Beide Gruppen legten am ersten Tag der Trainingsphase (Tag -3) noch sehr viel Strecke beim Suchen der versteckten Plattform zurück. Schon an Tag -2 waren die Werte deutlich abgesunken und blieben über den weiteren Versuch nahezu konstant (siehe Abb. 19).

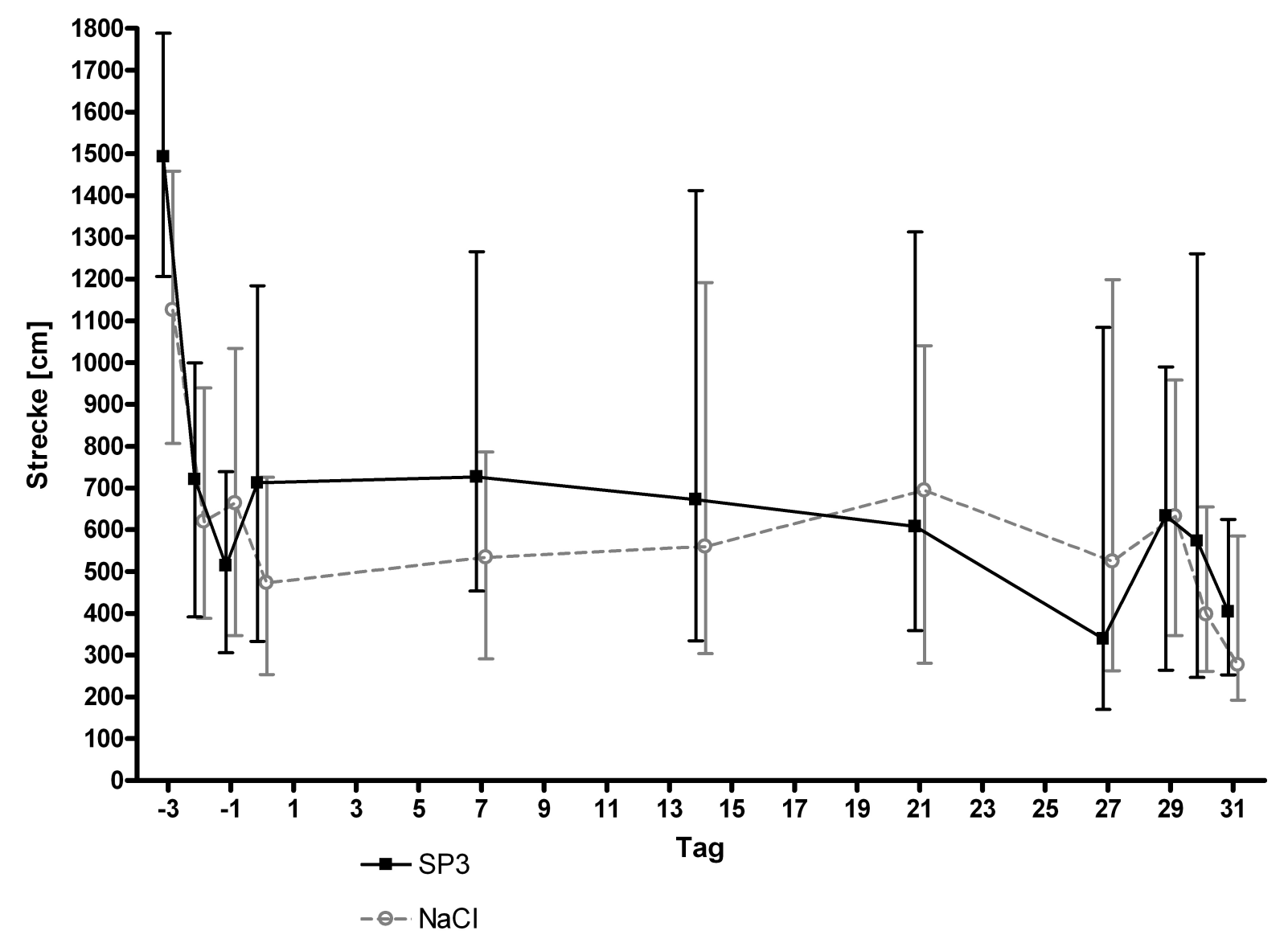

Abb. 19: Zurückgelegte Strecke im Morris Water Maze der mit SP3-infizierten $(n=22)$ und nicht infizierten ( $n=24) \mathrm{Tg}^{+}$-Mäuse über den gesamten Versuch. Dargestellt sind die Mediane und 25./75. Perzentile der zurückgelegten Strecke in $\mathrm{cm}$ zu den einzelnen Versuchszeitpunkten. Es lassen sich keine signifikanten Unterschiede zwischen den beiden Gruppen über den gesamten Versuch finden.

Analog zur zurückgelegten Strecke, zeigte sich bei der Geschwindigkeit im Morris Water Maze kein Unterschied zwischen den beiden Versuchsgruppen [AUC (cm/s x Tag): 627,3 $(382,5 / 716,5)$ für SP3 vs. 566,5 (445,8/719,5) für NaCl; P = 0,9299] (siehe Abb. 20). 


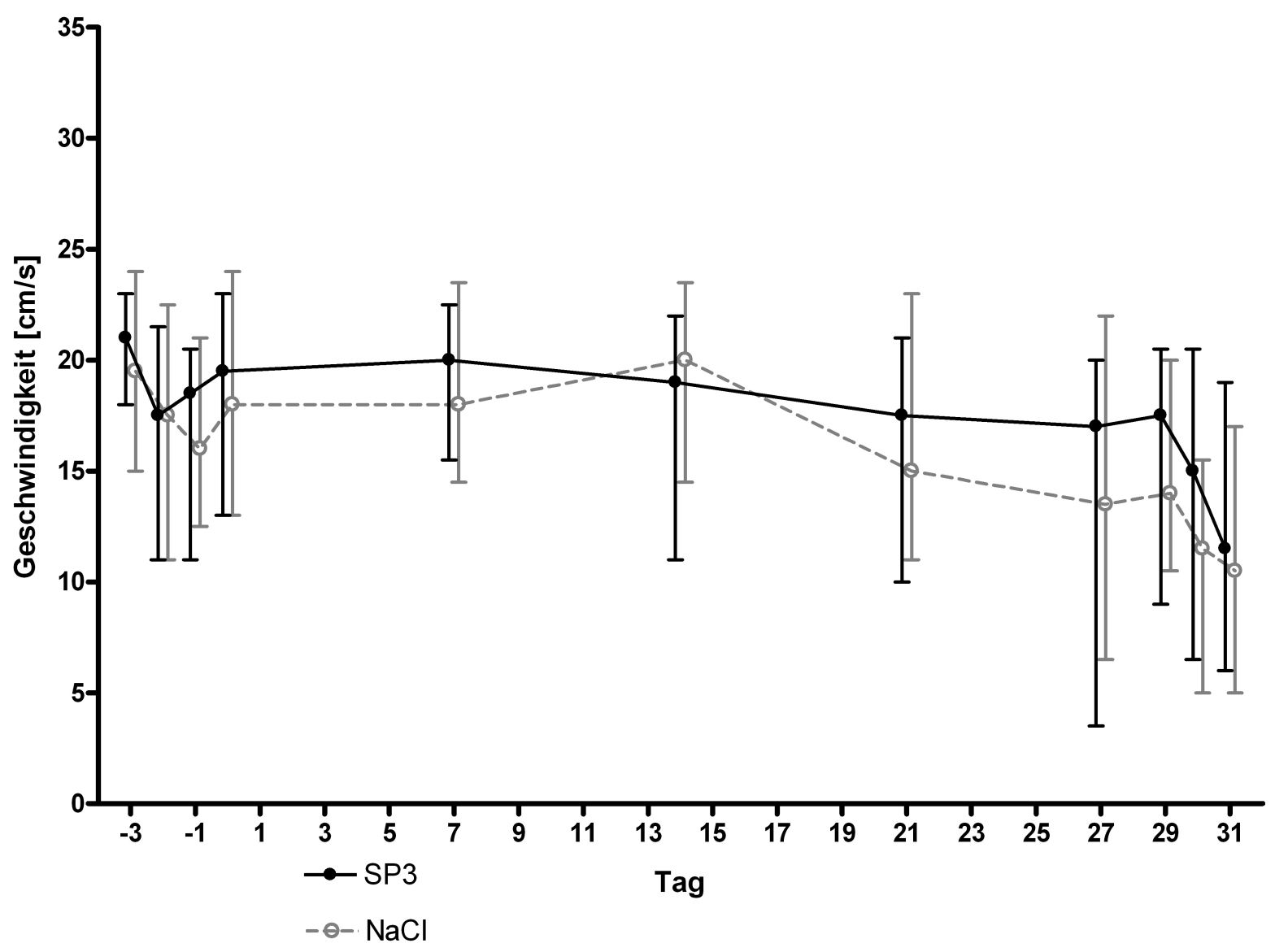

Abb. 20: Erreichte Geschwindigkeit im Morris Water Maze für SP3-infizierte $(n=22)$ und nicht infizierte $(n=24) \mathrm{Tg}^{+}$-Mäuse über den gesamten Versuch. Dargestellt sind die Mediane und 25./75. Perzentile der erreichten Durchschnittsgeschwindigkeit in $\mathrm{cm} / \mathrm{sek}$ zu den einzelnen Versuchszeitpunkten. Es ließen sich keine signifikanten Unterschiede zwischen den beiden Gruppen über den gesamten Versuch finden.

\subsubsection{Aß-Gehalt im Gehirn am Ende des Versuches}

Das Gehirngewebe zur Durchführung der ELISAs wurde den Mäusen am Versuchsende im Rahmen der Präparation entnommen (siehe auch Kapitel 2.8.1). Neben der Untersuchung des löslichen $A \beta-G e h a l t e s$ im Gehirn wurde auch die Konzentration von unlöslichem $A \beta$ bestimmt.

Der Gehalt an löslichem Aß 1-40 im Gehirn unterschied sich nicht signifikant bei SP3- und nicht-infizierten Mäusen [245,4 $\pm 123,4$ pg/ml für SP3 vs. 232,9 $\pm 133,6$ pg /ml für NaCl; P $=0,7445]$. Auch der Gehalt des löslichen $A \beta$ 1-42 war nicht signifikant unterschiedlich 
[168,5 $\pm 127,4 \mathrm{pg} / \mathrm{ml}$ für SP3 vs. $213,8 \pm 159,8 \mathrm{pg} / \mathrm{ml}$ für $\mathrm{NaCl} ; \mathrm{P}=0,2959]$. Bei der Betrachtung des unlöslichen $A \beta$ fiel ein weitaus höherer Gehalt von unlöslichem $A \beta$ 1-40 gegenüber unlöslichem $A \beta$ 1-42 auf. Getrennt beleuchtet, zeigten sich jedoch keine Unterschiede zwischen SP3- und Kontrollgruppe bezüglich des Gehaltes an unlöslichem $A \beta$ 1-40 und $A \beta$ 1-42. Für den Gehalt des unlöslichen $A \beta$ 1-40 fanden sich Werte von 270,6 $\pm 25,30 \mathrm{pg} / \mathrm{ml}$ bei den SP3-Mäusen und 259,0 $\pm 22,32 \mathrm{pg} / \mathrm{ml}$ bei den NaCl-Mäusen $(P=0,1065)$. Auch bei dem unlöslichen $A \beta$ 1-42 konnten keine signifikanten Unterschiede gefunden werden $(74,94 \pm 13,84 \mathrm{pg} / \mathrm{ml} \mathrm{SP} 3$ vs. $72,91 \pm 11,92 \mathrm{pg} / \mathrm{ml} \mathrm{NaCl}, \mathrm{P}=0,5948)$ (siehe Abb. 21).

A

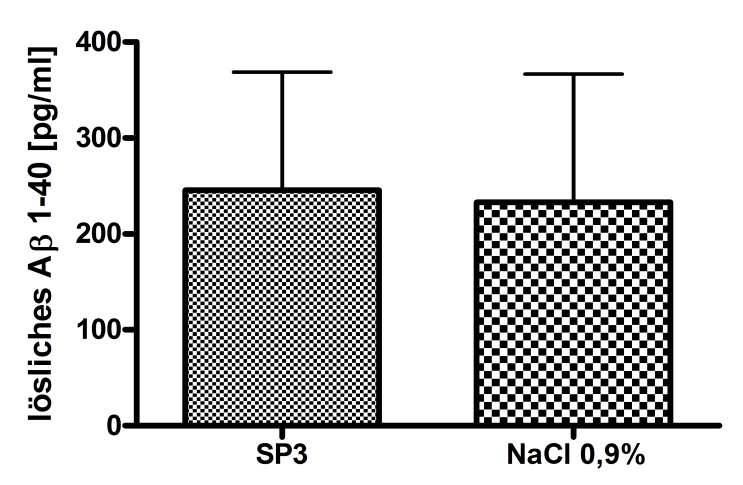

C

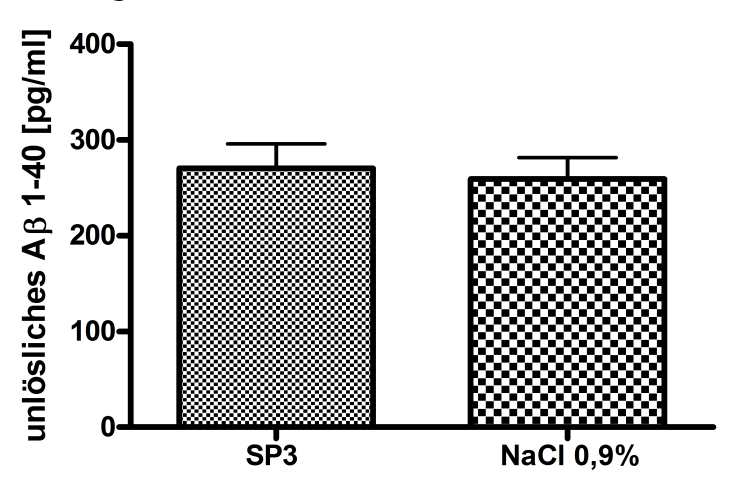

B

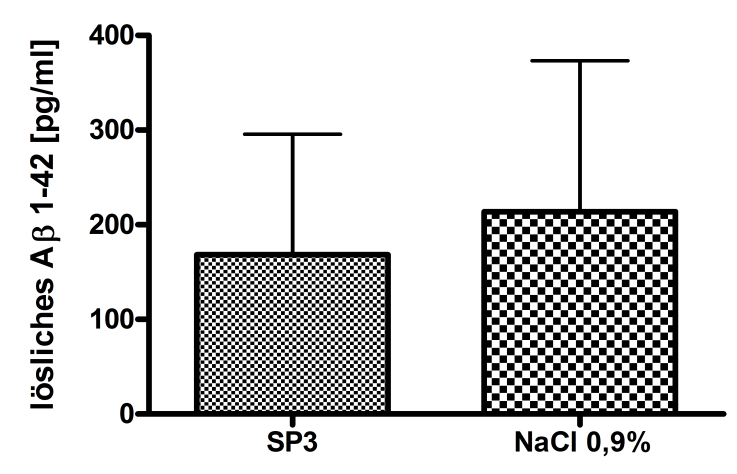

D

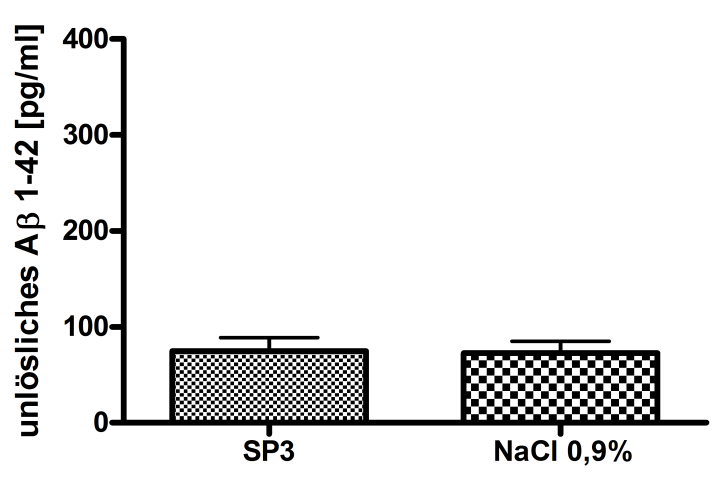

Abb. 21: $A \beta-G e h a l t$ im Gehirn der SP3-infizierten (n = 22) und NaCl-Mäuse $(n=24)$ für $A$ : lösliches $A \beta$ 1-40. $B$ : lösliches $A \beta$ 1-42. $C$ : unlösliches $A \beta$ 1-40. $D:$ unlösliches $A \beta$ 1-42. Angegeben sind die Mittelwerte \pm Standardabweichungen des $A \beta-G e h a l t e s$ in $\mathrm{pg} / \mathrm{ml}$. Es ließen sich keine signifikanten Unterschiede bezüglich der einzelnen Aß-Konzentrationen zwischen SP3und $\mathrm{NaCl}-M a ̈ u s e n$ finden. 


\subsubsection{Aß-Gehalt im Verlauf der Infektion}

In den Gehirnen der mit $S$. pneumoniae infizierten $\mathrm{Tg}^{+}$-Mäuse, die zu verschiedenen Zeitpunkten während des Versuches verstorben waren (durch Infektion bedingt oder durch Altersschwäche), wurden ebenfalls die Konzentrationen von löslichem und unlöslichem $A \beta$ 1-40 und 1-42 mittels ELISA bestimmt.

Dabei fällt auf, dass die Konzentrationen des löslichen $A \beta$ im Gegensatz zu denen des unlöslichen $A \beta$ starken Schwankungen unterlagen (siehe Abb. 22).

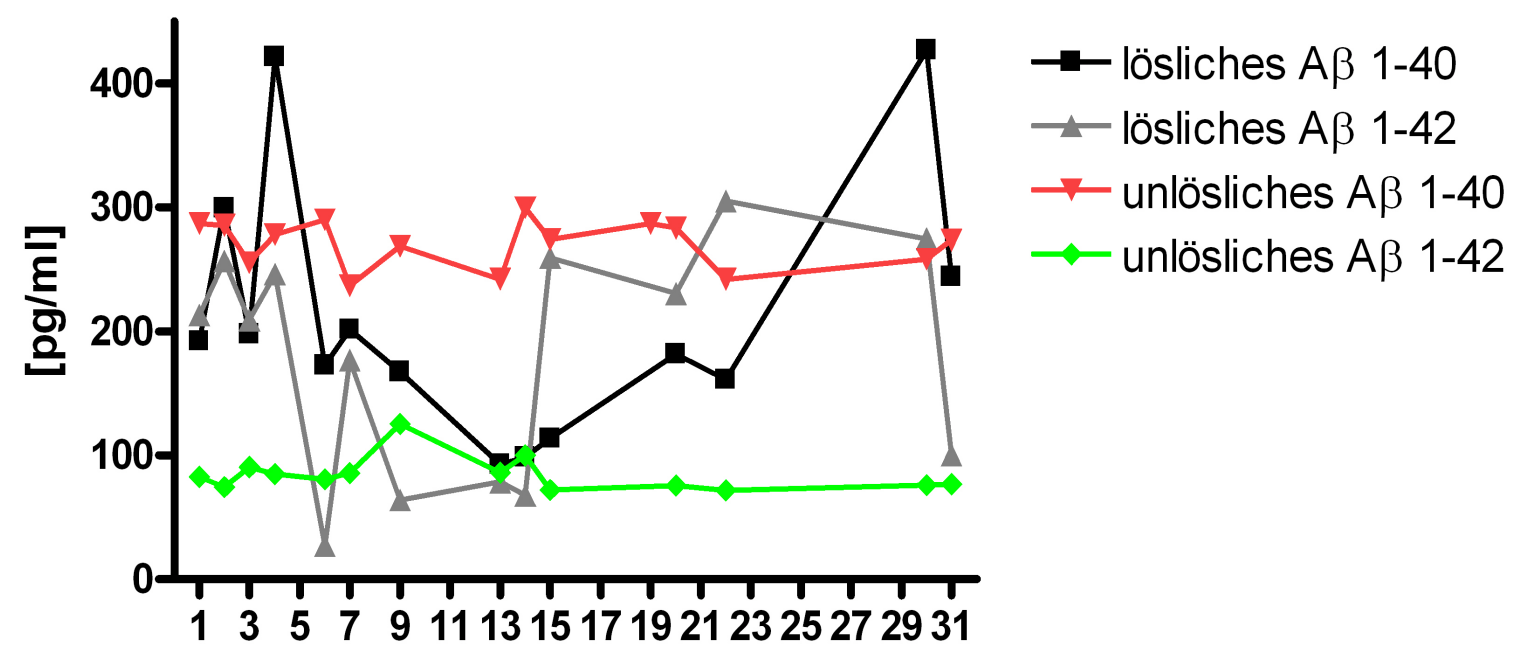

Abb. 22: Gehalt von löslichem und unlöslichem $A \beta$ bei S. pneumoniae-infizierten Tg $^{+}-$ Mäusen im Verlauf des Versuches. Dargestellt sind die Mediane der A $\beta$-Konzentration in pg/ml. Im Gegensatz zum recht konstant bleibenden unlöslichen $A \beta-G e h a l t$ schwankte die Konzentration des löslichen $A \beta$.

Zur besseren Auswertung erfolgte die Einteilung der infizierten $\mathrm{Tg}^{+}$-Mäuse in 3 Gruppen. Gruppe 1 umfasst jene S. pneumoniae-infizierten $\mathrm{Tg}^{+}$-Mäuse, welche in der akuten Infektionsphase vor Abschluss der Antibiose verstorben waren (Tag 1 bis 5.). Gruppe 2 umfasst alle Mäuse, welche in der Postinfektionsphase (Tag 6 bis 28) verstarben. Die Gruppe 3 besteht aus den Mäusen, die bis zum Tag 29 und bis zum Ende des Versuches überlebt hatten. Beim Vergleich der Konzentration des löslichen $A \beta$ 1-40 zeigte sich eine signifikant niedrigere $A \beta-K o n z e n t r a t i o n$ in der Postinfektionsphase im Vergleich zur Infektionsphase $[280,9 \pm 153,0 \mathrm{pg} / \mathrm{ml}$ Infektions- vs. 153,8 $\pm 50,85 \mathrm{pg} / \mathrm{ml}$ Postinfektionsphase; $P=0,0027]$. Danach stieg die lösliche $A \beta$ 1-40 Konzentration wieder 
auf Werte der Infektionsphase an. Bei der Betrachtung des löslichen A 1 1-42 fiel dieses Schwankungsverhalten ebenfalls auf. Es war jedoch nicht so stark ausgeprägt wie beim Iöslichen $A \beta$ 1-40 und erreichte auch keine statistische Signifikanz. Die Konzentrationen des unlöslichen $A \beta$ 1-40/1-42 blieben über die drei unterschiedlichen Abschnitte nahezu konstant (siehe Abb. 23).
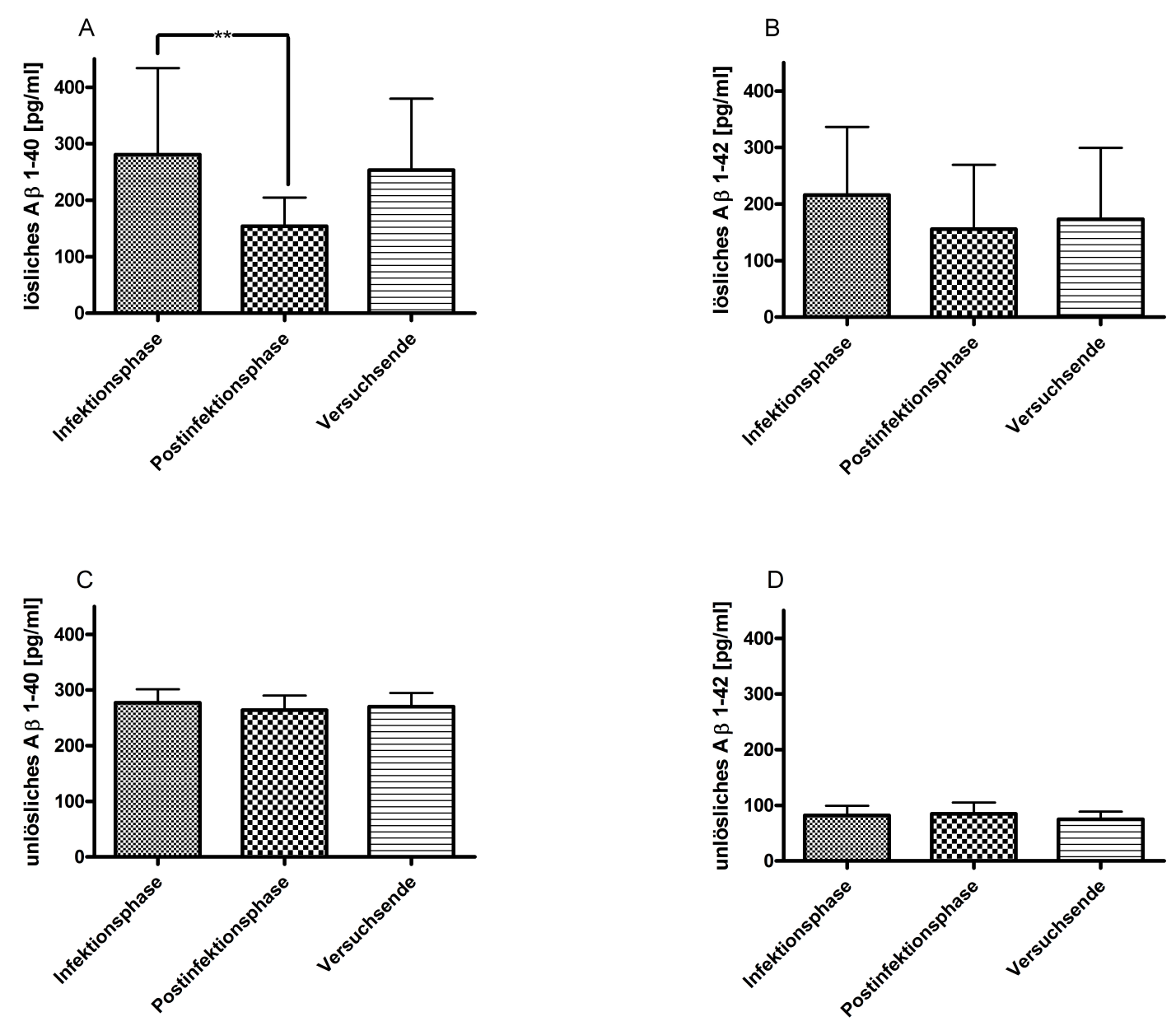

Abb. 23: Gehalt von löslichem und unlöslichem $A \beta$ 1-40 und 1-42 bei $S$. pneumoniaeinfizierten $\mathrm{Tg}^{+}$-Mäusen im Verlauf des Versuches. A: Iösliches A $\beta$ 1-40. B: lösliches $A \beta$ 1-42. $C$ : unlösliches $A \beta$ 1-40. $D$ : unlösliches $A \beta$ 1-42. Angegeben sind die Mittelwerte und die Standardabweichungen der $\mathrm{A} \beta-$ Gehalte in $\mathrm{pg} / \mathrm{ml}$. Die Gruppeneinteilung erfolgte in Infektionsphase $(n=11)$, Postinfektionsphase $(n=13)$ und Versuchsende $(n=23)$. Während das lösliche $A \beta$ in den einzelnen Phasen des Versuches Schwankungen unterlag, blieb der Gehalt des unlöslichen $A \beta$ stabil $\left({ }^{* *} P<0,01\right)$. 


\section{DISKUSSION}

\subsection{Vergleich zwischen transgenen und nicht-transgenen Mäusen des Stammes Tg2576 (vor intrazerebraler Infektion mit S. pneumoniae)}

Mausmodelle, die genetische Mutationen in bestimmten Abschnitten des Genoms aufweisen, werden häufig in biomedizinischer Forschung eingesetzt, um Krankheitsbilder besser verstehen zu können (Lassalle et al. 2008). Die transgenen Mäuse des Stammes Tg2576 besitzen in der Sequenz des humanen APP-Gens eine Doppelmutation, welche Auswirkungen auf ihre kognitiven Fähigkeiten haben (Hsiao et al. 1996). Auch die in dieser Arbeit erhobenen Ergebnisse stützen diese Feststellungen.

Die transgenen Mäuse der Tg2576-Mauslinie haben erhebliche Defizite beim Finden der versteckten Plattform im Morris Water Maze. An den 4 Trainingstagen zeigten sie ein geringeres Lernverhalten als ihre nicht-transgenen Artgenossen. Da sie durchweg mehr Strecke bei gleichzeitig höherer Durchschnittsgeschwindigkeit benötigen, um auf der Plattform anzukommen, scheint es Unterschiede im Suchverhalten zu geben. Es ist anzunehmen, dass diese transgenen Mäuse angestrengter, unkoordinierter und hektischer im Suchvorgang agieren. Mit Hilfe des beschriebenen Versuchsaufbaus des Morris Water Maze ist es möglich, Unterschiede bezüglich der kognitiven Fähigkeiten zwischen transgenen Mäusen und nicht-transgenen Mäusen zu detektieren. Kontroverse Meinungen finden sich in der Literatur bezüglich des Zeitpunktes des Nachlassens der kognitiven Fähigkeiten für die Tg2576-Mäuse. Hsiao et al. geben hierfür ein Alter von 9 Monaten an, getestet durch den Morris Water Maze, während King und Arendash einen Zeitpunkt von 19 Monaten postulieren (Hsiao et al 1996, King und Arendash 2002). Die in dieser Arbeit verwendeten Mäuse des Stammes Tg2576 hatten bei Versuchsbeginn ein Alter von 11-14 Monaten und zeigten Unterschiede in ihren kognitiven Fähigkeiten, welche knapp an der Signifikanzgrenze lagen. Es ist jedoch zu berücksichtigen, dass der Versuchsaufbau des Morris Water Maze bei Hsiao et al. als auch bei King et al. sowohl Unterschiede in der Durchführung als auch Unterschiede in der Testtagfrequenz im Vergleich zum hier verwendeten zeigt und das ganze Experiment unter anderen Ausgangsbedingungen durchgeführt wurde.

Andere Versuche unserer Arbeitsgruppe mit 2 bis 3 Monate alten C57BL/6-Mäusen zeigten ein gezielteres Suchverhalten der Mäuse. Diese benötigten deutlich weniger Zeit, 
um die versteckte Plattform im gleichen Morris-Water-Maze-Aufbau zu finden (Tauber et al. 2009). Es ist jedoch festzuhalten, dass sowohl nicht-transgene Mäuse des Stammes Tg2576 als auch Mäuse des Stammes C57BL/6 einen Rückgang der kognitiven Fähigkeiten bei Alterung, wahrscheinlich begründet durch den normalen Alterungsprozess, zeigen (King und Arendash 2002, Murphy et al. 2006).

Bei der Betrachtung der Ausgangsgewichte zeigten sich deutlich niedrigere Werte bei den transgenen Tg2576-Mäusen. Allgemein sind sie leichter und zierlicher als ihre nicht transgenen Artgenossen. Dies lässt vermuten, dass sie weniger Muskelmasse und körperliche Fitness besitzen. Unterstützt wird diese These durch die signifikant schlechteren Ergebnisse im Rotarod-Test und im Seiltest.

Die $A \beta-H y p o t h e s e$ der $A D$ beschreibt, dass $A \beta$-Plaqueablagerungen verantwortlich sind für Neurotoxizität und Neurodegeneration, die schlussendlich zu einer Demenzsymptomatik führt (Hardy und Allsop 1991). Der Hauptbestandteil dieser Plaqueablagerung ist aggregiertes $A \beta$. Die transgenen Mäuse produzieren mutiertes humanes APP, weil sie zusätzlich das Gen dafür bekommen haben. Die nicht-transgenen Mäuse sollten gar kein humanes APP produzieren, da sie diese Mutation im APP-Gen nicht besitzen (Hsiao et al. 1996). Die transgenen Mäuse zeigen einen schnellen Anstieg von $A \beta$ im Alter von 6

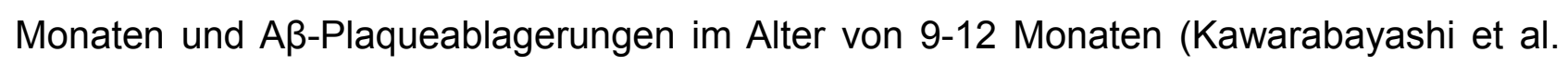
2001). Durch die Quantifizierung mittels ELISA konnte diese Aussage sowohl für A 1 1-40 als auch A 1-42 bestätigt werden. Neben der durchgeführten PCR zur Genotypisierung bestätigt dieses Ergebnis die genetische Mutation im APP-Gen bei der transgenen Gruppe. Die Unterschiede in der $A \beta-K o n z e n t r a t i o n$ waren jedoch weitaus geringer als von den Entwicklern dieses Mausmodells beschrieben. Hsiao et al. geben für lösliches A 1-40 einen bis um das 5-Fache höheren Wert bei $\mathrm{Tg}^{+}$-Mäusen als bei $\mathrm{Tg}^{-}$-Mäusen an. Für das lösliche $A \beta$ 1-42 wird ein 14-Fach erhöhter Wert beschrieben (Hsiao et al. 1996). Für das lösliche $A \beta$ 1-40 fanden sich in den in dieser Arbeit durchgeführten Analysen bei den $\mathrm{Tg}^{+}-$ Mäusen um das 30-Fach erhöhte Werte, während lösliches A 1-42 nur doppelt so hoch in der transgenen wie in der nicht-transgenen Population war. Andere Proteinextraktionen und Unterschiede in der Durchführung der Proteinbestimmung können diese Tatsache zwar erklären, jedoch nicht vollständig rechtfertigen. 


\subsection{Empfindlichkeit der transgenen und nicht-transgenen Mäuse des Stammes Tg2576 auf eine intrazerebrale Infektion mit S. pneumoniae}

Die phänotypischen Unterschiede vor allem des Ausgangsgewichtes der beiden Populationen ließen eine unterschiedliche Empfindlichkeit auf eine Infektion vermuten. $S$. pneumoniae ist ein häufigen Erreger für die bakterielle Meningitis. Neben einer hohen Letalität beim Menschen, selbst unter intensivmedizinischer Betreuung, leiden Patienten häufig an Spätfolgen der Meningitis (Bohr et al. 1984, Durand et al. 1993, Pfister et al. 1993). Die transgenen Mäuse als auch die nicht-transgenen Mäuse zeigten einen ähnlichen Gewichtsverlauf unter Infektion. Allerdings waren die Gewichte der nicht transgenen Gruppe über den gesamten Versuch durchweg höher. In beiden Gruppen fällt kurz nach Infektion trotz antibiotischer Behandlung das Gewicht erheblich ab. Unter antibiotischer Therapie kommt es wieder zum Anstieg bis fast auf den Ausgangswert. In diesem Punkt verhalten sich die beiden Populationen nahezu gleich.

Unterschiede finden sich jedoch bezüglich der Empfindlichkeit der $\mathrm{Tg}^{+}-$und Tg-Mäuse auf die zentralnervöse Infektion mit $S$. pneumoniae. Die größte Sterblichkeit in beiden Gruppen trat 1-3 Tage nach Infektion auf. Es konnte gezeigt werden, dass die transgene Gruppe eine mehr als doppelt so hohe Sterblichkeit unter intrazerebraler Infektion mit S. pneumoniae hat wie die nicht-transgene Gruppe. Diese Erkenntnis ist nicht ungewöhnlich, da bei den transgenen Mäusen des Stammes Tg2576 bereits eine herabgesetzte Lebenserwartung feststellt werden konnte (King und Arendash 2002). Es ist außerdem bekannt, dass transgen veränderte Mauslinien im Allgemeinen eine niedrigere Lebenserwartung haben als die Wildtyppopulation. Dieser Umstand ist auf die chromosomale Instabilität aufgrund der transgenen Veränderung zurückzuführen. Wellmer führte dieselbe intrazerebrale Beimpfungsmethode mit dem gleichen Stamm S. pneumoniae an 2-3 Monate alten C57BI/6-Mäusen mit einer ähnlich hohen Keimzahlbelastung durch und erhielt ebenfalls hohe Letalitätsraten (Wellmer et al. 2000). Wellmer's Rate befand sich zwischen den Ergebnissen für die transgene und nicht transgene Gruppe. Dies zeigt, dass die intrazerebrale Inokulation von S. pneumoniae durch die Kalotte ein Procedere ist, welches für Mäuse ein erhebliches Trauma darstellt. Es ist zu erwähnen, dass der Zugangsweg durch die Kalotte kein normaler Eintrittsort für das Bakterium darstellt. Vielmehr verbreitet sich der Erreger infolge einer systemischen Infektion z.B. ausgelöst durch eine Pneumonie über die Blutbahn. Das verwendete Modell 
sollte lediglich dazu dienen, ein Entzündungsgeschehen mit ZNS-Beteiligung auszulösen. Allerdings scheint das veränderte Genom ebenfalls ausschlaggebend für eine erhöhte Sterblichkeit zu sein.

Ohne antibiotische Therapie mit Ceftriaxon waren alle 4 transgenen Kontrollmäuse nach 2 Tagen verstorben. In der Ausplattung der Kleinhirnhomogenate der Kontrollmäuse fanden sich höhere Keimzahlen als bei den Mäusen, die antibiotisch mit Ceftriaxon behandelt wurden waren. Hier konnte offenbar eine massive Vermehrung der Bakterien stattfinden.

$\mathrm{Ab}$ dem 3. Tag der Antibiose konnten keine Bakterien mehr in der transgenen und nichttransgenen Gruppe nachgewiesen werden. In der histologischen Untersuchung der Großhirne durch HE-Färbung konnten, bei den während des Versuches verstorbenen Mäusen, entzündliche Veränderungen nur bis zum 9. Tag nach Infektion gefunden werden. Damit ist bewiesen, dass zum einen die gewählte Dosis der intrazerebrale Infektion mit S. pneumoniae ohne antibiotische Therapie zum Tod der Mäuse führte und zum anderen die antibiotische Therapie mit Ceftriaxon die Letalität effektiv senkte.

Bei AD-Patienten kommt es im Endstadium der Erkrankung häufig zu Pflegebedürftigkeit, welche in Immobilität und Bettlägerigkeit gipfelt. Diese Patienten versterben häufig an Folgen von Infektionen wie Pneumonien oder Harnwegsinfekten. Die Ergebnisse der durchgeführten Versuche lassen vermuten, dass AD-Patienten auch eine verminderte Resistenz gegen bakterielle Infektionen haben. Die schnelle und gezielte Therapie ist hier um so wichtiger, da diese Patienten auch aufgrund ihres Alters, ihres Ausgangszustandes und ihres schlechteren Immunsystems anfälliger für Erkrankungen im Allgemeinen sind. Für das Überleben dieser Patienten sind frühe Antibiotikagaben und engmaschige medizinische Kontrollen besonders wichtig.

\subsection{Einfluss einer intrazerebralen Infektion mit S. pneumoniae auf transgene Mäuse des Stammes Tg2576}

Klinische Daten weisen darauf hin, dass systemische Infektionen bei Patienten mit neurodegenerativen Erkrankungen, wie z.B. der AD, zur Verschlimmerung der Symptomatik führen können und den Zustand vor allem der geistigen Fähigkeiten verschlechtern (Manos und Wu 1997, Griffin et al. 1998). Infektionen führen zu einem Progress der Erkrankung, der die klinische Situation des Patienten erheblich beeinflusst. In einer vergangenen Untersuchung der Arbeitsgruppe hatten mehrere systemische 
Infektionen mit $S$. pneumoniae keinerlei Einfluss auf den Progress von neurodegenerativen Erkrankungen wie der AD, der ALS und des Morbus Parkinson im Tiermodell. Speziell für die AD konnte keine Verschlechterung der kognitiven Fähigkeiten durch 4-malige intraperitoneale Infektion mit SP3 gefunden werden (Ebert et al. 2010).

Möglicherweise war der inflammatorische Stimulus nicht stark genug bzw. nicht langanhaltend genug, um den Verlauf der neurodegenerativen Erkrankung zu beeinflussen. Um einen stärkeren inflammatorischen Stimulus im Gehirn zu erreichen, wurde die Infektion in dieser Arbeit auf intrazerebralem Wege durchgeführt.

Für das Durchmachen einer schweren Infektion sprechen der Abfall des Gewichtes der SP3-Gruppe nach Infektion, sowie die schlechteren Ergebnisse im Rotarod-Test während der Infektionsphase. Es ließen sich in dieser Phase Verhaltensauffälligkeiten wie Somnolenz und motorische Defizite finden. Dies ist nicht ungewöhnlich, da die bakterielle Meningitis, z.B. ausgelöst durch S. pneumoniae, genau diese klinischen Bilder erzeugen kann (Stevenson 1973, Koedel et al. 2002). Das Gewicht der NaCl-Gruppe blieb hingegen über den ganzen Versuch nahezu gleich. Im Rotarod-Test fanden sich bei der $\mathrm{NaCl}$ Gruppe in der Zeit der Infektionsphase sogar bessere Ergebnisse. Nach Therapie mit Ceftriaxon verschwanden sowohl die angesprochenen Verhaltensauffälligkeiten als auch die motorischen Unterschiede zwischen den beiden Gruppen. Am Ende des Versuches hatte sich auch das Gewicht der SP3-Gruppe wieder auf den Ausgangswert normalisiert.

Die kognitiven Fähigkeiten wurden mithilfe des Morris Water Maze analysiert. Hierbei fanden sich keine statistischen Unterschiede über den gesamten Versuch zwischen infizierten und nicht-infizierten transgenen Mäusen. Bei der Betrachtung der Zeit, welche bis zum Erreichen der versteckten Plattform benötigt wurde, war zwar ein Unterschied vor allem in der Infektionsphase zu erkennen, der aber keine statistische Signifikanz erreichte. Dies war durch die großen individuellen Unterschiede zwischen den einzelnen Mäusen innerhalb der Gruppen bedingt. Die Zeitwerte glichen sich zum Ende des Versuches wieder an. Im Testabschnitt der versetzten Plattform konnte man keinerlei Unterschiede mehr zwischen den beiden Gruppen aufzeigen. Auch die zurückgelegte Strecke und die Durchschnittsgeschwindigkeit waren nicht unterschiedlich in den beiden Gruppen. Die durchgeführte intrazerebrale Infektion mit $S$. pneumoniae hatte keine Auswirkung auf die kognitiven Fähigkeiten der $\mathrm{Tg}^{+}$-Mäuse in diesem Versuchsaufbau. Anzumerken ist, dass in Kapitel 4.1 zwar gezeigt werden konnte, dass das verwendete Morris Water Maze geeignet ist, klinische Unterschiede zwischen AD- und nicht-AD-Maus aufzuzeigen. Es ist jedoch möglich, dass es nicht sensitiv genug testet, um die Verschlechterung der 
neuropsychologischen Fähigkeiten einer AD-Maus infolge einer Infektion zu detektieren. Es ist weiterhin denkbar, dass die Infektion mit S. pneumoniae nicht lange genug wirken konnte, um ein chronisches Entzündungsgeschehen auszulösen bzw. das durch die neurodegenerative Grunderkrankung bereits bestehende Entzündungsgeschehen zu verstärken. Jedoch war es nicht möglich, die Zeit zwischen Infektion und 1. Antibiose weiter auszudehnen. Die verwendeten transgenen Mäuse waren nach 22 Stunden in so schlechter klinischer Verfassung, dass es nicht möglich gewesen wäre, noch länger mit der 1. Antibiose abzuwarten. Die ohnehin hohe Sterblichkeit unterstreicht, dass dies nicht sinnvoll gewesen wäre.

Experimente mit der systemischen Applikation von LPS, einem Virulenzfaktor gramnegativer Bakterien, an Mäusen haben gezeigt, dass dieser Stimulus eine neurodegenerative Erkrankungen wie die ALS verschlimmern kann (Nguyen et al 2004). Allerdings konnte eine solche Beeinflussung bis jetzt nicht mit lebenden Bakterien nachgewiesen werden. In vitro-Studien zeigen, dass aktivierte Mikrogliazellen, abhängig von der Dosis des zugeführten infektiösen Materials, neuroprotektiv oder neurotoxisch wirken können ( $\mathrm{Li}$ et al. 2007). Cunningham und Kollegen konnten am Prionen-Modell bereits zeigen, dass die Gabe von Lipopolysacchariden zur Ausschüttung von proinflammatorisch wirkender Zytokine, zur Aktivierung von Mikroglia, zu einem Absterben von Neuronen und in der Folge zu einem Progress der neurodegenerativen Erkrankung im Mausmodell führen (Cunningham et al 2005, Cunningham et al. 2008). Es ist jedoch anzumerken, dass die erwähnten Studien mit unphysiologisch hohen Dosen von LPS durchgeführt wurden.

Die Lyse von Gram-positiven Bakterien wie S. pneumoniae durch $\beta$-Lactamantibiotika führt zur Freisetzung von Bakterienprodukten, die einen starken Stimulus für die Aktivierung des angeborenen Immunsystems darstellen (Nau und Eiffert 2002). Weitere Studien der Arbeitsgruppe unterstützen diese Aussage und stellen Pneumolysin, einen Virulenzfaktor von S. pneumoniae, als einen potenten Stimulus für die Aktivierung des Immunsystems dar (Ebert et al. 2005).

Es ist geplant, weitere Studien mit einem gramnegativen Bakterium, das LPS als Zellwandbestandteil besitzt, in gleicher Versuchsanordnung durchzuführen. Hier bietet sich ein Erreger wie E. coli an (Chen et al. 2008). E. coli ist ein weitverbreiteter Erreger für Harnwegsinfekte, welche auch häufig bei pflegebedürftigen Patienten infolge eines liegenden Dauerkatheters auftreten (Bagshaw und Laupland 2006). Die klinische Relevanz ist leicht herzustellen, da diese Art von Infektion über Septikämie in ein 
systemisches Entzündungsgeschehen übergreifen kann. Aktuell laufende Studien der Arbeitsgruppe konnten zeigen, dass die Zeit zwischen intrazerebraler Infektion mit E. coli und erster Antibiose erheblich länger ausgedehnt werden können als das bei $S$. pneumoniae der Fall ist. Die Letalität der Tiere fiel ebenfalls mit $E$. coli niedriger aus. Mit diesem Modell scheint es also eher möglich zu sein, einen nicht so akuten Verlauf der zerebralen und systemischen Infektion herbeizuführen. Alternativ könnten Modelle zur Auslösung von septischer Arthritis, Endokarditis oder Weichteilinfektionen mit z.B. Staphylococcus aureus genutzt werden, die ebenfalls das Potential besitzen, systemische Infektionen herbeizuführen (Tarkowski et al. 2001).

Diese Ausführungen zeigen, dass es äußert schwierig ist, einen Versuchsaufbau zu erstellen, welcher in der Lage ist, ein chronisches Entzündungsgeschehen, wie es im klinischen Alltag auftritt, zu imitieren.

Dem Protein $A \beta$ kommt eine erhebliche Rolle in der Pathophysiologie der $A D$ zu. Die Ablagerungen von $A \beta-P e p t i d e n$ im ZNS in Form von Amyloid-Plaques sind typische Kennzeichen der AD (Jellinger 2008). Die wissenschaftlichen Meinungen stützen die

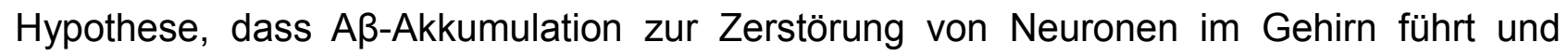
dadurch kognitive Defizite ausgelöst werden (Hardy 2006, Wisniewski und Konietzko 2008). Durch intensive Forschungen wird versucht, den pathologischen Mechanismus zu verstehen und damit Diagnostik und Therapiestrategien zu verbessern.

Für das lösliche $A \beta$ 1-40 und $A \beta$ 1-42 konnten keine Unterschiede zwischen Infektionsund Kontrollgruppe gefunden werden. Ebenso verhielt es sich mit den Ergebnissen für das unlösliche $A \beta$ 1-40 bzw. $A \beta$ 1-42. Die durchgeführte intrazerebrale Infektion mit S. pneumoniae hatte also keinen Einfluss auf die Konzentrationen von A $\beta$ 1-40 bzw. 1-42 (weder in löslicher noch in unlöslicher Form) im Tg2576-Mausmodell.

Aufgrund der hohen Sterblichkeit der Infektionsgruppe wurde der A $\beta$-Gehalt für all jene Tiere bestimmt, die während des Versuches verstorben waren. Hierbei war zu erkennen, dass der $A \beta-G e h a l t$ sich im Verlauf des Versuches für lösliches $A \beta$ 1-40 bzw. 1-42 zu verändern schien. Für lösliches $A \beta$ 1-40 fanden sich in der Postinfektionsphase (nach antibiotisch abgedeckter Infektion) signifikante Schwankungen. So kam es zu einem Absinken der A $\beta$-Menge in der Postinfektionsphase. Am Ende des Versuches stieg diese Konzentration wieder auf Werte der Infektionsphase (während der Antibiosephase) an. Ähnliche Tendenzen zeigte auch der Gehalt für lösliches $A \beta$ 1-42. Jedoch waren die Unterschiede nicht signifikant. Demgegenüber blieb der Gehalt für unlösliches A 1 -40 
und 1-42 über den gesamten Versuchsaufbau stabil. Da diese Werte nur retrospektiv anhand einer kleinen Anzahl von Versuchstieren erhoben wurden, zeigen diese Ergebnisse nur Tendenzen an. Es müssten weitere Studien speziell auf die Untersuchung des $A \beta-G e h a l t e s$ unter Infektion mit $S$. pneumoniae oder einem anderen Bakterium durchgeführt werden, um diese Ergebnisse zu überprüfen. Eine intrazerebrale Infektion mit S. pneumoniae scheint jedoch einen Einfluss auf den Gehalt von löslichem, nicht aber von unlöslichem $A \beta$ 1-40 und 1-42 zu haben.

$A \beta$-Ablagerungen können Mikroglia aktivieren. Aktivierte Mikroglia hat die Fähigkeit, $A \beta$ zu phagozytieren (Sheng et al. 2003, Sly et al. 2001). Es ist bekannt, dass sowohl intraperitoneal als auch intrazerebral verabreichte Gaben von LPS zu einer Beeinflussung des $A \beta-G e h a l t e s ~ i m ~ G e h i r n$ führen (Herber et al 2007). Einmalige LPS-Gaben in hippokampale Bereiche des Gehirns von transgenen Mäusen können die A $\beta$ Ablagerungen nach Injektion reduzieren (DiCarlo et al. 2001, Quinn et al. 2003). Über 3 Monate verabreichte LPS-Gaben erhöhen dagegen den A $\beta-G e h a l t$ im Gehirn von APPMäusen (Sheng et al. 2003). Chronische LPS-Injektionen erhöhen den A -Gehalt im Gehirn, während die akute, einmalige Gabe die A $\beta$-Formationen reduzieren kann (Morgan et al. 2005). Der zeitliche Zusammenhang scheint also eine entscheidende Rolle für die A $\beta$-Ablagerung/Reduktion zu spielen.

Scholtzova et al. konnte durch Stimulationen der angeborenen Immunantwort über den Toll-like-Rezeptor 9 im Tg2576-Mausmodell eine Reduktion von A 1-40 und A 1-42 in corticalen und hippokampalen Bereichen zeigen (Scholtzova et al. 2009). Entzündliche Geschehen haben demnach einen Einfluss auf den Gehalt von A $\beta$ im ZNS. Allerdings konnte Ebert et al. keinen Einfluss einer rezidivierenden intraperitonealen Infektion mit $S$. pneumoniae auf den A 1-40 und 1-42 Gehalt im Mausmodell zeigen (Ebert et al. 2010). Auch hier wäre die Verwendung eines LPS-haltigen Bakteriums, wie E. coli, für weitere Studien denkbar.

Es ist jedoch noch nicht abschließend geklärt, in wie weit der Aß-Gehalt im Liquor mit den kognitiven Defiziten der Patienten korreliert. In der klinischen Routine wird der Quotient zwischen $A \beta$ 1-42 und $A \beta$ 1-40 im Liquor diagnostisch verwendet. Kawarabayashi und Kollegen machen jedoch den unlöslichen Teil des $A \beta$, welcher nicht im Liquor vorliegt, für die Abnahme der Gedächtnisleistung verantwortlich (Kawarabayashi et al. 2001). Die kognitive Leistungsfähigkeit verhält sich umgekehrt proportional zu den Ablagerungen von $A \beta$ im frontalen und hippokampalen Kortex bei doppelt transgenen APP-Mäusen (Gordon et al. 2001). Westerman konnte hingegen keine Korrelation zwischen Gedächtnisverlust 
und unlöslichen $A \beta-A b l a g e r u n g e n$ bei 17 Monaten alten Tg2576-Mäusen finden. In dieser Studie wurde eine Untergruppe von $A \beta$ für die kognitiven Ausfallerscheinungen der Tg2576-Mäuse verantwortlich gemacht, welche eher der Gruppe der löslichen Aß-Fraktion zuzuordnen ist. Diese These wurde dadurch unterstützt, dass in der Studie alte Mäuse mit hohen unlöslichen $A \beta-K o n z e n t r a t i o n e n ~ k e i n e r l e i$ Gedächtnisausfälle aufwiesen (Westerman et al. 2002). Die klassische Amyloid-Hypothese, die besagt, dass aggregiertes $A \beta$ für das Zustandekommen des demenziellen Erscheinungsbild verantwortlich ist, wurde hier abgeändert. In diesem Zusammenhang sei erwähnt, das $A \beta$ Peptide durch Bildung von Pyroglutamat vor enzymatischem Abbau geschützt und somit sehr viel stabiler als $A \beta$ 1-42 sind (Sergeant et al. 2003). Weiterhin bilden $A \beta-P y r o g l u t a m a t$ 3-42-Peptide schneller $\beta$-Faltblatt-Strukturen aus, neigen stärker zur Aggregation und besitzen insgesamt eine höhere Toxizität als $A \beta$ 1-42 (He und Barrow 1999, Russo et al. 2002). Ebenfalls von Interesse ist, dass diese Pyroglutamat-Peptide als eine der am häufigsten vorkommenden $A \beta-S p e z i e s$ im Gehirn von AD-Patienten identifiziert werden konnten (Piccini et al. 2005). Die Ausführungen zeigen, dass an dieser Stelle intensive Forschungsarbeit gefragt ist, um die genaue Pathogenese der AD besser verstehen zu können. 


\section{ZUSAMMENFASSUNG}

Die Verschlechterung des klinisch-neurologischen und neuropsychologischen Status von Patienten mit $A D$ ist ein häufig beobachtetes klinisches Phänomen, das durch einige klinische Studien belegt wird. Eine Hypothese ist, dass das im Rahmen von neurodegenerativen Prozessen, z.B. durch $A \beta$, bereits aktivierte angeborene Immunsystem des ZNS besonders empfindlich auf eine zusätzliche Stimulation durch Bakterienbestandteile reagiert und dass es dadurch $\mathrm{zu}$ einer verstärkten Neurodegeneration kommt. Systemische Gaben von LPS führten im Mausmodell zu einer Verschlechterung der ALS und der Prionenerkrankung. Der negative Einfluss einer echten bakteriellen Infektion auf den Verlauf der AD konnte bisher allerdings noch nicht gezeigt werden.

In der vorliegenden Arbeit wurde der Einfluss einer einmaligen intrazerebralen Infektion mit S. pneumoniae, dem häufigsten Erreger respiratorischer Infekte beim Erwachsenen, auf 11-14 Monate alte Tg2576-Mäuse (Mausmodell der AD) untersucht. Den nicht-infizierten Mäusen wurde $0,9 \% \mathrm{NaCl}$ injiziert. Alle Mäuse wurden über 5 Tage alle 12 Stunden antibiotisch mit Ceftriaxon behandelt. Vor Infektion und für einen Zeitraum von 5 Wochen post infectionem erfolgte eine regelmäßige Testung mit Hilfe des Morris Water Maze, des Seiltests und des Rotarod-Tests. An den Gehirnen verstorbener bzw. getöteter Tiere wurde eine HE-Färbung durchgeführt und die Konzentrationen von löslichem und unlöslichem $A \beta$ 1-40 und 1-42 mittels ELISA bestimmt.

Die Sterblichkeit war trotz antibiotischer Therapie in der transgenen Gruppe (53\%) doppelt so hoch wie in der nicht-transgenen Gruppe (25\%). Die Ergebnisse der durchgeführten neuropsychologischen Tests zeigten keine signifikanten Unterschiede zwischen infizierten und nicht-infizierten transgenen Tieren. Bei Versuchsende fanden sich keine Unterschiede zwischen infizierten und nicht-infizierten transgenen Tieren bezüglich der Konzentrationen von löslichem und unlöslichem $A \beta$ 1-40 und 1-42.

Die Ergebnisse dieser Arbeit zeigen, dass an AD erkrankte Mäuse eine erhöhte Empfindlichkeit gegenüber einer bakteriellen ZNS-Infektionen mit S. pneumoniae haben. Der Verlauf der AD wurde in unserem Modell durch die intrazerebrale SP3-Infektion nicht beeinflusst. Dies lässt darauf schließen, dass adäquat behandelte bakterielle Infektionen den Verlauf von neurodegenerativen Erkrankungen weniger stark beeinflussen als vermutet. 


\section{LITERATURVERZEICHNIS}

Adu A, Armour CL (1995): Drug utilisation review (DUR) of the third generation cephalosporins. Focus on ceftriaxone, ceftazidime and cefotaxime. Drugs $\underline{50}, 423-439$

Akiyama H, Barger S, Barnum S, Bradt B, Bauer J, Cole GM, Cooper NR, Eikelenboom P, Emmerling M, Fiebich BL, et al. (2000): Inflammation and Alzheimer's disease. Neurobiol Aging 21, $383-421$

Aloisi F (2001): Immune function of microglia. Glia $\underline{36}, 165$ - 179

Andreasen N, Sjögren M, Blennow K (2003): CSF markers for Alzheimer's disease: total tau, phospho-tau and Abeta42. World J Biol Psychiatry 4, 147 - 155

Aslan M, Ozben T (2004): Reactive oxygen and nitrogen species in Alzheimer's disease. Curr Alzheimer Res 1, 111 - 119

Avrameas S (1969): Coupling of enzymes to proteins with glutaraldehyde: Use of the conjugates for the detection of antigens and antibodies. Immunochemistry $\underline{6}, 43-48$

Bagshaw SM, Laupland KB (2006): Epidemiology of intensive care unit-acquired urinary tract infections. Curr Opin Infect Dis $\underline{19}, 67-71$

Balachandran P, Hollingshead SK, Paton JC, Briles DE (2001): The autolytic enzyme lytA of Streptococcus pneumoniae is not responsible for releasing pneumolysin. $\mathrm{J}$ Bacteriol $183,3108-3116$

Bauer J, Hüll M, Berger M (1995): Pathogenetic factors of Alzheimer disease. Z Gerontol Geriatr $\underline{28}, 155-162$

Bentley SD, Aanensen DM, Mavroidi A, Saunders D, Rabbinowitsch E, Collins M, Donohoe K, Harris D, Murphy L, Quail MA, Samuel G, Skovsted IC, Kaltoft MS, Barrell B, Reeves PR, Parkhill J, Spratt BG (2006): Genetic analysis of the capsular biosynthetic 
locus from all 90 pneumococcal serotypes. PLoS Genet $\underline{2}$, e31

Bergan T (1987): pharmacokinetic properties of cephalosporins. Drugs $\underline{34}$, 89-104

Bermejo P, Martín-Aragón S, Benedí J, Susín C, Felici E, Gil P, Ribera JM, Villar AM (2008): Differences of peripheral inflammatory markers between mild cognitive impairment and Alzheimer's disease. Immunol Lett 117, 198 - 202

Bickel H (2001): Dementia in advanced age: estimating incidence and health care costs. Z Gerontol Geriatr $\underline{34}, 108-115$

Böcker W, Denk H, Heitz PhU, Moch H: Zentrales Nervensystem; in: Pathologie; hrsg. v. Böcker W, Denk H, Heitz PhU, Moch H; Elsevier Gmbh, München 2008, 309 - 312

Bohr V, Pauson OB, Rasmussen N (1984): Pneumococcal meningitis. Late neurologic sequelae and features of prognostic impact. Arch Neurol 41, 1045 - 1049

Bonev BB, Gilbert RJ, Andrew PW, Byron O, Watts A (2001): Structural analysis of the protein/lipid complexes associated with pore formation by the bacterial toxin pneumolysin. J Biol Chem 276, 5714 - 5719

Bonotis K, Krikki E, Holeva V, Aggouridaki C, Costa V, Baloyannis S (2008): Systemic immune aberrations in Alzheimer's disease patients. J Neuroimmunol 193, 183 - 187

Brogden RN, Ward A (1988): Ceftriaxone. A reappraisal of its anctivity and pharmacokinetic properities, an an update on its therapeutic use with particular reference to once-daily administration. Drugs $\underline{35}, 604-645$

Buxbaum JD, Koo EH, Greengard P (1993): Protein phosphorylation inhibits production of Alzheimer amyloid beta/A4 peptide. Proc Natl Acad Sci U S A 90, 9195 - 9198

Callahan MJ, Lipinski WJ, Bian F, Durham RA, Pack A, Walker LC (2001): Augmented senile plaque load in aged female beta-amyloid precursor protein-transgenic mice. Am $\mathrm{J}$ Pathol $\underline{158}, 1173-1177$ 
Chen J, Buchanan JB, Sparkman NL, Godbout JP, Freund GG, Johnson RW (2008): Neuroinflammation and disruption in working memory in aged mice after acutestimulation of the peripheral innate immune system. Brain Behav Immun 22, 301 - 311

Cockeran R, Anderson R, Feldman C. (2002): The role of pneumolysin in the pathogenesis of Streptococcus pneumoniae infection. Curr Opin Infect Dis $\underline{15}, 235$ - 239

Cunningham C, Wilcockson DC, Campion S, Lunnon K, Perry VH (2005): Central and systemic endotoxin challenges exacerbate the local inflammatory response and increase neuronal death during chronic neurodegeneration. J Neurosci $\underline{25}, 9275$ - 9284

Cunningham C, Campion S, Lunnon K, Murray CL, Woods JFC, Deacon RMJ, Rawlins JNP, Perry VH (2008): Systemic inflammation induces acute behavioral and cognitive changes and accelerates neurodegenerative disease. Biol Psychiatry $\underline{65}, 304$ - 312

Dagan R (2000): Treatment of acute otitis media - challenges in the era of antibiotic resistance. Vaccine $\underline{19}, 9-16$

DiCarlo G, Wilcock D, Henderson D, Gordon M, Morgan D (2001): Intrahippocampal LPS injections reduce Abeta load in APP+PS1 transgenic mice. Neurobiol Aging 22, 1007 1012

Durand ML, Calderwood SB, Weber DJ, Miller SI, Southwick FS, Caviness VSJ, Swartz MN (1993): Acute bacterial meningitis in adults. A review of 493 episodes. N Engl J Med $\underline{328}, 21-28$

Ebert S, Gerber J, Bader S, Mühlhauser F, Brechtel K, Mitchell TJ, Nau R. (2005): Dosedependent activation of microglial cells by Toll-like receptor agonists alone and in combination. J Neuroimmunol 159, 87 - 96

Ebert S, Goos M, Rollwagen L, Baake D, Zech WD, Esselmann H, Wiltfang J, Mollenhauer 
B, Schliebs R, Gerber J, Nau R. (2010): Recurrent systemic infections with Streptococcus pneumoniae do not aggravate the course of experimental neurodegenerative diseases. $J$ Neurosci Res $\underline{88}, 1124-1136$

Eckert A (2005): Calcium hypothesis in dementia. Significance of nimodipine in dementia therapy. Pharm Unserer Zeit 34, 392 - 398

Engelhart MJ, Geerlings MI, Meijer J, Kiliaan A, Ruitenberg A, van Swieten JC, Stijnen T, Hofman A, Witteman JC, Breteler MM (2004): Inflammatory proteins in plasma and the risk of dementia: the rotterdam study. Arch Neurol $61,668-672$

Engvall E, Perlman P (1971): Enzyme-linked immunosorbent assay (ELISA). Quantitative assay of immunoglobulin $\mathrm{G}$. Immunochemistry $\underline{8}, 871$ - 874

Esch FS, Keim PS, Beattie EC, Blacher RW, Culwell AR, Oltersdorf T, McClure D, Ward PJ (1990): Cleavage of amyloid beta peptide during constitutive processing of its precursor. Science $\underline{248}, 1122-1124$

Estler CJ: Antiinfektiva, Pharmaka zur Behandlung und Verhütung von Infektionen (Chemotherapeutika, Antibiotika, Desinfektionsmittel); in: Pharmakologie und Toxikologie; hrsg. v. Estler CJ; Schattauer-Verlag, Stuttgart, New York 2000, 595 - 682

Evin G, Weidemann A (2002): Biogenesis and metabolism of Alzheimer's disease Abeta amyloid peptides. Peptides $\underline{23}, 1285-1297$

Facklam R (2002): What happened to the Streptococci: Overview of taxonomic and nomenclature changes. Clin Microbiol Rev $\underline{15}, 613-630$

Fillit HM, O Connell AW, Refolo LM (2002): Strategies for drug discovery for cognitive aging and Alzheimer's disease. J Mol Neurosci $\underline{19}, 1$ - 3

Folstein MF, Folstein SE, Mc'Hugh PR (1975): „Mini-mental state". A practical method for grading the cognitive state of patients for the clinician; J Psychiatr Res 12, 189 - 98 
Frenkel LD (1988): Once- daily administration of ceftriaxon for the tratment of selected serious bacterial infectiion in childeren. Pediatrics $\underline{82}, 486-491$

Friedländer C (1882): Über die Schizomyceten bei der akuten fibrösen Pneumonie. Virchows Arch Pathol Anat Physiol Klin Med 구, 319 - 324

Geldmacher DS, Whitehouse PJ (1997): Differential diagnosis of Alzheimer's disease. Neurology $\underline{48}, 52$ - 59

Geula C, Nagykery N, Nicholas A, Wu CK (2008): Cholinergic neuronal and axonal abnormalities are present early in aging and in Alzheimer disease. $J$ Neuropathol Exp Neurol $\underline{67}, 309-318$

Gibson RL, Nizet V, Rubens CE (1999): Group B streptococcal beta-hemolysin promotes injury of lung microvascular endothelial cells. Pediatr Res $\underline{45}, 626$ - 34

Godoy MCP, Tarelli R, Ferrari CC, Sarchi MI, Pitossi J (2008): Central and systemic IL-1 exacerbates neurodegeneration and motor symptoms in a model of Parkinson's disease. Brain 131, $1880-1894$

Gordon MN, King DL, Diamond DM, Jantzen PT, Boyett KV, Hope CE, Hatcher JM, DiCarlo G, Gottschall WP, Morgan D, Arendash GW (2001): Correlation between cognitive deficits and Abeta deposits in transgenic APP+PS1 mice. Neurobiol Aging 22, 377 - 385

Griffin WS, Sheng JG, Royston MC, Gentleman SM, McKenzie JE, Graham DI, Roberts GW, Mrak RE (1998): Glial-neuronal interactions in Alzheimer's disease: the potential role of a 'cytokine cycle' in disease progression. Brain Pathol $\underline{8}, 65$ - 72

Grossberg GT (2005): Effect of rivastigmine in the treatment of behavioral disturbances associated with dementia: review of neuropsychiatric impairment in Alzheimer's disease. Curr Med Res Opin 21, 1631 - 1639

Haass C, Selkoe DJ (2007): Soluble protein oligomers in neurodegeneration: lessons from the Alzheimer's amyloid ß-peptide. Nat Rev $\underline{8}, 101$ - 112. 
Hallauer JF, Schons M, Smala A, Berger K (2000): Untersuchung von Krankheitskosten bei Patienten mit Alzheimer-Erkrankung in Deutschland. Gesundheitsökonomie Qualitätsmanagement $\underline{5}, 73-79$

Hardy J (2006): A hundred years of Alzheimer's disease research. Neuron $\underline{5}, 3-13$

Hardy J, Allsop (1991): D Amyloid deposition as the central event in the aetiology of Alzheimer's disease. Trends Pharmacol Sci 12, 383 - 388

He W, Barrow CJ (1999): The A beta 3-pyroglutamyl and 11-pyroglutamyl peptides found in senile plaque have greater beta-sheet forming and aggregation propensities in vitro than full-length A beta. Biochemistry $\underline{38}, 10871$ - 10877

Henrichsen J (1999): Typing of Streptococcus pneumoniae: past, present, and future. Am J Med 107, 50 - 54.

Herber DL, Mercer M, Roth LM, Symmonds K, Maloney J, Wilson N, Freeman MJ, Morgan D, Gordon MN (2007): Microglial activation is required for Abeta clearance after intracranial injection of lipopolysaccharide in APP transgenic mice. $\mathrm{J}$ Neuroimmune Pharmcol 2, $222-231$

Herbert H, Dörries R: Spezielle Bakteriologie; in: Duale Reihe Medizinische Mikrobiologie; hrsg. v. Bob A, Bob K; Georg Thieme Verlag, Stuttgart 2005, 315 - 317

Herrmann I, Kellert M, Schmidt H, Mildner A, Hanisch UK, Brück W, Prinz M, Nau R. (2006): Streptococcus pneumoniae infection aggravates experimental autoimmune encephalomyelitis via Toll-like receptor 2. Infect Immun $\underline{74}, 4841$ - 4848

Hoban DJ, Doern GC, Fluit AC, Roussel-Delvallez M, Jones RN (2001): Worldwide prevalence of antimicrobial resistance in Streptococcus pneumoniae, Haemophilus influenzae, and Moraxella catarrhalis in the SENTRY Antimicrobial Surveillance Program, 1997-1999. Clin Inf Dis $\underline{32}, 81$ - 84 
Holmes C, El-Okl M, Williams AL, Cunningham C, Wilcockson D, Perry VH (2003): Systemic infection, interleukin 1beta, and cognitive decline in Alzheimer's disease. J Neurol Neurosurg Psychiatry $\underline{74}, 788$ - 789

Hsiao KK, Borchelt DR, Olson K, Johannsdottir R, Kitt C, Yunis W, Xu S, Eckman C, Younkin S, Price D et al. (1995): Age-related CNS disorder and early death in transgenic FVB/N mice overexpressing Alzheimer amyloid precursor proteins. Neuron 15, 1203 1218.

Hsiao K, Chapman P, Nilsen S, Eckman C, Harigaya Y, Younkin S, Yang F, Cole G (1996): Correlative memory deficits, Abeta elevation, and amyloid plaques in transgenic mice. Science $274,99-102$

Hüll M, Voigt-Radloff S (2008): Nonmedical treatment of dementia. Nervenarzt $\underline{79}$, 159 164

In't Veld BA, Ruitenberg A, Hofman A, Launer LJ, van Duijn CM, Stijnen T, Breteler MMB, Stricker BHC (2001): Nonsteroidal antiinflammatory drugs and the risk of Alzheimer's disease. N Engl J Med $\underline{345}, 1515$ - 1521

Jellinger KA (2008): Neuropathological aspects of Alzheimer disease, Parkinson disease and frontotemporal dementia. Neurodegener Dis $\underline{5}, 118-121$

Jellinger KA, Bancher C (1996): AD neuropathology. Neurology $\underline{46}, 1186$ - 1187

Jones BJ, Roberts DJ (1968): The quantiative measurement of motor inco-ordination in naive mice using an acelerating rotarod. J Pharm Pharmacol 20, 302 - 304

Kawahara M (2004): Disruption of Calcium homeostasis in the pathogenesis of Alzheimer's disease and other conformational diseases. Curr Alzheimer Res 1, 87 - 95

Kawarabayashi T, Younkin LH, Saido TC, Shoji M, Hsiao Ashe K, Younkin SG (2001): Agedependent changes in brain, CSF, and plasma amyloid beta protein in the Tg2576 transgenic mouse model of Alzheimer's disease. J Neurosci 21, 373 - 381 


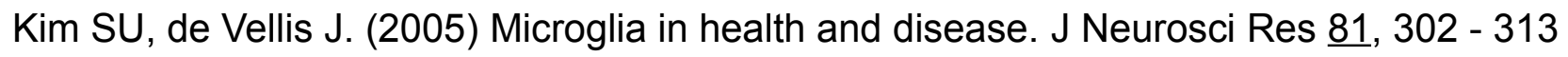

King DL, Arendash GW (2002): Behavioral characterization of the Tg2576 transgenic model of Alzheimer's disease through 19 months. Physiol Behav 75, 627 - 642

Klein NC, Cunha BA (1995): Third-generation cephalosporins. Med Clin North Am $\underline{79}, 705$ $-719$

Koedel U, Scheld WM, Pfister HW (2002): Pathogenesis and pathophysiology of pneumococcal meningitis. Lancet Infect Dis $\underline{2}, 721-736$

Lassalle JM, Halley H, Daumas S, Verret L, Francés B (2008): Effects of the genetic background on cognitive performances of TG2576 mice. Behav Brain Res 191, 104 - 110

Lee M, Sparatore A, Del Soldato P, McGeer E, McGeer PL. (2010): Hydrogen sulfidereleasing NSAIDs attenuate neuroinflammation induced by microglial and astrocytic activation. Glia $\underline{58}, 103-113$

Lehéricy S, Delmaire C, Galanaud D, Dormont D (2007): Neuroimaging in dementia. Presse Med $\underline{36}, 1453$ - 1463

Li L, Lu J, Tay SSW, Moochhala SM, He BP (2007): The function of microglia, either neuroprotection or neurotoxicity, is determined by the equilibrium among factors released from activated microglia in vitro. Brain Res $\underline{1159}, 8$ - 17

Lock RA, Paton JC, Hansman D (1988 a): Comparative efficacy of pneumococcal neuraminidase and pneumolysin as immunogens protective against Streptococcus pneumoniae. Microb Pathog $\underline{5}, 461-467$

Lock RA, Paton JC Hansman D (1988 b): Purification and immunological characterization of neuraminidase produced by Streptococcus pneumoniae. Microb Pathog 4, 33 - 43

Lott IT, Head E (2001): Down syndrome and Alzheimer's disease: a link between 
development and aging. Ment Retard Dev Disabil Res Rev 7, 172 - 178

Lucas CE (1991): Splenic trauma. Choise of managment. Ann Surg 213, 98 - 112

Lykouras L, Gournellis R (2011): Behavioral and psychological symptoms of dementia and their management. Psychiatrike 22, $24-33$

Manos PJ, Wu R (1997): The duration of delirium in medical and postoperative patients referred for psychiatric consultation. Ann Clin Psychiatry $\underline{9}, 219$ - 26

Marksteiner J, Hinterhuber H, Humpel C (2007): Cerebrospinal fluid biomarkers for diagnosis of Alzheimer's disease: beta-amyloid(1-42), tau, phospho-tau-181 and total protein. Drugs Today (Barc) $\underline{43}, 423-31$

Marsland AL, Gianaros PJ, Abramowitch SM, Manuck SB, Hariri AR (2008): Interleukin-6 covaries inversely with hippocampal grey matter volume in middle-aged adults. Biol Psychiatry 64, 484 - 490

Mattson MP, Barger SW, Cheng B, Lieberburg I, Smith-Swintosky VL, Rydel RE (1993): $\beta$ Amyloid precursor protein metabolites and loss of neuronal calcium homeostasis in Alzheimer's disease. Trends Neurosci 16, 409 - 414

Mattsson N, Zetterberg H, Hansson O, Andreasen N, Parnetti L, Jonsson M, Herukka SK, van der Flier WM, Blankenstein MA, Ewers M, Rich K, Kaiser E, Verbeek M, Tsolaki M, Mulugeta E, Rosén E, Aarsland D, Visser PJ, Schröder J, Marcusson J, de Leon M, Hampel H, Scheltens P, Pirttilä T, Wallin A, Jönhagen ME, Minthon L, Winblad B, Blennow K (2009): CSF biomarkers and incipient Alzheimer disease in patients with mild cognitive impairment. JAMA. $\underline{302}, 385$ - 393

McGeer EG, Yasojima K, Schwab C, McGeer PL (2001): The pentraxins: possible role in Alzheimer'sdisease and other innate inflammatory diseases. Neurobiol Aging 22, 843 848 
McGeer PL, McGeer EG (2004): Inflammation and neurodegeneration in Parkinson's disease. Parkinsonism Relat Disord $\underline{10}, 3-7$

McGeer PL, Itagaki S, Boyes BE, McGeer EG (1998): Reactive microglia are positive for HLA-DR in the substantia nigra of Parkinson's and Alzheimer's disease brains. Neurology $\underline{38}, 1285-1291$

Mielke M, Stück B: Streptococcus pneumoniae, Pneumokokken; in: Infektionskrankheiten; hrsg. v. Suttorp N, Mielke M u.a.; Georg Thieme Verlag, Stuttgart, New York 2004, 155 157

Mills J, Reiner PB (1999): Regulation of amyloid precursor protein cleavage. J Neurochem $\underline{72}, 443-60$

Miquel J, Blasco M (1978): A simple technique for evaluation of vitality loss in aging mice, by testing their muscular coordination and vigor. Exp Gerontol 13, $389-396$

Mitchell TJ (2000): Virulence factors and the pathogenesis of disease caused by Streptococcus pneumoniae. Res Microbiol 151, 413 - 419

Möller HJ, Graeber MB (1998): The case described by Alois Alzheimer in 1911. Historical and conceptual perspectives based on the clinical record and neurohistological sections. Eur Arch Psychiatry Clin Neurosci $\underline{248}, 111$ - 122

Morgan D, Gordon MN, Tan J, Wilcock D, Rojiani AM (2005): Dynamic complexity of the microglial activation response in transgenic models of amyloid deposition: implications for Alzheimer therapeutics. J Neuropathol Exp Neurol. 또, 743 - 753

Morris, R (1984): Developments of a water-maze procedure for studying spatial learning in the rat. J Neurosci Methods. 11, 47 - 60

Mosconi L, Brys M, Glodzik-Sobanska L, De Santi S, Rusinek H, de Leon MJ (2007): Early 
detection of Alzheimer's disease using neuroimaging. Exp Gerontol 42, 129 - 138

Mulder M, Terwel D (1998): Possible link between lipid metabolism and cerebral amyloid angiopathy in Alzheimer's disease: A role for high-density lipoproteins? Haemostasis $\underline{28}$, $174-194$

Mundy LS, Janoff EN, Schwebke KE, Shanholtzer CJ, Willard KE (1998): Ambiguity in the identificatio of Streptococcus pneumoniae. Optochin, bile solubility, quellung, and the AccuProbe DNA probe test. Am J Clin Pathol 109, 55 - 61

Murdoch DA (1998): Gram-positiv anaerobic cocci. Clin Microbiol Rev 11, 81 - 120

Murphy GG, Rahnama NP, Silva AJ (2006): Investigation of age-related cognitive decline using mice as a model system: behavioral correlates. Am J Geriatr Psychiatry 14, 1004 1111

Myers AJ, Goate AM (2001): The genetics of late-onset Alzheimer's disease. Curr Opin Neurol $\underline{14}, 433-440$

Nau R, Eiffert H (2002): Modulation of release of proinflammatory bacterial compounds by antibacterials: potential impact on course of inflammation and outcome in sepsis and meningitis. Clin Micorbiol Rev $\underline{15}, 95$ - 110

Nau R, Wellmer A, Soto A, Koch K, Schneider O, Schmidt H, Gerber J, Michel U, Brück W. (1999): Rifampin reduces early mortality in experimental Streptococcus pneumoniae meningitis. J Infect Dis $\underline{179}, 1557-1560$

Nau R, Sörgel F, Eiffert H (2010): Penetration of drugs through the blood-cerebrospinal fluid/blood-brain barrier for treatment of central nervous system infections. Clin Microbiol $\operatorname{Rev} \underline{23}, 858-883$

Nee LE, Lippa CF (1999): Alzheimer's disease in 22 twin pairs - 13-year follow-up: hormonal, infectious and traumatic factors. Dement Geriatr Cogn Disord 10, 148 - 151 
Nguyen MD, Julien JP, Rivest S. (2002): Innate immunity: the missing link in neuroprotection and neurodegeneration? Nat Rev Neurosci $\underline{3}, 216$ - 227

Nguyen MD, D'Aigle T, Gowing G, Julien JP, Rivest S (2004): Exacerbation of motorneuron disease by chronic stimulation of innate immunity in a mouse model of amyotrophic lateral sclerosis. J Neurosci $\underline{24}, 340$ - 349

Ondrejcak T, Klyubin I, Hu NW, Barry AE, Cullen WK, Rowan MJ (2010): Alzheimer's disease amyloid beta-protein and synaptic function. Neuromolecular Med 12,13 - 26

Perry VH, Cunningham C, Holmes C (2007): Systemic infections and inflammation affect chronic neurodegeneration. Nat Rev Immunol $\underline{7}, 161$ - 167

Pfister HW, Feiden W, Einhäupl KM (1993): Spectrum of complications during bacterial meningitis in adults. Results of a prospective clinical study. Arch Neurol $\underline{50}, 575-581$

Piccini A, Russo C, Gliozzi A, Relini A, Vitali A, Borghi R, Giliberto L, Armirotti A, D'Arrigo C, Bachi A, Cattaneo A, Canale C, Torrassa S, Saido TC, Markesbery W, Gambetti P, Tabaton M (2005): beta-amyloid is different in normal aging and in Alzheimer disease. J Biol Chem 280, 34186 - 34192

Pihlajamäki M, Kotilainen P, Kaurila T, Klaukka T, Palva E, Huovinen (2001): Macrolideresistant Streptococcus pneumoniae and use of antimicrobial agents. Clin Infect Dis $\underline{33}$, 483 - 488

Prasad K, Kumar A, Gupta PK, Singhal T (2007): Third generation cephalosporins versus conventional antibiotics for treating acute bacterial meningitis. Cochrane Database Syst Rev Issue $\underline{4}$.

Pull CB (1995): DSM-IV. Encephale 5, $15-20$

Qiu C, Kivipelto M, von Strauss E (2009): Epidemiology of Alzheimer's disease: occurrence, determinants, and strategies toward intervention. Dialogues Clin Neurosci 11, 
$111-128$

Quinn J, Montine T, Morrow J, Woodward WR, Kulhanek D, Eckenstein F (2003): Inflammation and cerebral amyloidosis are disconnected in an animal model of Alzheimer 's disease. J Neuroimmunol 137, 32 - 41

Raivich G, Banati R (2004): Brain microglia and blood-derived macrophages: molecular profiles and functional roles in multiple sclerosis and animal models of autoimmune demyelinating disease. Brain Res Rev $\underline{46}, 261$ - 281

Reinert RR, Al-Lahham A, Lemperle M, Tenholte C, Briefs C, Haupts S, Gerards HH, Lutticken R (2002): Emergence of macrolide and penicillin resistance among invasive pneumococcal isolates in Germany, J Antimicrobiol Chemother 49, 61 - 68

Reinert RR, Reinert S, van der Linden M, Cil MY, Al-Lahham A, Appelbaum A (2005): Antimicrobial susceptibility of Streptococcus pneumoniae in eight Europian countries from 2001 to 2003. Antimicrob Agents Chemother 49, 2903 - 2913

Reitz C, Brickman AM, Brown TR, Manly J, DeCarli C, Small SA, Mayeux R (2009): Linking hippocampal structure and function to memory performance in an aging population. Arch Neurol $\underline{66}, 1385$ - 1392

Richard F, Amouyel P (2001): Genetic susceptibility factors for Alzheimer's disease. Eur J Pharmacol $\underline{412}, 1$ - 12

Roberts JA, Lipman J (2009): Pharmacokinetic issues for antibiotics in the critically ill patient. Crit Care Med 37, $840-51$

Rosin H, Henschler D: Antibiotika und Chemotherapeutika; in: Allgemeine und spezielle Pharmakologie und Toxikologie. hrsg. v. Forth W, Henschler D, Rummel W, Starke K; Akademischer Verlag, Heidelberg, Oxford 1996, 677 - 787

Rubins JB, Duane PG, Clawson D, Charboneau , Young A, Niewoehner DE (1993): Toxicity of pneumolysin to pulmonary alveolar epithelial cells. Infect Immun $\underline{61}, 1352$ - 
Rubins JB, Charboneau D, Fasching C, Berry AM, Paton FC, Alexander JE, Adrew PW, Mitchell TJ, Janoff EN (1996): Distinct roles for pneumolysin's cytotoxic and complement activities in the pathogenesis of pneumococcal pneumonia. Am J Respir Crit Care Med $153,1339-1346$

Russo C, Violani E, Salis S, Venezia V, Dolcini V, Damonte G, Benatti U, D'Arrigo C, Patrone E, Carlo P, Schettini G (2002): Pyroglutamate-modified amyloid beta-peptides-AbetaN3(pE)--strongly affect cultured neuron and astrocyte survival. J Neurochem $\underline{82}$, 1480-1489

Saiki RK, Gelfand DH, Stoffel S, Scharf SJ, Higuchi R, Horn GT, Mullis KB, Erlich HA (1988): Primer-Directed Enzymatic Amplification of DNA with a Thermostable DNA Polymerase. Science $\underline{239}, 487-491$

Schliebs R, Arendt T (2006): The significance of the cholinergic system in the brain during aging and in Alzheimer's disease. J Neural Transm 113, 1625 - 1644

Scholtzova H, Kascsak RJ, Bates KA, Boutajangout A, Kerr DJ, Meeker HC, Mehta PD, Spinner DS, Wisniewski T (2009): Induction of toll-like receptor 9 signaling as a method for ameliorating Alzheimer's disease-related pathology. J Neurosci $\underline{29}$, 1846 - 1854

Selkoe DJ (2001): Alzheimer's disease: genes, proteins, and therapy. Physiol Rev 81, 741 766

Sergeant N, Bombois S, Ghestem A, Drobecq H, Kostanjevecki V, Missiaen C,Wattez A, David JP, Vanmechelen E, Sergheraert C, Delacourte A (2003): Truncated beta-amyloid peptide species in pre-clinical Alzheimer's disease as new targets for the vaccination approach. J Neurochem 85, 1581 - 1591

Sheng JG, Bora SH, Xu G, Borchelt DR, Price DL, Koliatsos VE (2003): Lipopolysaccharide-induced-neuroinflammation increases intracellular accumulation of amyloid precursor protein and amyloid beta peptide in APPswe transgenic mice. Neurobiol 
Dis $\underline{14}, 133-145$

Shulman KI, Gold DP, Cohen CA, Zucchero CA (1993): Clock-drawing and dementia in the community: A longitudinal study. Int J Geriatr Psychiatry $\underline{8}, 487$ - 496

Sisodia SS (1992): Secretion of the beta-amyloid precursor protein. Ann N Y Acad Sci $\underline{674}$, $53-57$

Sly LM, Krzesicki RF, Brashler JR, Buhl AE, McKinley DD, Carter DB, Chin JE (2001): Endogenous brain cytokine mRNA and inflammtory responses to lipopolysaccharide are elevated in the Tg2576 mouse model of Alzheimer's disease. Brain Res Bull $\underline{56}, 581$ - 588

Smith JD (2000): Apolipoprotein E4: an allele associated with many diseases. Ann Med $\underline{32}, 118-127$

Sokol W (2001): Epidemiology of sinusitis in the primary care setting: results from the 1999-2000 respiratory surveillance program. Am J Med 17, 19 - 24

Soto M, Reynish E, Nourhashémi F, Vellas B (2007): Clinical aspects of Alzheimer disease. Presse Med 36, 1491 - 1499

Sternberg GA (1881): Fatal form of septicaemis in the rabbit, produced by subcutaneus injection of human salvia. An experimental research. Health Bull (Edinb) $\underline{188}, 781$ - 783

Stertz G: Alois Alzheimer; in: Neue Deutsche Biographie (NDB). Band 1; hrsg. v. Historische Kommission bei der Bayerischen Akademie der Wissenschaften; Duncker \& Humblot, Berlin 1953, S. 236

Stevenson J (1973): Bacterial meningitis and tuberculous meningitis. Br Med J 1973,2, 411 $-414$

Streit WJ (2002): Microglia as neuroprotective, immunocompetent cells of the CNS. Glia $\underline{40}, 133-139$ 
Streit WJ (2004): Microglia and Alzheimer's disease pathogenesis. J Neurosci Res $\underline{77}, 1$ 8

Suzuki N, Cheung TT, Cai XD, Odaka A, Otvos L Jr, Eckman C, Golde TE, Younkin SG (1994): An increased percentage of long amyloid beta protein secreted by familial amyloid beta protein precursor (beta APP717) mutants. Science 264, 1336 - 1340

Tan ZS, Beiser AS, Vasan RS, Roubenoff R, Dinarello CA, Harris TB, Benjamin EJ, Au R, Kiel DP, Wolf PA, Seshadri S (2007): Inflammatory markers and the risk of Alzheimer disease: the Framingham Study. Neurology $\underline{68}, 1902$ - 1908

Tarkowski A, Collins LV, Gjertsson I, Hultgren OH, Jonsson IM, Sakiniene E, Verdrengh M (2001): Model systems: modeling human staphylococcal arthritis and sepsis in the mouse. Trends Microbiol $\underline{9}, 321$ - 326

Tauber SC, Bunkowski S, Ebert S, Schulz D, Kellert B, Nau R, Gerber J (2009): Enriched environment fails to increase meningitis-induced neurogenesis and spatial memory in a mouse model of pneumococcal meningitis. J Neurosci Res $\underline{87}, 1877$ - 1883

Thompson HC, Eisenstein TK (1975): Biological properties of an immunogenic pneumococcal subcellular preparation. Infect Immun 13, 750 - 757

Tomasz A, Munoz R (1995): Beta-Lactam antibiotic resistance in gram-positive bacterial pathogens of the upper respiratory tract: a brief overview of mechanisms. Microb Drug Resist 1, 103 - 109

Turner MR, Cagnin A, Turkheimer FE, Miller CCJ, Shaw CE, Brooks DJ, Leigh PN, Banati RB (2004): Evidence of widespread cerebral microglial activation in amyotrophic lateral sclerosis: an $\left[{ }^{11} \mathrm{C}\right](\mathrm{R})-\mathrm{PK} 11195$ positron emission tomography study. Neurobiol Dis $\underline{15}, 601$ - 609

Van Everbroeck B, Dobbeleir I, De Waele M, De Leenheir E, Lübke U, Martin JJ, Cras P (2004): Extracellular protein deposition correlates with glial activation and oxidative stress 
in Creutzfeldt-Jakob and Alzheimer's disease. Acta Neuropathol 108,194 - 200

Vicioso BA (2002): Dementia: when is it not Alzheimer disease? Am J Med Sci 324, 84 - 95

Wellmer A, Noeske C, Gerber J, Munzel U, Nau R. (2000): Spatial memory and learning deficits after experimental pneumococcal meningitis in mice. Neurosci Lett 296, 137 - 140

Westerman MA, Cooper-Blacketer D, Mariash A, Kotilinek L, Kawarabayashi T, Younkin LH, Carlson GA, Younkin SG, Ashe KH (2002) The relationship between Abeta and memory in the Tg2576 mouse model of Alzheimer's disease. J Neurosci 22, 1858 - 1867

Williams AJ, Nadel S (2001): Bacterial meningitis: current controversies in approaches to treatment. CNS Drugs $\underline{15}, 909$ - 919

Wisniewski T, Konietzko U (2008): Amyloid-beta immunisation for Alzheimer's disease. Lancet Neurol $\underline{7}, 805-811$

Yaffe K, Kanaya A, Lindquist K, Simonsick EM, Harris T, Shorr RI, Tylavsky FA, Newman AB (2004 ): The metabolic syndrome, inflammation, and risk of cognitive decline. JAMA 292. $2237-2242$

Zhou S, Zhou H, Walian PJ, Jap BK (2007): Regulation of gamma-secretase activity in Alzheimer's disease. Biochemistry $\underline{46}, 2553$ - 2563

Zimmermann M, Gardoni F, Di Luca M (2005): Molecular rationale for the pharmacological treatment of Alzheimer's disease. Drugs Aging Suppl 1, 27 - 37 


\section{Danksagung}

Zunächst möchte ich mich bei meiner Betreuerin, Frau Dr. med. Sandra Ebert, für die Unterstützung während der Planung und Durchführung meiner Arbeit bedanken. Sie war mit ihren konstruktiven Vorschlägen eine große Hilfe und hatte immer ein offenes Ohr für Fragen und Probleme. Außerdem vermittelte sie mir auch über die Doktorarbeit hinaus wissenschaftliche Kenntnisse und Fähigkeiten im Bereich der Laborarbeit, die für meinen zukünftigen beruflichen Alltag von Wichtigkeit sind.

Ich danke Herrn Prof. Dr. med. Roland Nau für die Überlassung des interessanten Themas, die geduldige und hilfsbereite Unterstützung und vor allem seine freundliche Art, mit seinen Mitarbeitern umzugehen.

Eine Danksagung gilt der gesamten Arbeitsgruppe Nau, der ich für die Hilfsbereitschaft zu Dank verpflichtet bin. Auf ihre Hilfe und Unterstützung konnte ich mich immer verlassen. 


\section{Lebenslauf}

Am 16.03.1986 wurde ich, Benedikt Kellert, als Sohn von Frau Dipl. psych. Elke Kellert, geb. Jahn, und Herrn Dipl. med. Michael Kellert als drittes von vier Geschwistern in Erfurt geboren. Von 1992 bis 1996 besuchte ich die Christian-Reichart-Schule, Staatliche Grundschule 19 in Erfurt und darauffolgend die Edith-Stein-Schule, Gymnasium in katholischer Trägerschaft, welche ich im Jahre 2004 mit Erwerb der Allgemeinen Hochschulreife verließ.

Im Wintersemester 2004/2005 begann ich mein Studium der Humanmedizin an der GeorgAugust-Universität Göttingen. Die Famulaturen im Rahmen des Studiums leistete ich in den Fachbereichen Chirurgie und Urologie ab.

Im Februar 2010 begann ich das Praktische Jahr, welches ich in den Bereichen Chirurgie, Urologie und Innere Medizin in Durban (Republik Südafrika), St. Gallen (Schweiz) und Herzberg absolvierte. Im April 2011 schloss ich mein Studium mit dem Zweiten Abschnitt der Ärztlichen Prüfung ab. Seit dem 01.09.2011 arbeite ich als Ausbildungsassistent in der Klinik für Allgemein-, Viceral- und Gefäßchirurgie im Katholischen Krankenhaus „St. Johann Nepomuk" Erfurt.

Die vorgelegte Dissertation begann ich im Jahre 2007 in der Abteilung Neurologie an der Universität Göttingen unter der Doktorvaterschaft von Herrn Prof. Dr. med. Roland Nau und der Betreuung von Dr. med. Sandra Ebert. 